\title{
HIGH-Q INTEGRATED INDUCTORS ON TRENCHED SILICON ISLANDS
}

\author{
A Thesis \\ Presented to \\ The Academic Faculty \\ By \\ Mina Raieszadeh \\ In Partial Fulfillment \\ Of the Requirements for the Degree \\ Master of Science in the \\ School of Electrical and Computer Engineering
}

Georgia Institute of Technology

April 2005 


\section{HIGH-Q INTEGRATED INDUCTORS ON TRENCHED SILICON ISLANDS}

Approved by:

Dr. Farrokh Ayazi, Avdisor

School of Electrical and Computer Engineering Georgia Institute of Technology

Dr. Mark G. Allen

School of Electrical and Computer Engineering Georgia Institute of Technology

Dr. Joy Laskar

School of Electrical and Computer Engineering Georgia Institute of Technology

Date Approved: April 15, 2005 


\section{ACKNOWLEDGEMENTS}

I would like to express my deepest gratitude and appreciation to my advisor Dr. Farrokh Ayazi, without whom this work would not have been possible. He has provided me with constant help and support and has always kept his office door open at me. I would also like to thank my thesis committee members, Dr. Mark G. Allen and Dr. Joy Laskar for their support. I want to acknowledge my colleagues in the IMEMS group for their help and useful discussions. A special thank goes to Pejman for all his help with cleanroom fabrication. I also would like to thank Sang-Woong Yoon for his help in measurements. The MiRC cleanroom staff at the Georgia Institute of Technology has been very helpful with special mention to Gary Spinner, Vinny Nguyen and Charlie Suh. Last but not least, I would like to thank my parents for their endless love and support. 


\section{TABLE OF CONTENTS}

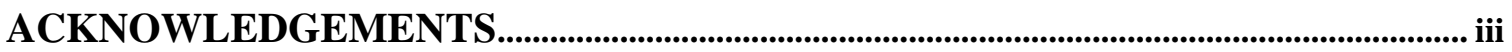

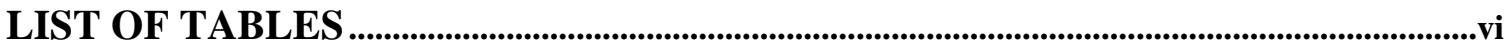

LIST OF FIGURES................................................................................................................. vii

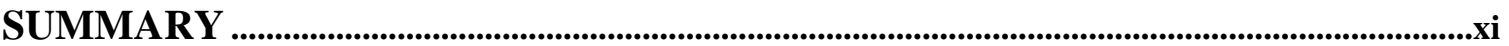

\section{CHAPTER}

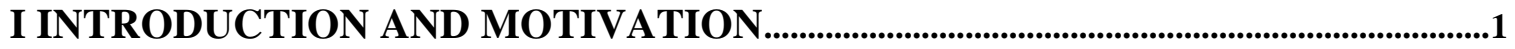

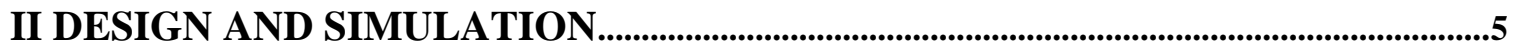

2.1. INDUCTOR PHYSICAL MODEL ........................................................................... 5

2.2 INDUCTOR MODEL PARAMETER EXTRACTION ..................................................... 7

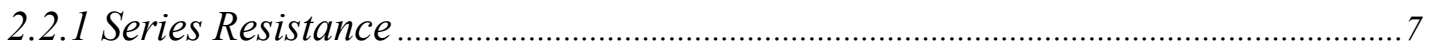

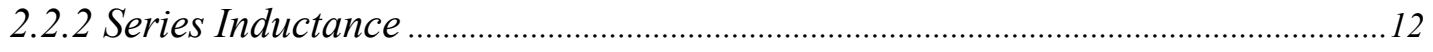

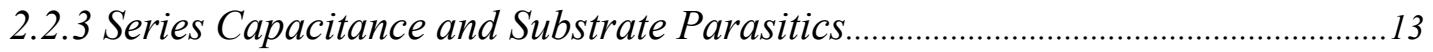

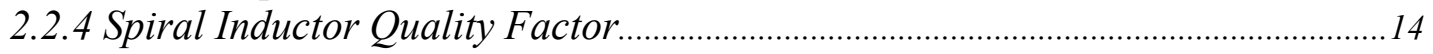

2.3 TRENCHED Si ISLAND FOR REDUCED SUBSTRATE LOSS ..................................... 17

2.4 Thick electroplated Cu for ReduCEd Metal LosS ....................................... 18

2.5 OPTIMIZATION OF THE INDUCTOR PHYSICAL DIMENSIONS .................................. 18

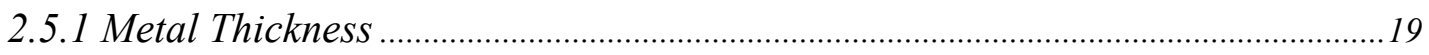

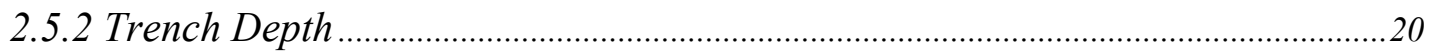

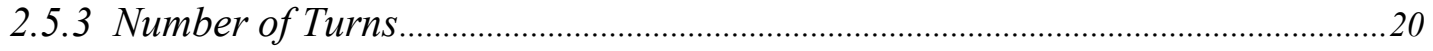

2.5.4 Trenched Island Area .....................................................................................................21

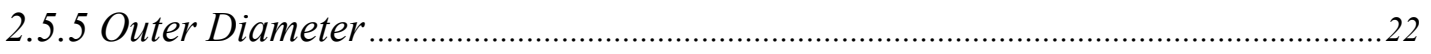

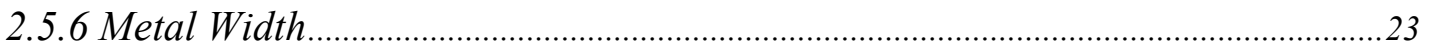

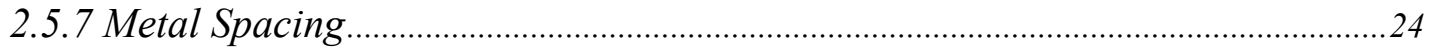

2.5.8 Shape of the Inductor (Round/Rectangular/Round-edge) ......................................26

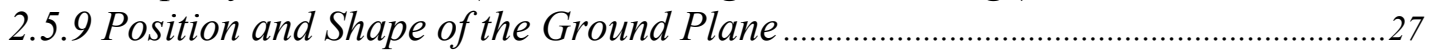


3.1. PROCESS FLOW 28

3.2. Covering THE TRENCHES ...................................................................... 34

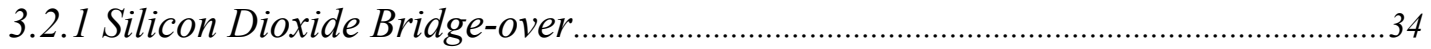

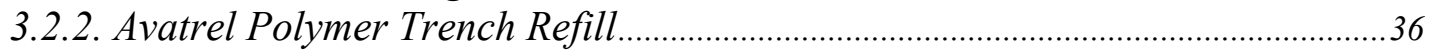

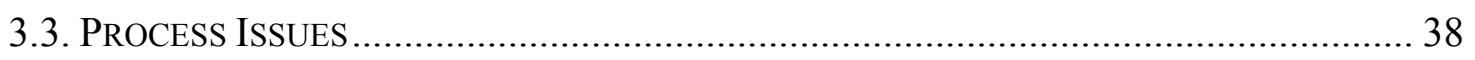

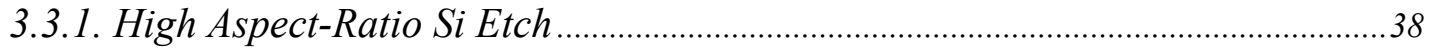

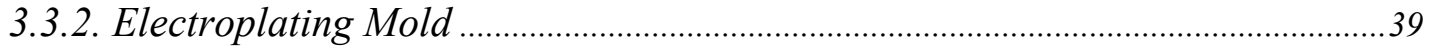

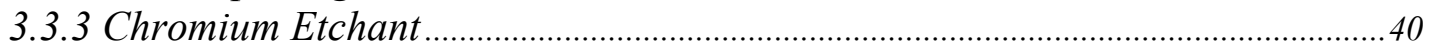

IV MEASUREMENT AND CHARACTERIZATION ....................................................41

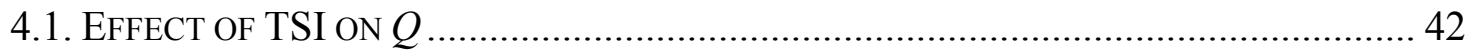

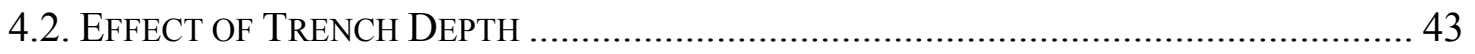

4.3. EFFECT OF OXIDE THICKNESS ....................................................................... 44

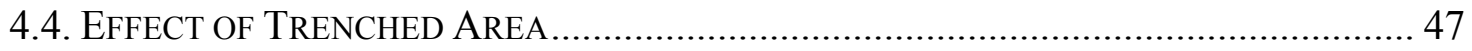

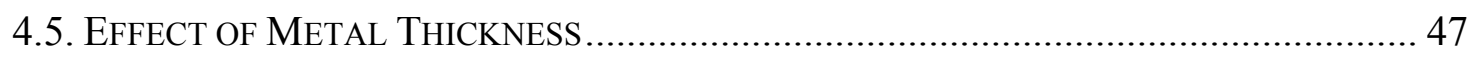

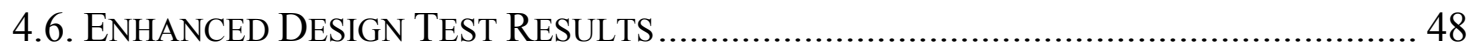

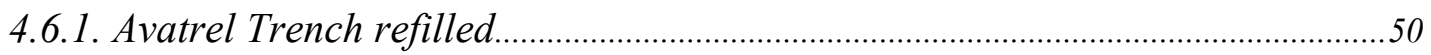

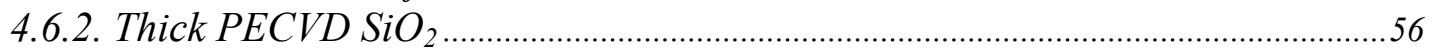

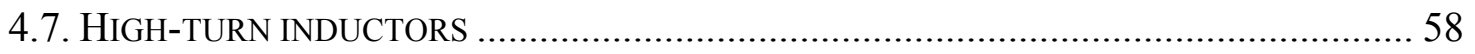

4.8. MODELING AND PARAMETER EXTRACTION ....................................................... 61

V CONCLUSION AND FUTURE DIRECTIONS ......................................................65

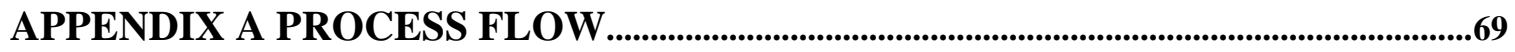

APPENDIX B SIMULATED $Q$ AND L OF FABRICATED INDUCTORS ..................73

REFERENCES ........................................................................................................................................ 


\section{LIST OF TABLES}

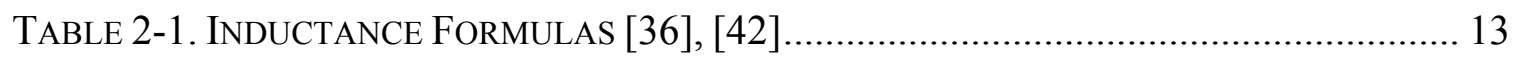

TABLE 3-1. RECIPE TO ETCH TRENCHES IN THE STS ICP SYSTEM. ................................... 29

TABLE 3-2. RECIPE TO DEPOSIT $\mathrm{SIO}_{2}$ IN THE UNAXIS PECVD TOOL. ............................ 29

TABLE 3-3. DRY ETCH RECIPE OF $\mathrm{SIO}_{2}$ IN PLASMA-THERM ICP SYSTEM.......................... 31

TABle 3-4. Comparison of electrical properties of AVATrel With BCB AND

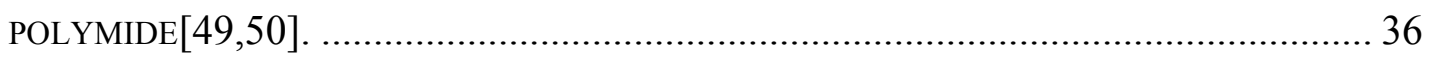

TABLE 4-1. EXTRACTED EQUIVALENT PARAMETERS OF A 1NH INDUCTOR FABRICATED ON

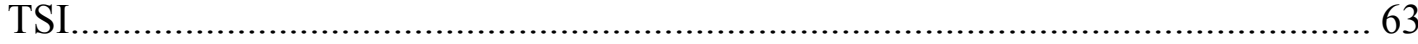

TABLE 4-2. EXTRACTED EQUIVALENT PARAMETERS OF A 0.9NH INDUCTOR FABRICATED ON OI. 64 


\section{LIST OF FIGURES}

FIGURE 2-1. LAYOUT OF A MICROMACHINED PLANAR SPIRAL INDUCTOR. 5

FiguRE 2-2. THE ELECTRICAL MODEL OF AN ON-CHIP SPIRAL INDUCTOR (L=OVERALL LENGTH OF THE INDUCTOR, $\mathrm{W}=$ LINE WIDTH, $\mathrm{T}_{\mathrm{OX}}=\mathrm{SIO}_{2}$ THICKNESS BETWEEN $2^{\mathrm{ND}}$ METAL LAYER AND SUBSTRATE, $\varepsilon O X=\mathrm{SIO}_{2}$ PERMITTIVITY, $\mathrm{N}=$ NUMBER OF CROSSOVER BETWEEN THE TWO METAL LAYERS, $\mathrm{T}_{\mathrm{OX}} \mathrm{M} 1-\mathrm{M} 2=\mathrm{SIO}_{2}$ THICKNESS BETWEEN THE METAL LAYERS, $\delta=$ METAL SKIN DEPTH, T=METAL THICKNESS, $\rho=$ METAL RESISTIVITY, $\mu=$ METAL PERMEABILITY, $\mathrm{C}_{\mathrm{SUB}}=$ SUBSTRATE CAPACITANCE PER UNIT AREA, $\mathrm{G}_{\mathrm{SUB}}=$ SUBSTRATE CONDUCTANCE PER UNIT AREA, F=OPERATION FREQUENCY). 6

FIGURE 2-3. EFFECTIVE AREA OF CURRENT FLOW AT HIGH FREQUENCIES WHERE (A) W/H $\rightarrow 0$ $\operatorname{AND}(B) \mathrm{W} / \mathrm{H} \rightarrow \infty$. 10

Figure 2-4. CURRENT DENSITY OF A 1.5-TURN INDUCTOR AT $1 \mathrm{GHz}$ AND $10 \mathrm{GHz}$ (A) AT THE BOTTOM SURFACE OF METAL, (B) AT HALF THE THICKNESS OF METAL, AND (C) AT THE TOP SURFACE OF METAL.

FIGURE 2-5. MOHAN'S PREDICTED INDUCTANCE VS. SONNET SIMULATION RESULTS FOR 5 DIFFERENT INDUCTORS.

FIGURE 2-6. (LEFT) QUALITY FACTOR VS. FREQUENCY FOR A ONE-TURN SPIRAL INDUCTOR AND (RIGHT) COMPARISON OF THE CALCULATED Q (BY EQ.2-14) AND SIMULATED Q $\left(\mathrm{D}_{\text {OUT }}=500 \mu \mathrm{M} \mathrm{W}=50 \mu \mathrm{M}\right.$, AND $\mathrm{T}_{\mathrm{METAL}}=15 \mu \mathrm{M} . \rho=10 \Omega$.CM $)$. 17

Figure 2-7. Q VS. METAL THICKNESS USING SONNET THICK METAL MODEL. N=20 FOR $26 \mu \mathrm{M}$ THICK INDUCTOR AND N=5 FOR $6 \mu \mathrm{M}$ METAL.

FIgURE 2-8. Q VS. OXIDE THICKNESS $\left(\mathrm{T}=4 \mu \mathrm{M}, \quad \mathrm{W}=40 \mu \mathrm{M}, \mathrm{S}=10 \mu \mathrm{M}, \quad \mathrm{D}_{\text {OUT }}=400 \mu \mathrm{M}\right.$ $\mathrm{L}=2.9 \mathrm{NH})$.

Figure 2-9. Q VS. NUMBER OF TURNS $(\mathrm{F}=2.4 \mathrm{GHz}, \mathrm{L}=2.9 \mathrm{NH}, \mathrm{S}=5 \mu \mathrm{M}$ AND $\mathrm{W}=20 \mu \mathrm{M}$, $\mathrm{T}=6.75 \mu \mathrm{M})$. 21

FIGURE 2-10. Q VS. FREQUENCY FOR A ONE-TURN INDUCTOR WITH VARIOUS D DUT $(\mathrm{W}=40 \mu \mathrm{M})$.

Figure 2-11. FREQUENCY OF PEAK Q VS. Dout. FOR ONE TURN INDUCTORS WITH $\mathrm{W}=40 \mu \mathrm{M}$ 23

FIGURE 2-12. Q VS. CONDUCTOR WIDTH FOR (A) ONE-TURN 1NH INDUCTORS (B) $2.9 \mathrm{NH}$ INDUCTORS ( $\mathrm{S}=5 \mu \mathrm{M}$ AND N=2), AND (C) $2.9 \mathrm{NH}$ INDUCTORS ( $=5 \mu \mathrm{M}$ AND N=3). 24 
FiguRE 2-13. Q VS. SEPARATION FOR 2.9NH INDUCTORS WITH (A) W=10 $\mu \mathrm{M}, \mathrm{N}=3$ AND (B) $\mathrm{W}=40 \mu \mathrm{M}, \mathrm{N}=2$

FIGURE 2-14. Q VS. FREQUENCY ם- - ROUND SPIRAL AND $-\bullet$ RECTANGULAR SPIRAL

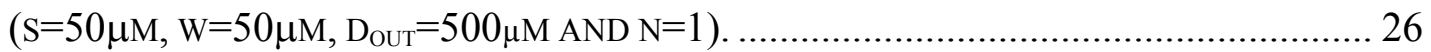

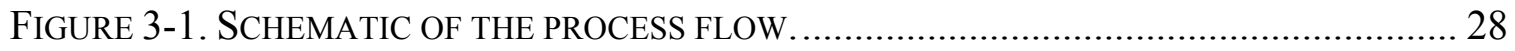

FIGURE 3-2. CROSS-SECTION SEM OF A 90

FigurE 3-3. SEM PICTURES OF (A) A $17 \mu \mathrm{M}$ THICK NR4-8000P USED AS THE ELECTROPLATING MOLD; (B) CLOSE-UP VIEW OF THE STRAIGHT PHOTORESIST SIDEWALLS, AND (C) HIGH ASPECT-RATIO (30:8) PHOTORESIST COLUMN. 31

Figure 3-4. Picture of THE ELECTROPLATING TANK, SHOWING THE ELECTROPLATING SETUP.

FIGURE 3-5. SEM PICTURE OF A ONE-TURN INDUCTOR ON TOP OF TSI $(\mathrm{W}=40 \mu \mathrm{M}$, $\left.\mathrm{D}_{\mathrm{OUT}}=860 \mu \mathrm{M}, \mathrm{T}_{\mathrm{METAL}}=26 \mu \mathrm{M}, \mathrm{Q}=45\right)$..... 33

FIGURE 3-6. SEM PICTURE OF A ONE-TURN ROUND INDUCTOR ON TSI WITH A CLOSE-UP VIEW OF THE THICK ELECTROPLATED CU $\left(\mathrm{W}=50 \mu \mathrm{M}, \mathrm{D}_{\mathrm{OUT}}=500 \mu \mathrm{M}, \mathrm{T}_{\mathrm{METAL}}=20 \mu \mathrm{M}\right.$, TRENCH DEPTH $=60 \mu \mathrm{M}, \mathrm{Q}=71)$.

Figure 3-7. SEM (LEFT) AND MiCROSCOPE (RIGHT) PICTURE OF A 3-TURN ROUND-EDGE

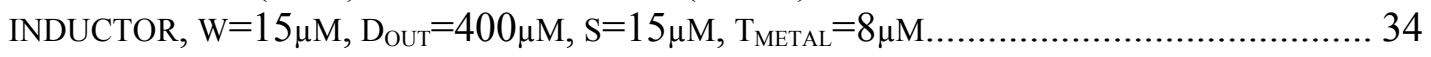

FIGURE 3-8. SEM PICTURE OF A 50 $\mu$ M DEEP TRENCHED SILICON ISLAND (TSI) 35

Figure 3-9. Close -UP VIEW OF the SMOOTh Surface OF A TSI (Surface ROUGHNESS $<0.3 \mu \mathrm{M})$. 36

Figure 3-10. Flaking OF AVATREL LAYER DUE TO HIGH-TEMPERATURE PROCESSING

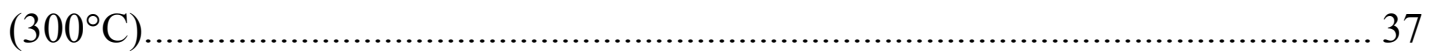

FIGURE 3-11. SEM PICTURE OF A 90 $\mu$ M DEEP TSI REFILLED BY AVATREL POLYMER......... 38

Figure 4-1. COMPARISON OF (A) MEASURED Q, AND (B) S-PARAMETER OF INDUCTORS ON OI, TSI AND $4 \mu \mathrm{M} \mathrm{SIO}_{2}$-COVERED SI SUBSTRATE. $\quad\left(\mathrm{T}_{\mathrm{METAL}}=25-30 \mu \mathrm{M}, \mathrm{W}=60 \mu \mathrm{M}\right.$, $\left.\mathrm{D}_{\text {OUT }}=825 \mu \mathrm{M}\right)$. 42

Figure 4-2. MEASURED Q VS. FREQUENCY SHOWING DEPENDENCY OF Q ON TRENCH DEPTH. $\left(\mathrm{T}_{\text {METAL }}=15 \mu \mathrm{M}, \mathrm{W}=60 \mu \mathrm{M}, \mathrm{D}_{\mathrm{OUT}}=833 \mu \mathrm{M}\right)$. 43 
FIGURE 4-3. QUALITY FACTOR VS. FREQUENCY, SHOWING THE DEPENDENCY OF Q ON OXIDE THICKNESS FOR A ONE-TURN ROUND SPIRAL INDUCTOR $(\mathrm{W}=60 \mu \mathrm{M}, \quad \mathrm{T}=30 \mu \mathrm{M}$, $\mathrm{D}_{\text {OUT }}=833 \mu \mathrm{M}$ AND L $\left.=1.3 \mathrm{NH}\right)$. 45

Figure 4-4. (A) MEASURED AND (B) SIMULATED Q OF A 0.9NH INDUCTOR WiTH VARIOUS OXIDE THICKNESSES $\left(\mathrm{T}_{\mathrm{METAL}}=15 \mu \mathrm{M}, \mathrm{W}=60 \mu \mathrm{M}, \mathrm{D}_{\mathrm{OUT}}=600 \mu \mathrm{M}\right)$. 46

FIGURE 4-5. CROSS-SECTION SEM VIEW OF A 50 $\mu \mathrm{M}$ THICK OI, SHOWING THE INCOMPLETE OXIDATION OF SI. 46

FIgURE 4-6. (LEFT) MEASURED Q OF A ONE-TURN INDUCTOR ON TSI WITH VARIOUS TRENCHED ISLAND AREA, AND (RIGHT) MICROSCOPE PICTURE OF THE INDUCTOR SHOWING THE DEFINITION OF X. $\left(\mathrm{T}_{\text {METAL }}=30 \mu \mathrm{M}, \mathrm{W}_{\text {METAL }}=100 \mu \mathrm{M}, \mathrm{D}_{\mathrm{OUT}}=1200 \mu \mathrm{M}\right) \ldots \ldots . .47$

Figure 4-7. MEASURED Q OF A ONE-TURN INDUCTOR ON TSI WITH DIFFERENT METAL THICKNESSES. 48

FIGURE 4-8. MEASURED (UPPER) Q, AND (LOWER) INDUCTANCE OF A ONE-TURN INDUCTOR ON TSI $\left(\mathrm{T}_{\text {METAL }}=20 \mu \mathrm{M}, \mathrm{W}=50 \mu \mathrm{M}, \mathrm{D}_{\text {OUT }}=500 \mu \mathrm{M}, \rho=100 \Omega\right.$.CM $)$. 49

Figure 4-9. MEASURED Q OF A $0.9 \mathrm{NH}$ INDUCTOR ON TSI $\left(\mathrm{T}_{\mathrm{METAL}}=20 \mu \mathrm{M}, \mathrm{W}=60 \mu \mathrm{M}\right.$,

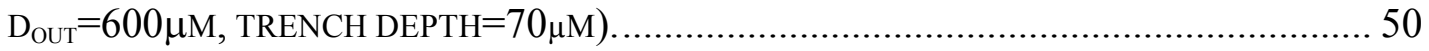

Figure 4-10. MEASURED (UPPER) Q AND (LOWER) L OF A ONE-TURN INDUCTOR ON $100 \mu \mathrm{M}$ DEEP AVATREL REFILLED TRENCHED SI $\left(\mathrm{W}=60 \mu \mathrm{M}, \mathrm{D}_{\text {OUT }}=600 \mu \mathrm{M}, \rho=10-20 \Omega . \mathrm{CM}\right) . \ldots . .51$

FIGURE 4-11. COMPARISON BETWEEN MEASURED Q OF A 0.9NH INDUCTOR FABRICATED ON OI AND AVATREL REFILLED TSI. 52

Figure 4-12. MEASURE Q OF A 0.8NH INDUCTOR ON 90 $\mu \mathrm{M}$ DEEP AVATREL REFILLED TSI. 53

Figure 4-13. MEASURE Q OF A 0.8NH INDUCTOR ON 50 $\mu \mathrm{M}$ DEEP AVATREL REFILLED TSI COATED WITH $20 \mu \mathrm{M}$ THICK AVATREL LAYER. 53

Figure 4-14. Cross-Section SEM viEW of A TSI FILlEd With AVATREL, AND COATED WITH A $20 \mu \mathrm{M}$ THICK LAYER OF AVATREL AND $4 \mu \mathrm{M}$ THICK LAYER OF PECVD SIO $\mathrm{SI}_{2} \ldots 54$

FIgURE 4-15. EXTRACTED DE-EMBEDDED Q OF A $1 \mathrm{NH}$ INDUCTOR ON 70 $\mu \mathrm{M}$ DEEP TSI $\left(\mathrm{W}=60 \mu \mathrm{M}, \mathrm{D}_{\mathrm{OUT}}=600 \mu \mathrm{M}, \rho=100 \Omega . \mathrm{CM}\right)$. 55

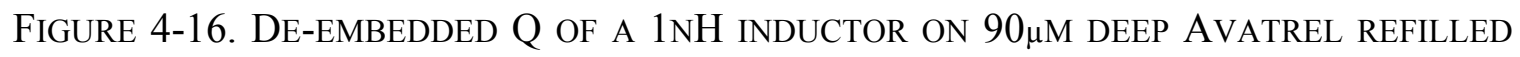
TRENCHED SI $\left(\mathrm{W}=60 \mu \mathrm{M}, \mathrm{D}_{\text {OUT }}=600 \mu \mathrm{M}, \rho=10 \Omega\right.$.CM $)$.

Figure 4-17. Measured Q OF A 0.9NH InduCtOR ON A $20 \mu \mathrm{M}$ ThICK $\mathrm{SiO}_{2}$ COATED Si SUBSTRATE $\left(\mathrm{W}=50 \mu \mathrm{M}, \mathrm{D}_{\mathrm{OUT}}=50 \mu \mathrm{M}\right)$. 56 
Figure 4-18. Simulated AND MEASURED Q OF A $0.9 \mathrm{NH}$ INDUCTOR ON $20 \mu \mathrm{M}$ THICK $\mathrm{SiO}_{2}$

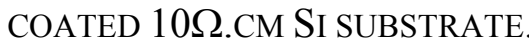

Figure 4-19. MeAsured Q OF A $1 \mathrm{NH}$ ON $20 \mu \mathrm{M}$ Thick $\mathrm{SiO}_{2}$ COATED $10 \Omega$.CM Si SUBSTRATE. 57

Figure 4-20. MEASURED Q OF A 1NH INDUCTOR ON 70 $\mu \mathrm{M}$ DEEP TSI, $20 \mu \mathrm{M}$ THICK PECVD $\mathrm{SIO}_{2}$ COATED SI, AND 90 $\mu \mathrm{M}$ DEEP AVATREL REFILLED TRENCHED Si SUBSTRATE...... 58

Figure 4-21. MEASURED Q OF A 1.1NH INDUCTOR ON TSI $\left(\mathrm{T}_{\mathrm{METAL} 1}=1.5 \mu \mathrm{M}, \mathrm{N}=1.5\right.$, $\mathrm{W}=40 \mu \mathrm{M}, \mathrm{S}=20 \mu \mathrm{M}$, AND $\left.\mathrm{D}_{\text {OUT }}=300 \mu \mathrm{M}\right)$. 59

Figure 4-22. MEASUREd Q OF A 1.3NH INDUCTOR ON TSI $\left(\mathrm{T}_{\mathrm{METAL}}=1.5 \mu \mathrm{M}, \mathrm{N}=1.5\right.$, $\mathrm{W}=30 \mu \mathrm{M}, \mathrm{S}=20 \mu \mathrm{M}$, AND $\left.\mathrm{D}_{\text {OUT }}=300 \mu \mathrm{M}\right)$. 59

Figure 4-23. (LEFT) MEASURED Q OF A 1.2NH INDUCTOR ON 20 $\mu \mathrm{M}$ THICK PECVD $\mathrm{SiO}_{2}$, (RIGHT) SEM PICTURE OF THIS INDUCTOR $\left(\mathrm{T}_{\text {METAL } 1}=1.5 \mu \mathrm{M}, \mathrm{N}=1.5, \mathrm{~W}=30 \mu \mathrm{M}, \mathrm{S}=20 \mu \mathrm{M}\right.$, AND $\left.D_{\text {OUT }}=300 \mu \mathrm{M}\right)$. 60

Figure 4-24. (UPPER) MEASURED Q OF A 3.3NH INDUCTOR ON $20 \mu \mathrm{M}$ THICK PECVD $\mathrm{SIO}_{2}$, (LOWER) SEM PICTURE OF THE INDUCTOR $\left(\mathrm{T}_{\mathrm{METAL}}=1.5 \mu \mathrm{M}, \mathrm{N}=2.5, \mathrm{~W}=20 \mu \mathrm{M}, \mathrm{S}=20 \mu \mathrm{M}\right.$, $\left.\mathrm{AND} \mathrm{D}_{\mathrm{OUT}}=400 \mu \mathrm{M}\right)$. 60

Figure 4-25. MEASURED AND MODELED Q VS. FREQUENCY OF A 1.04NH INDUCTOR ON TSI. 61

Figure 4-26. (A) EXTRaCted Q Qubstrate, AND (B) Q Qmetal OF A 1.04NH INDUCTOR ON TSI. 62

Figure 4-27. Modeled (A) METAL Resistance, AND (B) SUBSTRATE RESistanCE OF THE INDUCTOR SHOWN IN FIG. 4-25.

Figure 4-28. MEASURED AND MODELED Q VS. FREQUENCY OF A 0.9NH INDUCTOR ON OI. 64

Figure 5-1. CROSS-SECTION SEM VIEW OF A 90 $\mu \mathrm{M}$ DEEP TSI COATED WITH A $18 \mu \mathrm{M}$ THICK LAYER OF LOW-K DIELECTRIC.

FIGURE 5-2. SNAP-SHOT OF A FOUR-TURN INDUCTOR MASK WITH TRENCHES PERPENDICULAR TO THE METAL TRACE. 68 


\section{SUMMARY}

This thesis reports on a new implementation of high quality factor $(Q)$ copper $(\mathrm{Cu})$ inductors on CMOS-grade $(10-20 \Omega . \mathrm{cm})$ silicon $(\mathrm{Si})$ substrates using a fully CMOScompatible process. A low-temperature $\left(<300^{\circ} \mathrm{C}\right)$ fabrication sequence is employed to reduce the loss of $\mathrm{Si}$ wafers at $\mathrm{RF}$ frequencies by trenching the $\mathrm{Si}$ substrate. The high aspect-ratio (30:1) trenches are subsequently bridged over or refilled with a low-loss material to close the open areas and to create a rigid low-loss island (Trenched Si Island) on which the inductors can be fabricated. The method reported here does not require air suspension of the inductors, resulting in mechanically-robust structures that are compatible with any packaging technology. The metal loss of inductors is reduced by electroplating thick $(\sim 20 \mu \mathrm{m}) \mathrm{Cu}$ layer.

Fabricated inductors are characterized and modeled from S-parameter measurement. Measurement results are in good agreement with SONNET electromagnetic simulations. A one-turn $0.8 \mathrm{nH} \mathrm{Cu}$ inductor fabricated on a Trenched Silicon Island (TSI) exhibits high $Q$ of 71 at $8.75 \mathrm{GHz}$. Whereas, the identical inductor fabricated on a $20 \mu \mathrm{m}$ thick silicon dioxide $\left(\mathrm{SiO}_{2}\right)$ coated standard $\mathrm{Si}$ substrate has a maximum $Q$ of 41 at $1.95 \mathrm{GHz}$. Comparing the $Q$ of inductors on TSI with that of other micromachined Si substrates reveals the significant effect of trenching the $\mathrm{Si}$ in reduction of the substrate loss. This thesis outlines the design, fabrication, characterization and modeling of spiral type $\mathrm{Cu}$ inductors on the TSI's. 


\section{CHAPTER I}

\section{INTRODUCTION AND MOTIVATION}

With the rapid growth of the wireless communication market, silicon technology has matured to meet the demand for low-cost, high performance, and high level of integration. High- $Q$ integrated inductors can improve the performance and integrationlevel of radio frequency (RF) integrated circuits (IC) while reducing their power consumption and cost. Inductors are vastly used in voltage controlled oscillators (VCO), low noise amplifiers (LNA), power amplifiers (PA), mixers, filters and matching networks. However, on-chip inductors in commercially available CMOS processes exhibit poor $Q$ 's $(<15)$ due to the high-frequency loss of standard Si substrate and ohmic loss of thin metal layers [1]. While metal loss can be reduced by using thick highconductivity metals, the loss of $\mathrm{Si}$ substrate has remained the major barrier in reaching $Q$ 's comparable to that of off-chip inductors.

Common techniques employed to reduce the metal loss in inductors include the use of high conductivity metal layers [2], in particular, electroplating thick $\mathrm{Cu}$ layer [3, 4]; utilizing multi-level metal interconnects to increase the effective thickness of inductor, and series connection of multi-layer inductors in vertical direction to reduce area [5-10]. A 2.88- $\mathrm{nH}$ inductor is described in [2] that has a measured $Q$ of 12.1 at $3.3 \mathrm{GHz}$ in $\mathrm{Si}$ bipolar process using thick gold metal and high resistivity silicon wafer $(150 \sim 200 \Omega . c m)$. In [5-10], the approach is to increase the effective thickness of the spiral inductor and simultaneously reduce the inductor area by shunting spiral inductors in adjacent levels. 
The highest reported $Q$ 's using this technique are 9.3 at $4 \mathrm{GHz}$ for a $1.95 \mathrm{nH}$ inductor with a self-resonance frequency of $20 \mathrm{GHz}$ [5] and 13.1 at $5.65 \mathrm{GHz}$ with inductance of about $5 \mathrm{nH}[8]$. The major draw back of using multi-layer metal is simultaneous increase of the parasitic capacitance introduced between the layers. Nonetheless, the most effective way of reducing the metal loss is through electroplating a thick layer of high conductivity metal (e.g., $\mathrm{Cu})$.

Micromachining techniques have been utilized to reduce the substrate loss and increase the $Q$. Previously reported techniques include the use of thick isolating oxide layer [11, $12]$, use of porous silicon to increase the substrate resistance $[13,14]$, suspension of the inductors [15-17], use of 3-D structures such as toroids and self assembled solenoids [1820], and use of thick low-K dielectrics [21, 22]. Approaches taken to reduce the substrate loss can be divided in to two major categories: Reducing the loss of Si itself (e.g., oxidizing the $\mathrm{Si}$ ), or suppressing the effect of lossy Si substrate on the inductor. In [21, 22], the substrate loss is suppressed by using a thick BCB layer. The use of thin low-K dielectric materials alone is not sufficient to effectively reduce the substrate loss. Using suspended inductors, the highest reported $Q$ is 70 at $6 \mathrm{GHz}$ for an inductance value of $1.38 \mathrm{nH}[16]$. However, suspension may cause susceptibility to shock and vibrations and can complicate die packaging. Quality factor of 3-D and suspended inductors also drops because of the encapsulating material used for packaging [23]. 
No work has been done to reduce the loss of $\mathrm{Si}$ substrate through a low-temperature CMOS-compatible process. Silicon gets oxidized at more than $1000^{\circ} \mathrm{C}$ and the process of making porous $\mathrm{Si}$ is not CMOS compatible.

In [24], the Si loss is reduced by making deep high-aspect ratio trenches into the Si and subsequently oxidizing the $\mathrm{Si}$ left in-between the trenches at $1100^{\circ} \mathrm{C}$. Although this technique has a significant effect on the reduction of Si loss, the high processingtemperature makes it unsuitable for post-CMOS processing. On the other hand, oxidizing the remained $\mathrm{Si}$ is neither necessary to reduce the substrate loss nor it is required to seal the open areas. In fact, trenches can be bridged over by depositing a thin layer of $\mathrm{SiO}_{2}$ at $300^{\circ} \mathrm{C}$. Making trenches in the substrate reduces the substrate loss through disrupting the path of current flowing in the bulk of Si at high frequencies.

In this thesis, we have investigated the effect of trenching the Si on the inductor's quality factor. The height and width of the trenches as well as the area of the Trenched Si Islands are characterized by fabricating several spiral type inductors on TSI. Metal loss in the inductors is reduced by electroplating thick $(\sim 20 \mu \mathrm{m}) \mathrm{Cu}$ layer. Quality factor of the inductors on TSI is compared to the $Q$ 's of identical inductors on other types of micromachined substrates including Oxide Islands. A $0.8 \mathrm{nH} \mathrm{Cu}$ inductor fabricated on $T S I$ exhibits high $Q$ of 71 at $8.75 \mathrm{GHz}$ [26], while the maximum $Q$ of the same inductor on $20 \mu \mathrm{m}$ thick $\mathrm{SiO}_{2}$ is only 41 at $1.95 \mathrm{GHz}$. Comparison of $Q$ 's shows the remarkable effect of trenching the $\mathrm{Si}$ on improving the performance of the inductors at $\mathrm{RF}$ frequencies. 
This thesis is organized into five chapters. Chapter 1 provides literature review, introducing a new technique to reduce the substrate loss as the motivation behind this work. Chapter 2 reviews the physical model of planar spiral inductors on Si substrate. This chapter discusses their design and optimization, outlining the technique of reducing the $\mathrm{Si}$ loss by making trenches in the substrate. Chapter 3 describes the high- $Q \mathrm{Cu}$ inductors on Trenched Si Islands fabrication process. Chapter 4 presents the measured and characterization results of the high- $Q$ inductors, and provides discussion of these results. Finally, chapter 5 concludes the thesis and provides suggestions on future research direction. 


\section{CHAPTER II}

\section{DESIGN AND SIMULATION}

\subsection{Inductor Physical Model}

Figure 2-1 shows the layout of a planar micromachined spiral inductor [26]. The first metal layer, the routing layer, is sandwiched between two insulating layers. In this work, silicon dioxide is used as the insulation layer. In order to efficiently identify the optimal inductor layout and account for its parasitic in circuit simulations, an accurate equivalent model is required. A few equivalent electrical models for spiral inductors are available that describe the inductor behavior in a wide range of frequencies [27-34]. The simplest model is shown in Fig. 2-2, where $L_{s}$ represents the inductance of the spiral and is computed using either of the equations discussed in section 2.2.2.

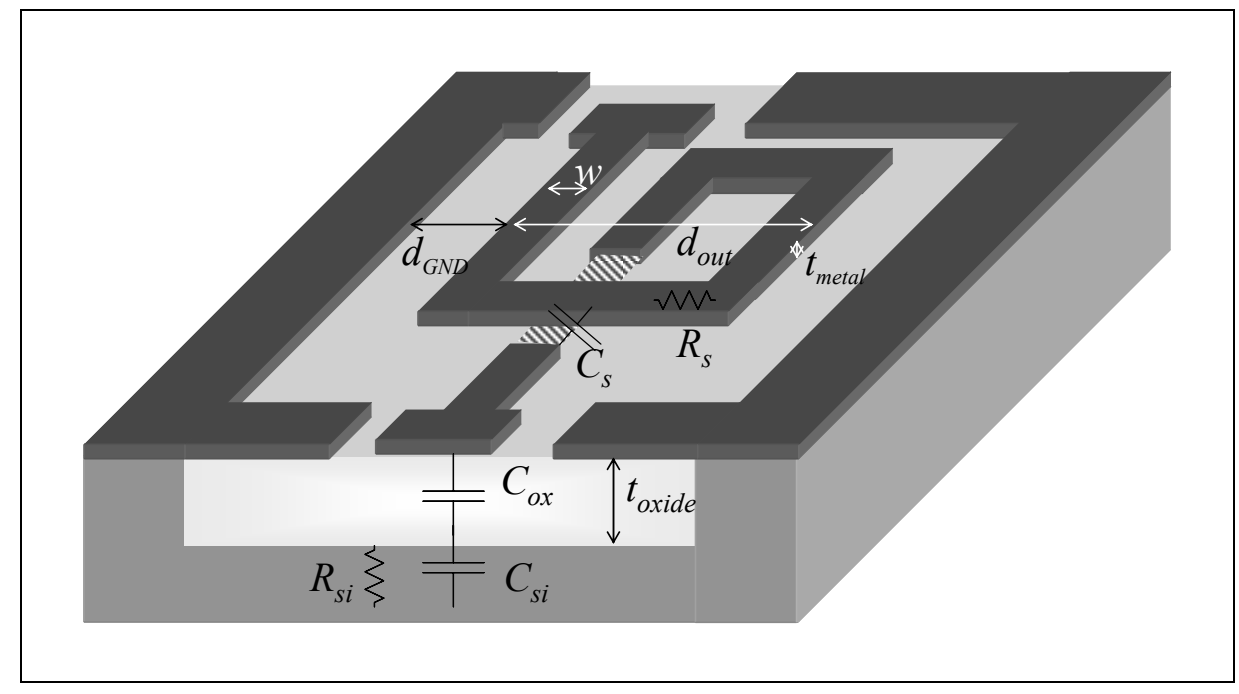

Figure 2-1. Layout of a micromachined planar spiral inductor. 
The resistance of the two metal layers is expressed by $R_{s}$. An approximate formula for $R_{s}$ is shown in Fig. 2-2, taking into account the skin depth of the conductor with finite thickness and current distribution in an isolated strip conductor [35]. The overlap between the metal layers allows direct capacitive coupling between the two terminals of the inductor. This feed-through path is modeled by the series capacitance; $C_{s} . C_{o x}$ models the silicon dioxide capacitance between the spiral turns and the silicon substrate. $C_{s i}$ and $R_{s i}$ model the capacitance and resistance of the Si substrate, respectively [28]. $C_{s u b}$ and $G_{s u b}$ are properties of the Si substrate and are extracted from measured data.

$$
\begin{aligned}
& C_{o x}=\frac{1}{2} \cdot l \cdot w \cdot \frac{\varepsilon_{o x}}{t_{o x}} \\
& C_{s}=n \cdot w^{2} \frac{\varepsilon_{o x}}{t_{o x M 1-M 2}} \\
& R_{s} \cong \frac{\rho \cdot l}{2(w+t) \cdot \delta}, \quad \delta=\sqrt{\frac{\rho}{\pi \mu f}} \\
& C_{s i}=\frac{1}{2} \cdot l \cdot w \cdot C_{s u b} \\
& R_{s i}=\frac{2}{l \cdot w \cdot G} \\
& L_{s}=\text { from Mohan 's Eq. }
\end{aligned}
$$

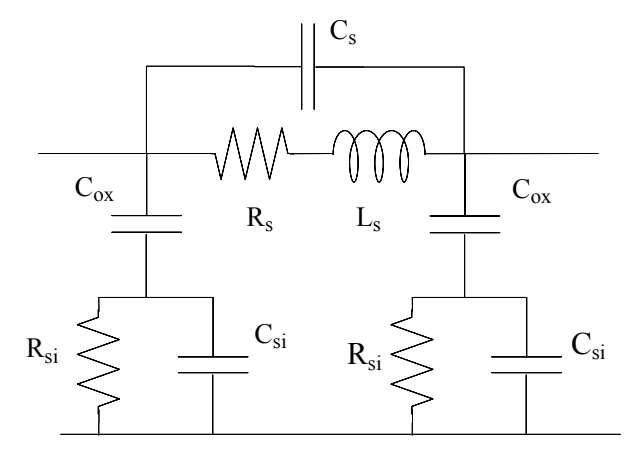

Figure 2-2. The electrical model of an on-chip spiral inductor (l=overall length of the inductor, $w=$ line width, $t_{o x}=\mathrm{SiO}_{2}$ thickness between $2^{\text {nd }}$ metal layer and substrate, $\varepsilon \mathrm{x}=$ $\mathrm{SiO}_{2}$ permittivity, $n=$ number of crossover between the two metal layers, $t_{\text {ox }} \mathrm{MI}-\mathrm{M} 2=\mathrm{SiO}_{2}$ thickness between the metal layers, $\delta=$ metal skin depth, $t=$ metal thickness, $\rho=$ metal resistivity, $\mu=$ metal permeability, $C_{\text {sub }}=$ substrate capacitance per unit area, $G_{\text {sub }}=$ substrate conductance per unit area, $f=$ operation frequency).

A more accurate model also includes the effect of the electromagnetic coupling between the substrate and the metal turns [29]. 


\subsection{Inductor Model Parameter Extraction}

\subsubsection{Series Resistance}

The current density in a conductor strip is uniform at dc. However, as frequency increases, the current density becomes non-uniform due to the formation of eddy currents. The eddy current effect occurs when a conductor is subjected to time-varying magnetic fields and is governed by Faraday's law [36, 37]. Eddy current manifest itself as skin and proximity effects. According to the Lenz's law, eddy currents produce their own magnetic fields to oppose the original field. In the case of the skin effect, the timevarying magnetic field due to the current flow in a conductor induces eddy currents in the conductor itself. The proximity effect takes place when a conductor is under the influence of a time-varying field produced by a nearby conductor carrying a time-varying current. In this case, eddy current is induced whether or not the first conductor carries current. If the first conductor does carry a time-varying current, then the skin-effect eddy current and the proximity-effect eddy current superpose to form the total eddy current distribution. Regardless of the induction mechanism, eddy currents reduce the net current flow in the conductor and hence increase the ac resistance. Since a spiral inductor is a multi-conductor structure, eddy currents are caused by both proximity and skin effects.

The distribution of eddy currents depends on the geometry of the conductor and its orientation with respect to the imposing time-varying magnetic field. The most critical parameter presenting the skin effect is the skin depth. The skin depth is also known as the "depth of penetration" since it describes the degree by which the electromagnetic field 
penetrates into the thickness of a conductor at high frequencies. The severity of the skin effect is determined by the ratio of skin depth to the conductor thickness. The eddy current effect is negligible only if the depth of penetration is much greater than the conductor thickness (e.g., at frequencies close to dc).

Current distribution in a conductor is strongly dependent on the location of the ground plane. In case of the isolated conductor, at low frequencies where the skin depth is in the order of the strip thickness, the current distribution is almost uniform across the thickness of the conductor. If this condition is satisfied, the ac resistance of the conductor per unit length can be calculated from:

$$
R_{a c_{f \rightarrow 0}}=R_{d c}=\frac{1}{\sigma w t} \quad t \leq 2 \delta
$$

where $\sigma$ is the metal conductivity, and $w$ and $t$ are the conductor width and thickness, respectively.

At high frequencies however, when the skin depth is much smaller than the strip thickness (say $t>4 \delta$ ), a nearly exponential penetration of the electric field distribution in the conductor can be observed. This behavior of the current distribution is used to find the approximate formula for the ac resistance of an isolated strip [35].

$$
R_{a c_{f->0}}=k \frac{l}{2 \sigma \delta(w+t)} \quad t \geq 4 \delta
$$


where $l, w$ and $t$ are the conductor length, width and thickness, respectively. $\sigma$ is the conductivity of the strip, and $\delta$ is the metal skin depth. $k$ is the correction factor, which depends on $w$ and $t$.

On the other hand, for a microstrip line with large $w / h$ ratio, current recedes to the bottom surface of the conductor [38-41]. The $w$ and $h$ are the width of the conductor and the thickness of the substrate (distance of the inductor structure to the ground plane), respectively. The current distribution is otherwise almost uniform across the height of the conductor. Figure 2-3 compares the current density distribution for two extreme cases of $w / h$ ratio. For microstrip conductors at high frequencies the effective thickness can then be approximated by

$$
t_{e f f}=\delta \cdot\left(1-e^{-t / \delta}\right)
$$

And as a result, the series resistance, $R_{s}$, can be expressed as

$$
R_{s}=\frac{\rho . l}{w . t_{e f f}}
$$

Based on Eq. 2-4, resistance of a microstrip line does not decrease by increasing it's thickness in excess of $5 \times$ skin depth. On the contrary, having an isolated strip structure for the inductor allows reduction of the series resistance by increasing the thickness of the conductor, even in excess of $5 \times$ skin depth. 


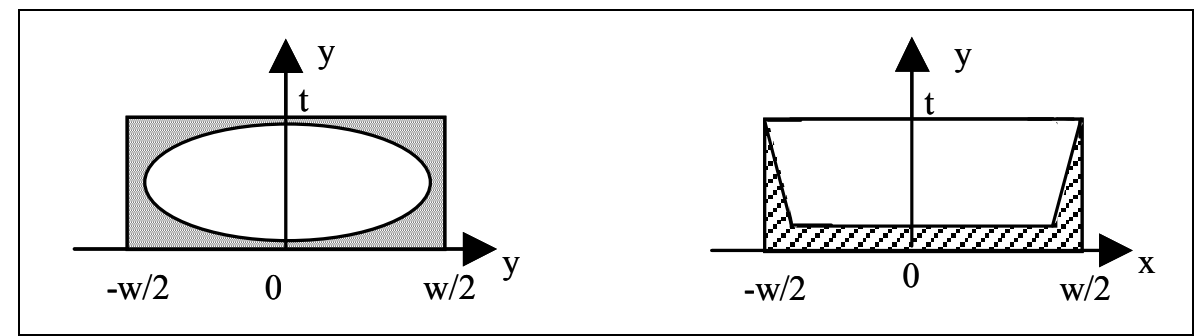

(a)

(b)

Figure 2-3. Effective area of current flow at high frequencies where (a) $\mathrm{w} / \mathrm{h} \rightarrow 0$ and (b) $\mathrm{w} / \mathrm{h} \rightarrow \infty$.

To take advantage of this phenomenon, inductor structures used in this thesis are coplanar with distant ground, knowing that coplanar structures with distant ground behave like isolated strips. Therefore, the equivalent series resistance can be calculated from:

$R_{s}=\sqrt{\left(\frac{l}{\sigma w t}\right)^{2}+\left(\frac{k l}{2 \sigma \delta(w+t)}\right)^{2}}$

SONNET simulation results also confirm that for coplanar structures with distant ground, current also flows on the top surface of the conductor. The verification of this fact is shown in Fig. 2-4 (red color shows the highest current density). At $10 \mathrm{GHz}$ the current is confined closer to the metal walls, showing the effect of the skin depth. 


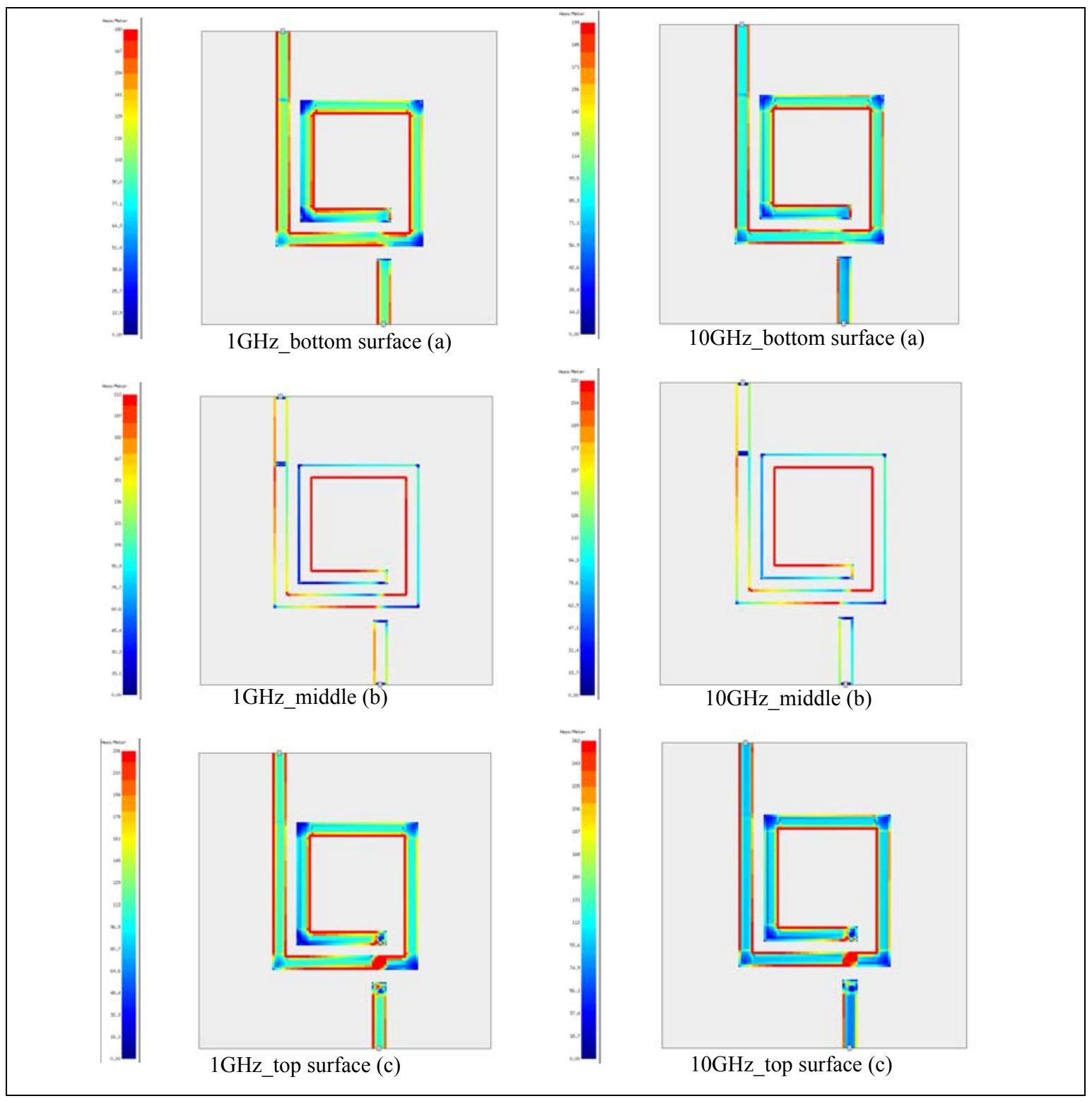

Figure 2-4. Current density of a 1.5-turn inductor at $1 \mathrm{GHz}$ and $10 \mathrm{GHz}$ (a) at the bottom surface of metal, (b) at half the thickness of metal, and (c) at the top surface of metal. 


\subsubsection{Series Inductance}

Many equations have been established to calculate the total inductance of a spiral inductor, based either on the Greenhouse theory or on the experimental results. Table 2-1 summarizes some of the proposed formulas. Greenhouse considers an n-turn rectangular spiral inductor as a set of $4 \mathrm{n}$ straight segments. The overall inductance of this inductor can be calculated by adding up the self-inductance of each straight segment and the mutual inductance between each two parallel segments [34]. Mohan's equation is based on experimental results and contains most geometrical features of the inductors [42]. This equation is verified by SONNET simulations and is used in this thesis. Figure 2-5 compares the inductance predicted by Mohan's equation with SONNET simulation results for 5 different inductors at the frequency of peak $Q$. The maximum inductance deviation is less than $20 \%$.

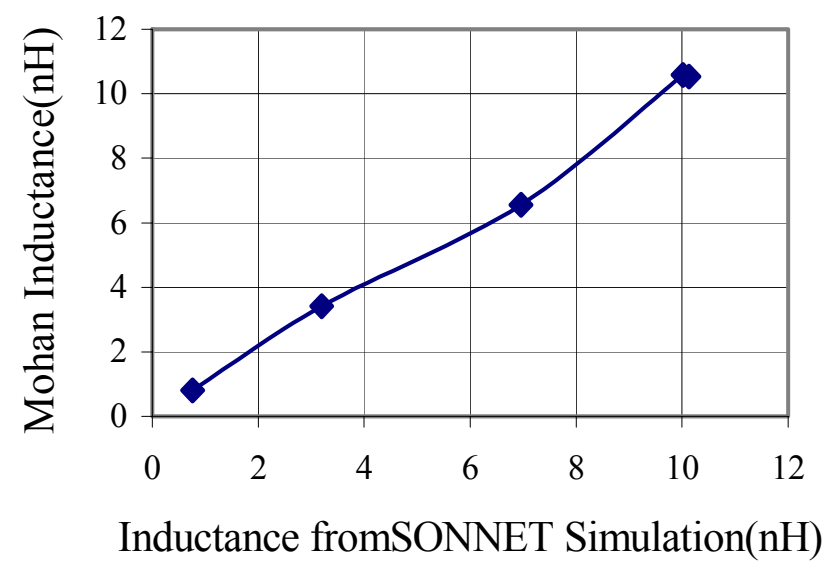

Figure 2-5. Mohan's predicted inductance vs. SONNET simulation results for 5 different inductors. 
Table 2-1. Inductance Formulas [43], [44]

\begin{tabular}{|c|c|}
\hline Voorman & $L_{\text {Voo }}=10^{-3} n^{2} d_{\text {avg }}$ \\
\hline Dill & $L_{\text {dill }}=8.5 \times 10^{-4} n^{5 / 3} d_{\text {avg }}$ \\
\hline Bryan & $L_{b r y}=2.41 \times 10^{-3} n^{5 / 3} d_{\text {avg }} \log \frac{4}{\rho}$ \\
\hline Ronkanien & $L_{r o n}=1.5 \times \mu_{0} n^{2} e^{-3.7(n-1)(w+s) / d_{o u t}}$ \\
\hline Crols & $L_{\text {cro }}=1.3 \times 10^{-4}\left(\frac{d_{\text {out }}^{3}}{w^{2}}\right) \eta_{a}^{5 / 3} \eta_{w}^{1 / 4}, \eta_{a}=\frac{\text { metal area }}{\text { total area }}, \eta_{w}=\frac{w}{w+s}$ \\
\hline Terman & $\begin{array}{l}L=0.0467 s n^{2}\left\{\log \left[2 s^{2} /(t+w)\right]-\log 2.414 s\right\}+ \\
0.02032 n^{2}\{0.914+[0.2235(t+w) / s\}\end{array}$ \\
\hline $\begin{array}{l}\text { Expanded } \\
\text { Grover(Green } \\
\text { house) }\end{array}$ & $\begin{array}{l}L_{T}=L_{0}+M_{+}-M_{-}, \quad L_{0}=\sum L_{x} \\
L_{x}=2 l_{x}\left\{\ln \left[2 l_{x} /(w+t)\right]+0.50049+\left[(w+t) / 3 l_{x}\right]\right\}\end{array}$ \\
\hline $\begin{array}{l}\text { Mohan's } \\
\text { Empirical } \\
\text { expression }\end{array}$ & $\begin{array}{l}L(n H)=\beta d_{o}^{\alpha_{1}} w^{\alpha_{2}} d_{\text {avg }}^{\alpha_{3}} n^{\alpha_{4}} s^{\alpha_{5}} \\
\beta=0.00162,\left\{\alpha_{i}\right\}_{i=1}^{5}=\{-1.21,-0.417,2.40,1.78,-0.03\}\end{array}$ \\
\hline \multicolumn{2}{|c|}{$\begin{array}{l}\text { t: conductor thickness, w: conductor width, s: line-line spacing, n: number of turns, } l_{x} \text { : } \\
\text { length of each segment, } M_{+} \text {and M.:positive and negative mutual } \\
\text { inductances, } \rho=\frac{d_{\text {out }}-d_{\text {in }}}{d_{\text {out }}+d_{\text {in }}}, d_{\text {avg }}=\frac{d_{\text {out }}+d_{\text {in }}}{2}\end{array}$} \\
\hline
\end{tabular}

\subsubsection{Series Capacitance and Substrate Parasitics}

As it was previously mentioned, $C_{s}$ represents the feed-through effect as well as the sidewall parasitic capacitances. The contribution of sidewall parasitic is negligible due to the insignificant voltage difference between the two adjacent strips, and $C_{s}$ can be calculated from:

$$
C_{s}=\frac{\varepsilon_{\text {dielectric }} A_{\text {overlap }}}{d}=n \cdot w^{2} \frac{\varepsilon_{o x}}{t_{o x M 1-M 2}}
$$


The high frequency loss of $\mathrm{Si}$ substrate is represented in $C_{s i}$ and $R_{s i}$. Specifically, $R_{s i}$ is originated from the creation of eddy currents in the low resistivity Si substrate and $C_{s i}$ models the high frequency capacitive effect occurring in the semi-conductors. To extract the substrate characteristic, dummy structures should be included on the substrate. Assume a rectangular dummy pad to have a measured impedance of $Z_{p a d} . R_{s i}$ and $C_{s i}$ can be approximated by:

$Z_{p a d}=R_{p a d}+\frac{1}{j \omega C_{p a d}}$

$R_{S i}=R_{\text {pad }} \times \frac{\text { pad area }}{\text { total inductor area }}$

$C_{S i}=C_{p a d} \times \frac{\text { total inductor area }}{\text { pad area }}$

Eq. 2-9

\subsubsection{Spiral Inductor Quality Factor}

The general expression for the quality factor is:

$$
Q=\frac{\text { energy stored }}{\text { energylost }}
$$

For inductors, the only desirable source of storing energy is magnetic field and hence any source of storing electric energy such as capacitances is considered as a parasitic. As a result, $Q$ of an inductor can be simplified as follow:

$Q=2 \pi \frac{\text { peak magnetic energy }- \text { peak electric energy }}{\text { Energy dissipated per cycleof oscillation }}$ 
The frequency at which the peaks of electric and magnetic energies are equal is called the self-resonance frequency $(S R F)$. Quality factor becomes zero at $S R F$. At frequencies higher than $S R F$, the inductor does not behave as an inductor anymore. There are two separated-source of energy dissipation in an inductor:

\section{Metal loss:}

This loss is due to the finite conductivity of the metal conductors together with the skin and proximity effects presented at high frequencies. $R_{s}$ in the equivalent circuit model represents the metal loss.

II. Substrate loss:

At RF frequencies, induced currents in the $\mathrm{Si}$ substrate limit the $Q$ by converting the electromagnetic energy into heat. Equations 2-12 and 2-13 show components of the induced current in the substrate at the presence of electromagnetic fields [45].

$\nabla \times H=j \omega \varepsilon^{\prime} E+\omega \varepsilon^{\prime} \tan \delta E+\sigma E$

$\nabla \times E=-j \omega \mu H, \quad J=\sigma E$ Eq. 2-13

where $\sigma$ and $\tan \delta$ represent the substrate conductivity and loss tangent, respectively; $\omega$ is the angular frequency, $\varepsilon^{\prime}$ and $\varepsilon^{\prime \prime}$ are the real and imaginary part of the substrate permittivity and $\mu$ is the permeability. For low-resistivity substrates such as CMOS-grade $\mathrm{Si}$, the electrically-induced current $(\sigma E)$ dominates over the dipole loss $\left(\omega \varepsilon^{\prime} \tan \delta E\right)$. However, for high-resistivity substrates the dipole loss is the determining loss 
mechanism. At higher frequencies, creation of the magnetically induced eddy current in low-resistivity substrates (Eq.2-13) also limits $Q$.

These two sources of loss are independent and the unloaded $Q$ can be expressed by [43]:

$\frac{1}{Q}=\frac{1}{Q_{\text {substrate }}}+\frac{1}{Q_{\text {metal }}}$

where $Q_{\text {substrate }}$ and $Q_{\text {metal }}$ represent the substrate loss and the ohmic loss of metal strips, respectively. At very low frequencies, the DC series resistance of the metal layers is the dominant mechanism for determining the $Q$. At higher frequencies, skin effect and proximity effects reduce the effective area of current flow and thus further limits the $Q$. At even higher frequencies, loss mechanisms present in the substrate settles the lower limit on the $Q$.

To investigate the validation of Eq.2-14 and to better understand the contribution of each loss-mechanism in $Q$, SONNET simulations were carried out. Two sets of simulation were performed to study the effect of each source of loss. Metal loss was determined by assuming that the inductor is elevated in vacuum. On the other hand, the substrate loss was considered by using ideal metal conductors. Figure 2-6 illustrates the SONNET simulation results. As can be seen, metal loss is the dominant loss mechanism at low frequencies, while the substrate loss sets the lower limit on the $Q$ at higher frequencies.

To obtain high- $Q$ inductors, the effect of both the substrate and the metal loss has been effectively suppressed. 

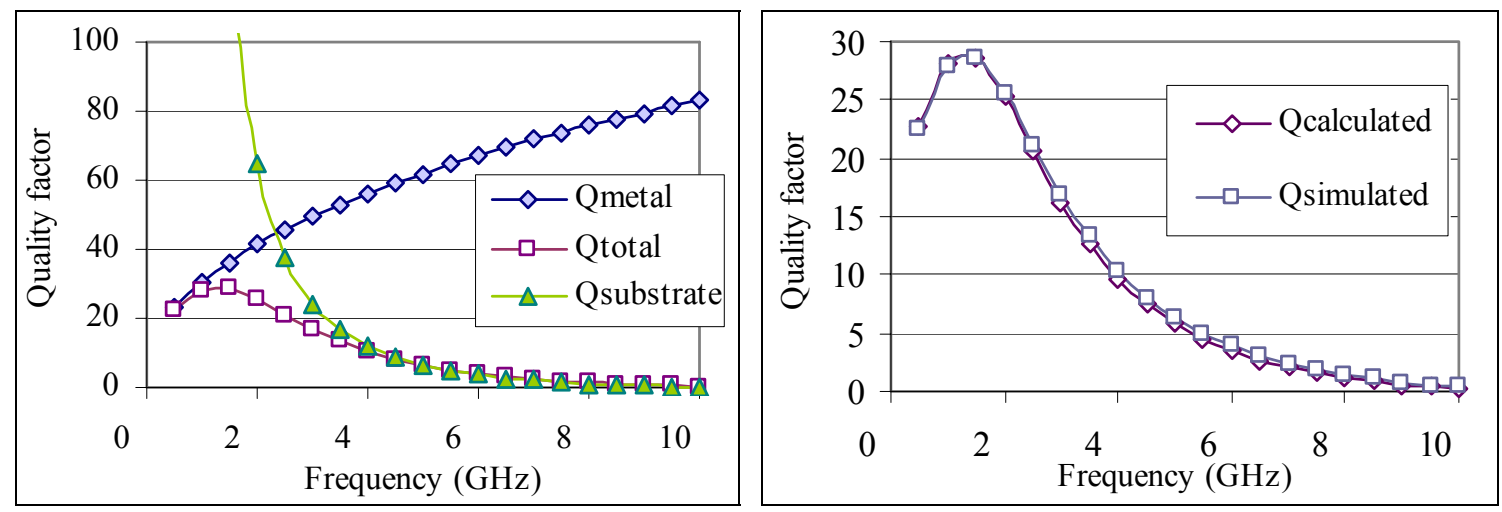

Figure 2-6. (Left) Quality factor vs. frequency for a one-turn spiral inductor and (right) Comparison of the calculated $Q$ (by Eq.2-14) and simulated $Q\left(d_{\text {out }}=500 \mu \mathrm{m} w=50 \mu \mathrm{m}\right.$, and $\left.t_{\text {metal }}=15 \mu \mathrm{m} . \rho=10 \Omega \mathrm{cm}\right)$.

\subsection{Trenched Si Island for Reduced Substrate Loss}

The substrate loss is reduced by trenching the $\mathrm{Si}$. As it was mentioned earlier, the creation of currents in the bulk of Si substrate reduces the $Q_{\text {substrate. }}$ Disrupting the path of current by slicing the substrate with deep high-aspect-ratio trenches reduces the substrate effective permittivity and conductivity, which in turn reduces the electrically- and magnetically-induced currents as well as the dipole loss. The trenches are made underneath the inductors to create an island of low-loss substrate (Trenched Si Island). Two low-temperature approaches are taken to create a rigid and smooth substrate by covering the trenched areas. These approaches include refilling the trenches with a lowloss dielectric material and bridging-over the trenches with a PECVD dielectric layer. Chapter 3 will fully elaborate on the technique taken to reduce the substrate loss. 


\subsection{Thick electroplated Cu for Reduced Metal Loss}

In this work, metal loss is reduced by electroplating thick $\mathrm{Cu}(\sim 20 \mu \mathrm{m})$ and eliminating the effect of ground plane by increasing the signal to ground distance in the inductor layout. The thickness of routing metal (first metal) and the insulating $\mathrm{SiO}_{2}$ layers are said by processing constrains. To alleviate the effect of routing layer on the overall $Q$, the length of this layer must be kept as short as possible.

\subsection{Optimization of the inductor physical dimensions}

In order to obtain the highest possible $Q$ for inductors fabricated on Trenched Si Islands (TSI), all physical dimensions of inductor are optimized using SONNET simulation tool. To find the optimized value of each parameter, all other parameters are kept constant. The optimized parameters are:

1) Metal thickness

2) Trench depth

3) Number of turns

4) Trenched island area

5) Outer diameter

6) Metal width

7) Metal spacing

8) Shape of the inductor (round/rectangular/octagon)

9) Position of the ground plane 


\subsubsection{Metal Thickness}

SONNET calculates the total surface impedance, impedance per unit area, of a thick metal by [41]:

$$
Z_{s}=\frac{(1+j) \rho}{1-e^{-\frac{(1+j) t}{N \delta}}}
$$

where $\rho$ is the metal resistivity, $\delta$ is the skin depth, $t$ is the metal thickness and $N$ is the number of conductor sheets that SONNET requires to estimate the thickness of the metal. By increasing $t$, surface resistance drops exponentially and therefore $Q$ increases. Figure 2-7 illustrates the dependency of the $Q$ on the metal thickness. Simulation results confirm the $Q$ improvement with metal thickness in excess of $5 \times \delta$.

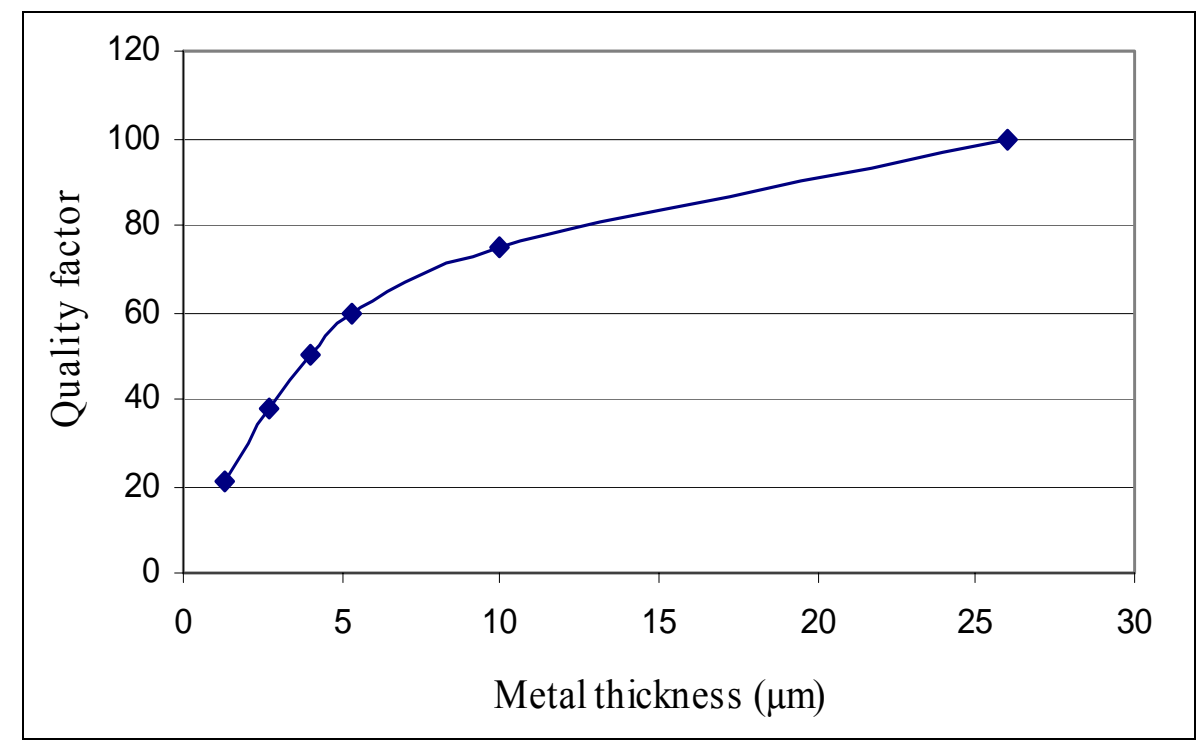

Figure 2-7. $Q$ vs. metal thickness using SONNET thick metal model. $N=20$ for $26 \mu m$ thick inductor and $N=5$ for $6 \mu \mathrm{m}$ metal. 


\subsubsection{Trench Depth}

Optimum value for the trench depth cannot be obtained by SONNET simulation tool as it is computationally intensive. To have an estimate of the required trench depth, simulations were done assuming the substrate is covered with a thick oxide layer. SONNET simulations indicate an increase in the inductor $Q$ with oxide thickness up to $50 \mu \mathrm{m}$ for a $2.9 \mathrm{nH}$ inductor (Fig. 2-8). The optimum value of the trench depth could be close to $50 \mu \mathrm{m}$ but needs to be obtained experimentally.

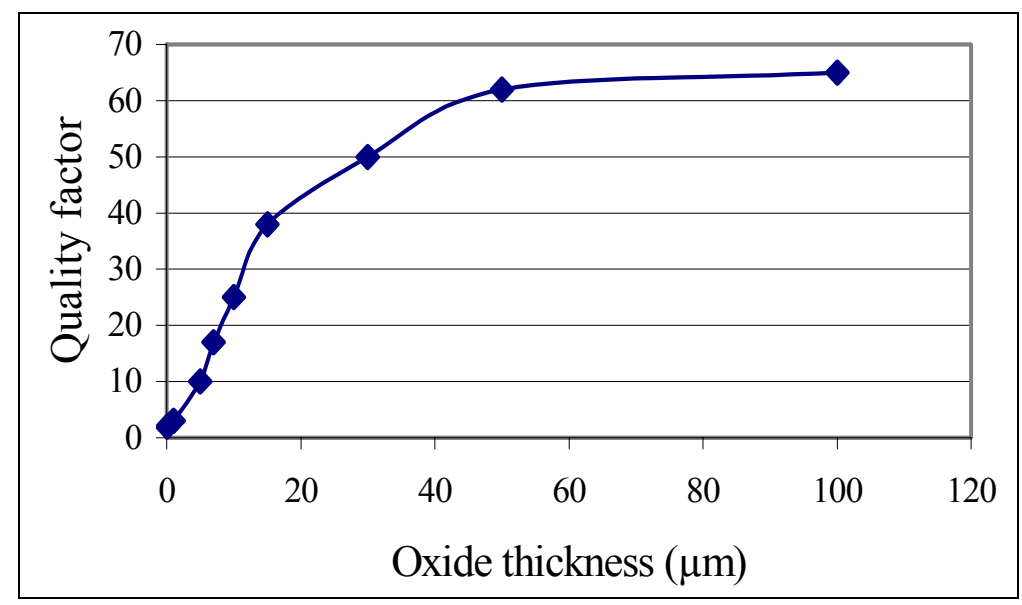

Figure 2-8. $Q$ vs. oxide thickness $\left(t=4 \mu \mathrm{m}, w=40 \mu \mathrm{m}, \mathrm{s}=10 \mu \mathrm{m}, d_{\text {out }}=400 \mu \mathrm{m} L=2.9 \mathrm{nH}\right)$.

\subsubsection{Number of Turns}

Increasing the number of turns results in smaller outer diameter for a specific inductance value. Accordingly, the inner diameter of the inductor reduces. Since the magnetic field is maximum at the center of the spiral inductor, the unwanted substrate current density is 
high near the center of the inductor. This induced current in the substrate will cause a reverse current to flow in the inner most conductors, resulting in an increase in the series resistance and decreases in the $Q$ [27]. Figure 2-9 demonstrates the validation of the above argument.

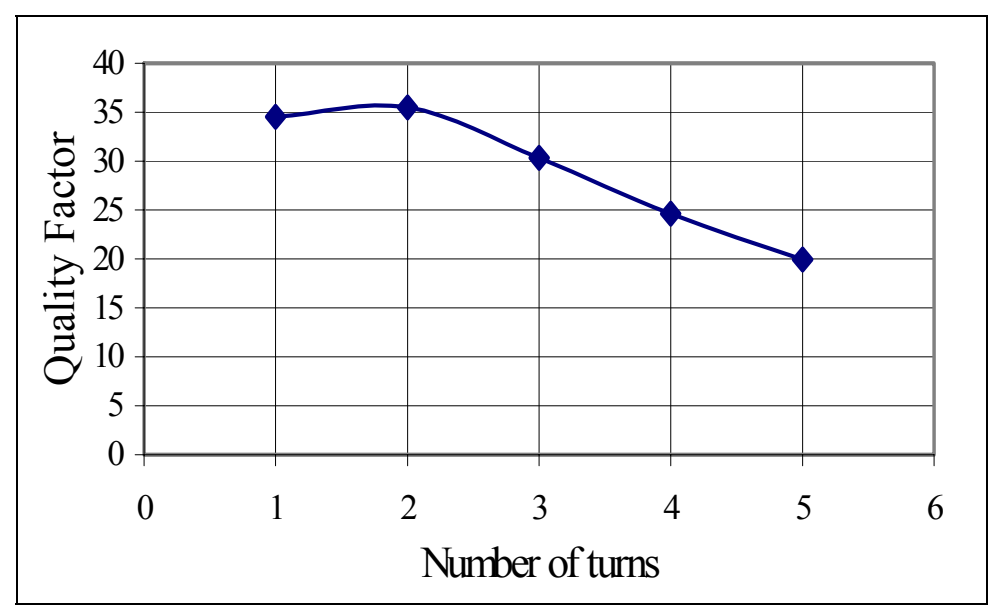

Figure 2-9. $Q$ vs. Number of turns $(f=2.4 \mathrm{GHz}, L=2.9 n \mathrm{H}, \quad s=5 \mu \mathrm{m}$ and $w=20 \mu \mathrm{m}$, $t=6.75 \mu \mathrm{m})$.

In our case, where the first metal layer is thin, one-turn inductors exhibit higher $Q$ compared to the multi-turn inductors of the same inductance value.

\subsubsection{Trenched Island Area}

SONNET cannot be used to optimize for the minimum required trenched area due to a bug in the tool. The minimum required trenched area must be attained experimentally. 


\subsubsection{Outer Diameter}

Smaller-size inductors have smaller substrate parasitic capacitance and thus higher selfresonance frequency. Increasing the outer diameter increases the series resistance and inductance. Since the inductance and resistance values increase at the same rate, the peak $Q$ remains almost constant. Figure 2-10 show the shift in the frequency of peak $Q$ versus frequency as the outer diameter of a one-turn spiral inductor changes. For a better comparison, frequency of peak $Q$ is sketched versus $d_{\text {out }}$ in Fig. 2-11. Maximum $Q$ occurs at lower frequency as the outer diameter increases [46].

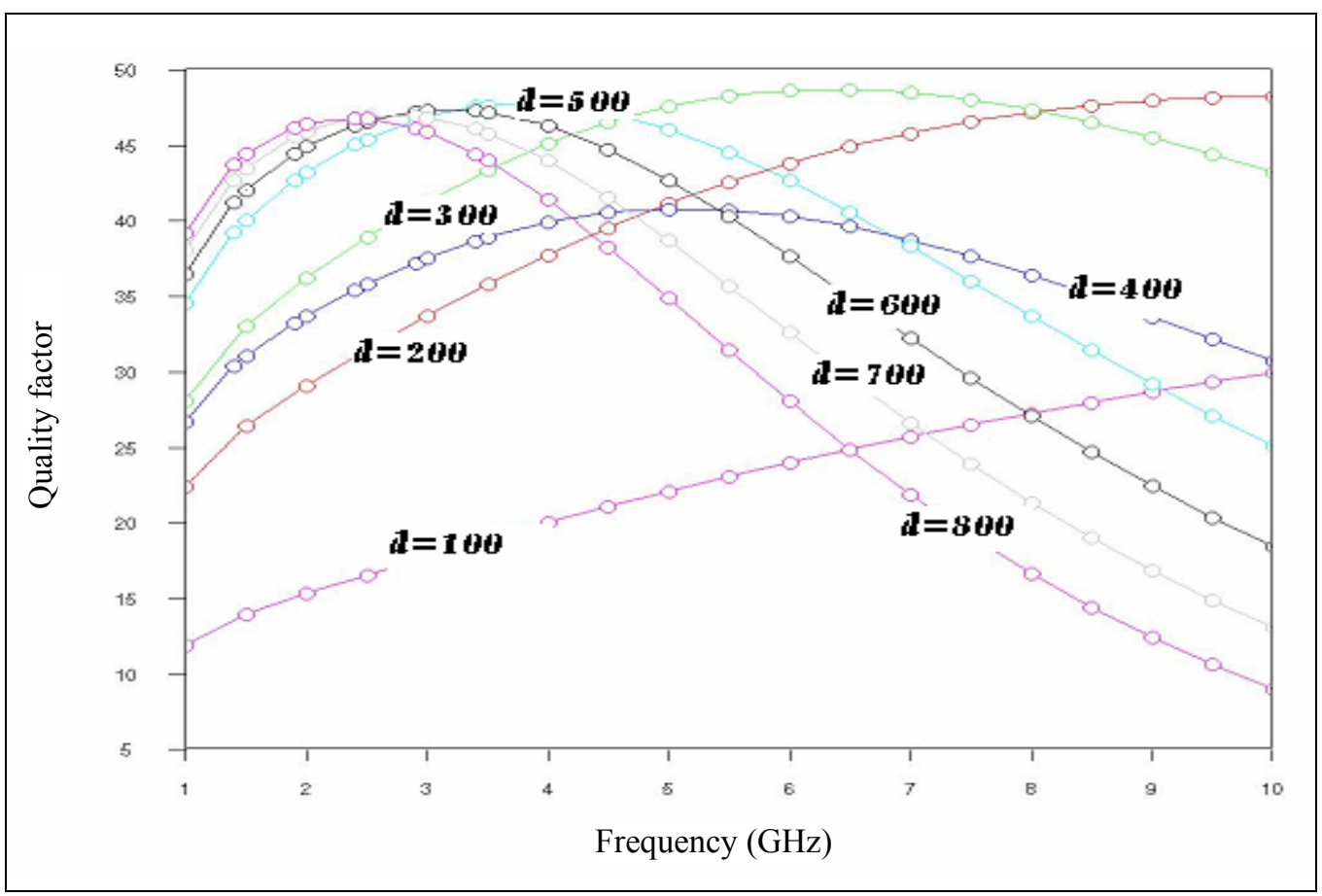

Figure 2-10. $Q$ vs. frequency for a one-turn inductor with various $d_{\text {out }}(w=40 \mu \mathrm{m})$. 


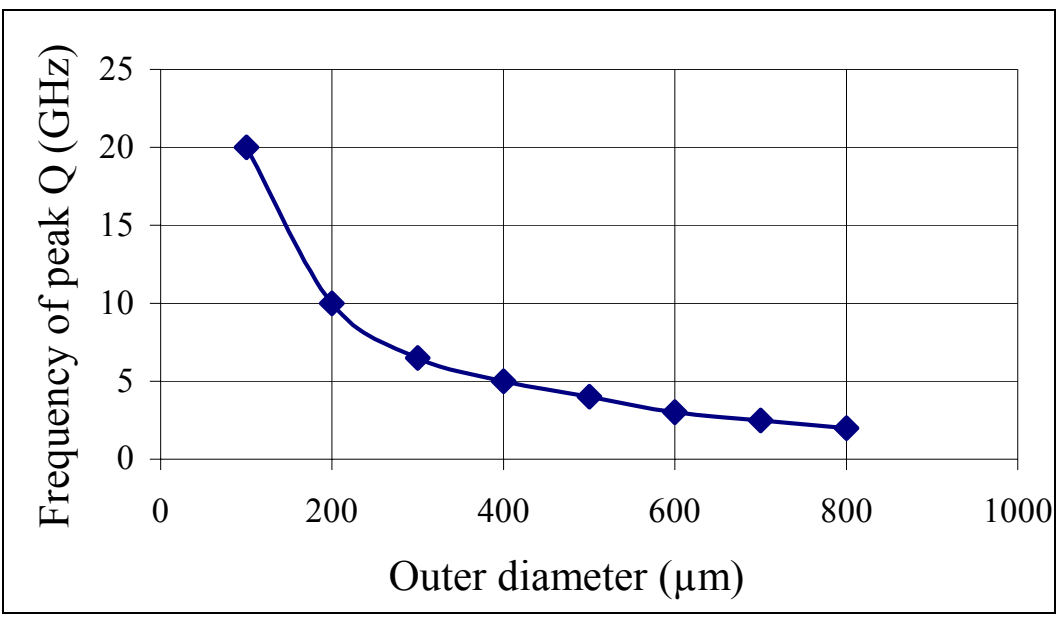

Figure 2-11. Frequency of peak $Q$ vs. $d_{\text {out. }}$ for one turn inductors with $\mathrm{w}=40 \mu \mathrm{m}$.

\subsubsection{Metal Width}

Variation of the conductor width $(w)$ affects the $Q$ in several ways. The primary consequence of increasing $w$ is reduction of the conductor's series resistance. On the other hand, increasing the conductor width has a negative effect on the $Q$ due to the simultaneous enlargement of the substrate parasitic capacitance. Metal width has an optimum value that must be designed for each specific inductor. Figure 2-12 shows the change in $Q$ as a function of $w$ for two different inductors.

Another consequence of increasing the metal width is reduction of the $S R F$ given that the substrate capacitance increases accordingly. 


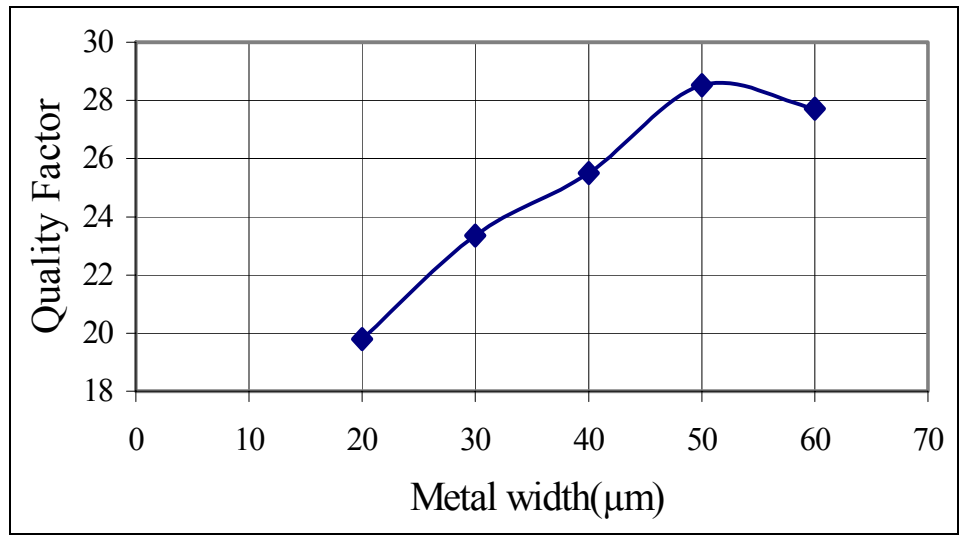

(a)

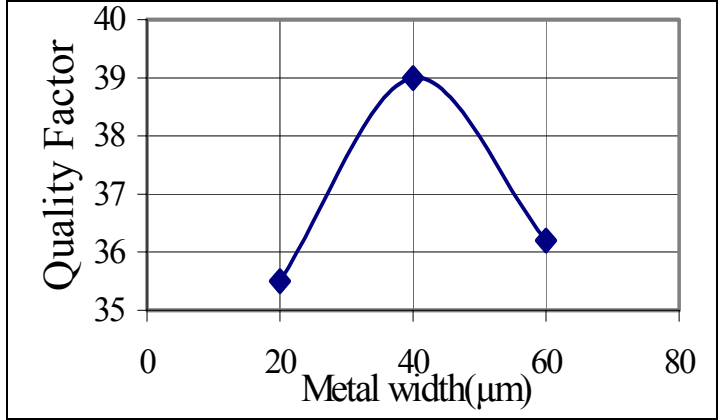

(b)

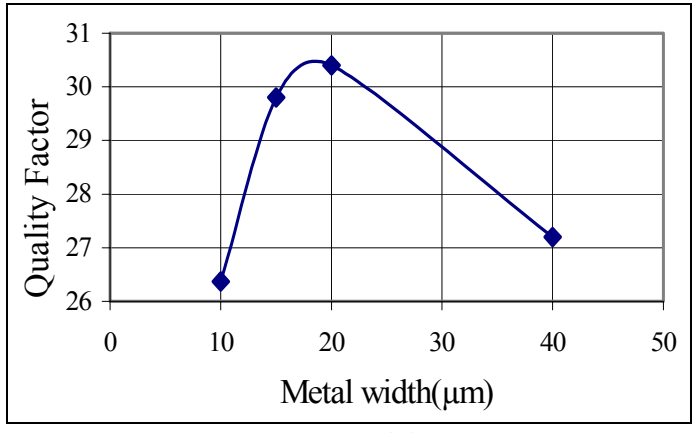

(c)

Figure 2-12. $Q$ vs. conductor width for (a) one-turn 1 nH inductors (b) $2.9 n H$ inductors $(s=5 \mu m$ and $n=2)$, and (c) $2.9 n H$ inductors $(s=5 \mu m$ and $n=3)$.

\subsubsection{Metal Spacing}

When working at low frequencies, minimum possible spacing determined by lithography resolution is favored to maximize the magnetic coupling (Eq. 2-16).

$$
\left.2 s_{\min }=3 \sqrt{\lambda\left(g+\frac{1}{2}\right.} z\right)
$$


where $s_{\min }$ is the minimum feature size, $\lambda$ is the light wavelength, $g$ is the gap between the mask and the substrate and $z$ is the thickness of the photoresist. At high frequencies proximity effects and magnetic coupling favor a larger value of spacing [27]. At $2.4 \mathrm{GHz}$ two sets of inductors with two and three number of turns were simulated. The results are shown in Fig. 2-13.

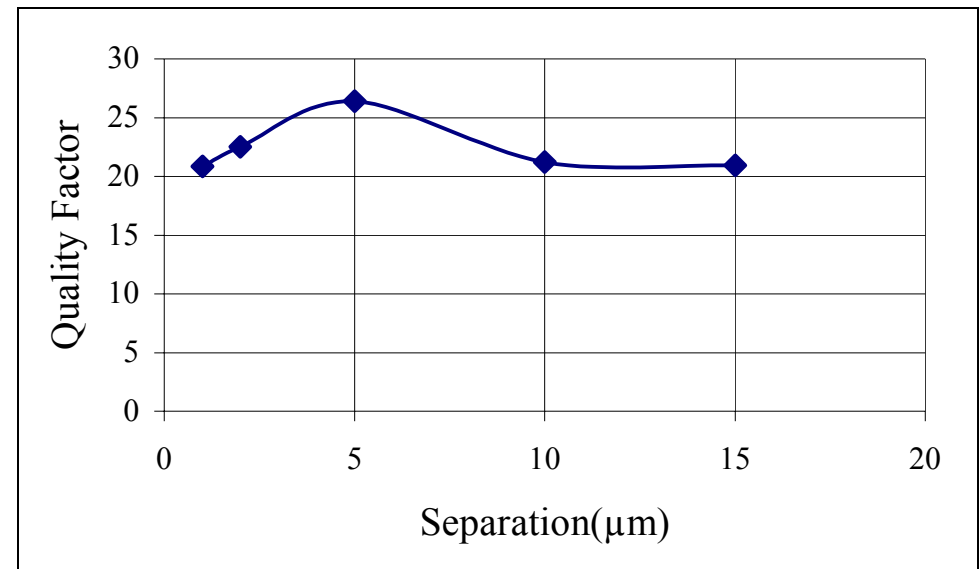

(a)

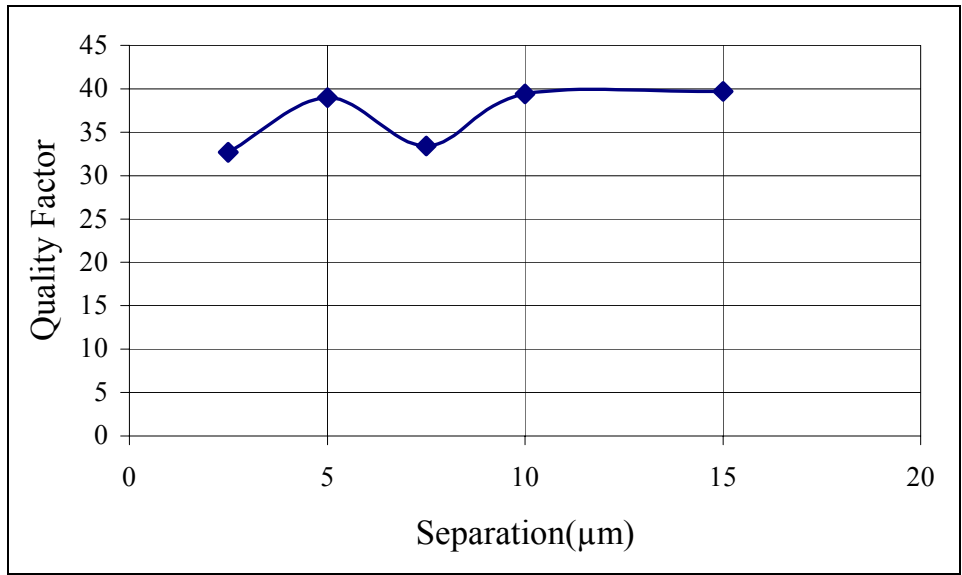

(b)

Figure 2-13. $Q$ vs. separation for 2.9nH inductors with (a) $w=10 \mu m, n=3$ and (b) $w=40 \mu m, n=2$. 


\subsubsection{Shape of the Inductor (Round/Rectangular/Round-edge)}

Current crowding at the sharp edges of the conductor reduces the effective width and increases the metal loss. Round spiral inductors exhibit higher $Q$ compared to the rectangular inductors due to the reduced current crowding effect. For the same reason, rectangular inductors with round edges show an improved $Q$ compared to inductors with sharp edges. $Q$ of a round inductor is about $25 \%$ better compared to its rectangular counter part (Fig. 2-14).

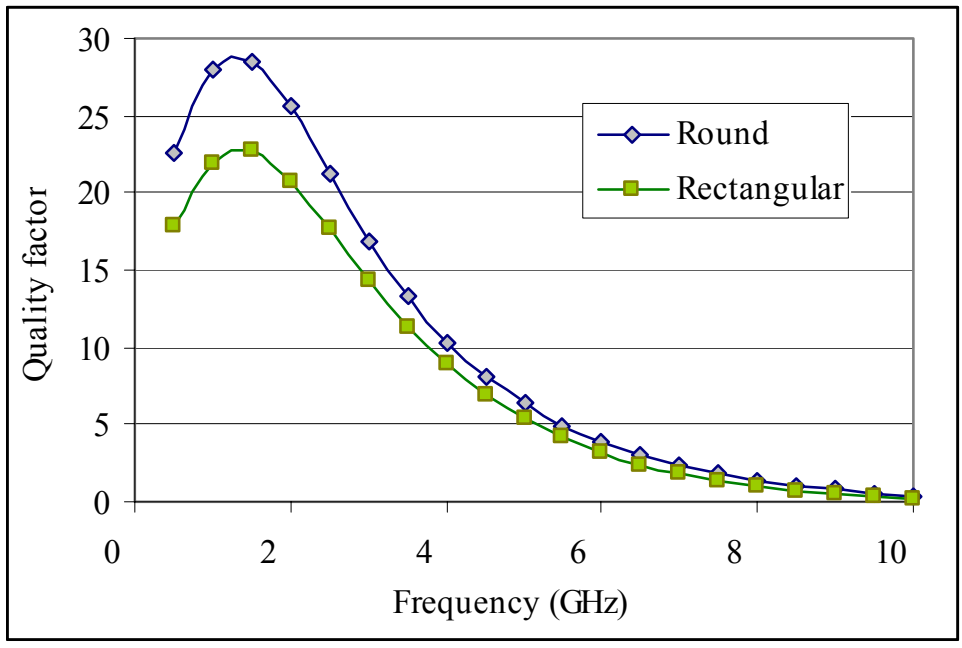

Figure 2-14. $Q$ vs. frequency $\square$ - round spiral and rectangular spiral $(s=50 \mu \mathrm{m}$, $w=50 \mu \mathrm{m}, d_{o u t}=500 \mu \mathrm{m}$ and $\left.n=1\right)$.

Rectangular inductors have a slightly higher inductance than round inductors with same physical dimensions. In Fig. 2-14 for instance, $L=0.96 \mathrm{nH}$ at $0.5 \mathrm{GHz}$ for the rectangular and $L=0.90 \mathrm{nH}$ for the round inductor. 


\subsubsection{Position and Shape of the Ground Plane}

Coplanar ground plane has less effect on the current distribution in the signal line compared to the ground plane underneath the inductor even when the ground plane is patterned. To minimize the effect of ground plane, the signal to ground distant must be increased. In this work, the distance of the coplanar ground to the closest conductor is kept at $500 \mu \mathrm{m}$. 


\section{CHAPTER III}

\section{FABRICATION}

\subsection{Process Flow}

Figure 3-1 shows the fabrication process flow for the $\mathrm{Cu}$ inductors on Trenched $\mathrm{Si}$

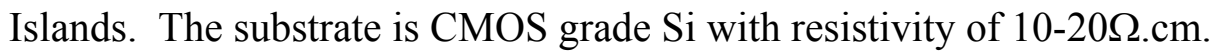

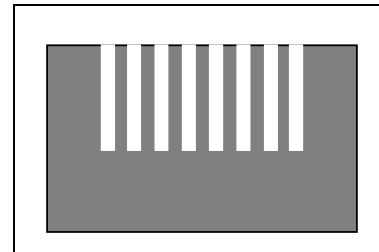

(a)

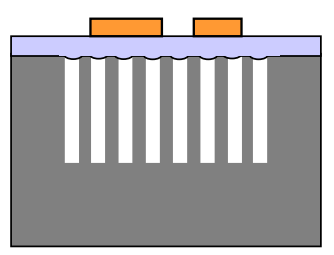

(c)

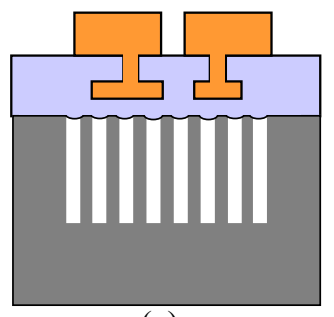

(e)

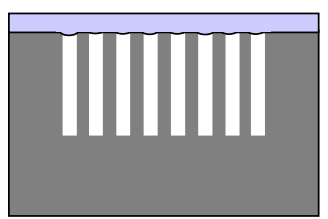

(b)

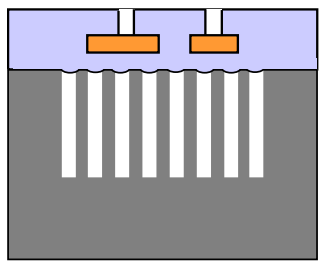

(d)

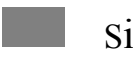

$\mathrm{Si}$

$\mathrm{SiO}_{2}$

$\mathrm{Cu}$

Figure 3-1. Schematic of the process flow.

The fabrication process has four masks. First, deep high-aspect-ratio (30:1) trenches are etched in the Si substrate using the Bosch process in the STS ICP tool. 
The standard factory recipe was modified to reduce the anisotropy of the Bosch process in order to further decrease the substrate loss. The etch recipe in the STS ICP is shown in Table 3-1. The etch time is increased from $10 \mathrm{sec}$ to $11 \mathrm{sec}$ while the passivation time is decreased to $7 \mathrm{sec}$ (from $8 \mathrm{sec}$ ) to increase the undercut.

Table 3-1. Recipe to etch trenches in the STS ICP system.

\begin{tabular}{|c|c|c|c|c|}
\hline $\begin{array}{c}\text { Passivation } \\
\text { time }(\mathrm{sec})\end{array}$ & Etch time (sec) & $\begin{array}{c}\text { Pressure } \\
\text { (mTorr) }\end{array}$ & $\begin{array}{c}\text { RF Platten } \\
\text { power (watts) }\end{array}$ & $\begin{array}{c}\text { RF Generation } \\
\text { power (watts) }\end{array}$ \\
\hline 7 & 11 & 8 & 12 & 600 \\
\hline
\end{tabular}

A 2-3 $\mu \mathrm{m}$ thick PECVD $\mathrm{SiO}_{2}$ layer is then deposited at $300^{\circ} \mathrm{C}$ to cover the openings and lower the substrate parasitic capacitances. The PECVD silicon dioxide deposition is nonuniform and therefore the deposited $\mathrm{SiO}_{2}$ bridges over the openings. The detailed recipe used in the UNAXIS PECVD system is shown in Table 3-2. The deposition rate is about $0.66 \mu \mathrm{m} / \mathrm{min}$.

Table 3-2. Recipe to deposit $\mathrm{SiO}_{2}$ in the UNAXIS PECVD tool.

\begin{tabular}{|c|c|c|c|c|c|c|}
\hline $\begin{array}{c}\text { Temperature } \\
\left({ }^{\circ} \mathrm{C}\right)\end{array}$ & $\begin{array}{c}\text { Pressure } \\
(\mathrm{mTorr})\end{array}$ & $\begin{array}{c}\mathrm{N}_{2} \mathrm{O} \\
\text { pressure } \\
(\mathrm{sccm})\end{array}$ & $\begin{array}{c}\mathrm{He} \\
\text { pressure } \\
(\mathrm{sccm})\end{array}$ & $\begin{array}{c}\mathrm{SiH}_{4} \\
\text { pressure } \\
(\mathrm{sccm})\end{array}$ & $\begin{array}{c}\text { RF power } \\
(\text { watts })\end{array}$ & $\begin{array}{c}\mathrm{DC} \\
\text { power } \\
(\text { watts })\end{array}$ \\
\hline 300 & 950 & 500 & 560 & 500 & 65 & 22 \\
\hline
\end{tabular}

Figure 3-2 shows the cross-section SEM view of a $90 \mu \mathrm{m}$ deep TSI. The etch time of the trenches is 1 hour and the required deposition time for $\mathrm{PECVD} \mathrm{SiO}_{2}$ layer is $45 \mathrm{~min}$. As it is shown in this figure, width of the Si bars is less than width of the trenches, due to the isotropic etching of the Si. 
The first metal layer is subsequently formed by evaporation and patterning of a $2 \mu \mathrm{m}$ thick Chromium (Cr) - $\mathrm{Cu}-\mathrm{Cr}$ layer. CVC E-beam evaporator was used for this purpose. The deposition rates of $\mathrm{Cr}$ and $\mathrm{Cu}$ are $3 \mathrm{~A}^{\circ} / \mathrm{sec}$ and $6 \mathrm{~A}^{\%} / \mathrm{sec}$, respectively. Chromium layer of $300 \mathrm{~A}^{\circ}$ thick was used as the adhesion layer between $\mathrm{Cu}$ and $\mathrm{SiO}_{2}$ since copper has a very poor adhesion to $\mathrm{SiO}_{2}$.

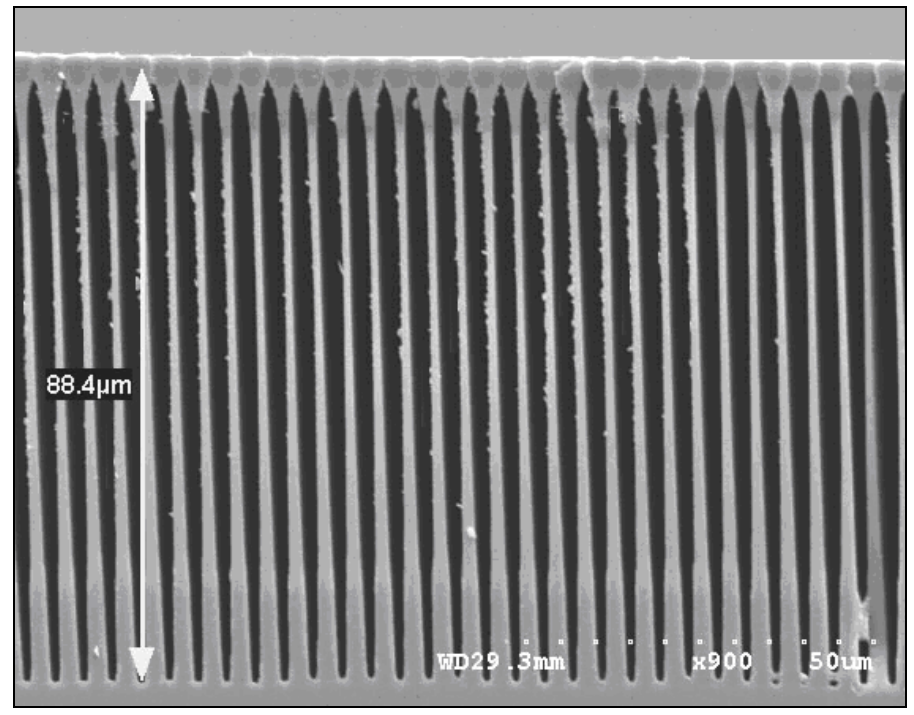

Figure 3-2. Cross-section SEM of a 90 4 m deep TSI.

To isolate the two metal layers, a $2 \mu \mathrm{m}$ thick $\mathrm{PECVD} \mathrm{SiO}_{2}$ is deposited at $300^{\circ} \mathrm{C}$ using the same recipe given in Table 3-2. Vias are subsequently opened using Plasma therm ICP system. The ICP etch process temperature is $60^{\circ} \mathrm{C}$. The recipe used in the Plasma-therm ICP system to anisotropically etch the $\mathrm{SiO}_{2}$ layer is given in Table 3-3. The etching rate is about $0.13 \mu \mathrm{m} / \mathrm{min}$ using this recipe. 
Table 3-3. Dry etch recipe of $\mathrm{SiO}_{2}$ in Plasma-therm ICP system.

\begin{tabular}{|c|c|c|c|c|}
\hline RF1 power & RF2 power & Pressure & $\mathrm{H}_{2}$ flow rate & $\mathrm{CF}_{4}$ flow rate \\
\hline $100 \mathrm{~W}$ & $250 \mathrm{~W}$ & $5 \mathrm{mTorr}$ & $2 \mathrm{sccm}$ & $20 \mathrm{sccm}$ \\
\hline
\end{tabular}

A $300 \mathrm{~A}^{\circ}-1000 \mathrm{~A}^{\circ}$ seed layer of $\mathrm{Cr}-\mathrm{Cu}$ is then sputter-deposited, followed by spin-coating and patterning of the electroplating mold. Thick NR4-8000P negative-tone photoresist from Futurrex Inc. has been used for this purpose, which produces high-aspect-ratio (4.5:1) and straight-sidewall columns as shown in Fig. 3-3 [47].

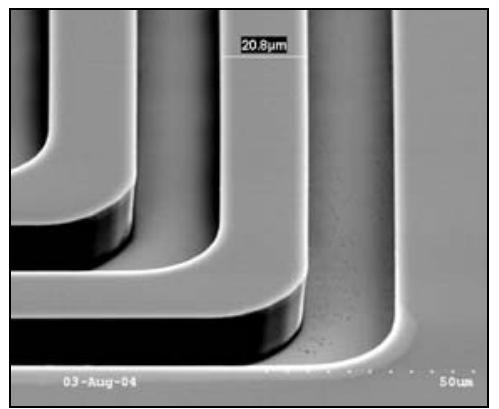

(a)

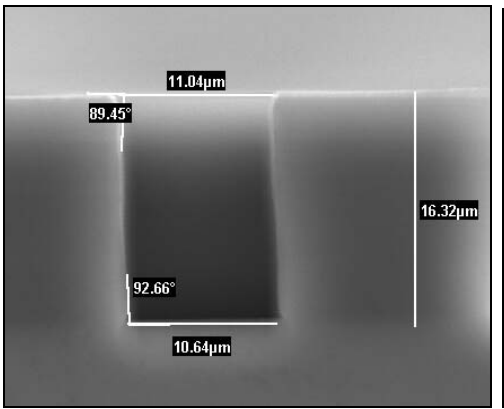

(b)

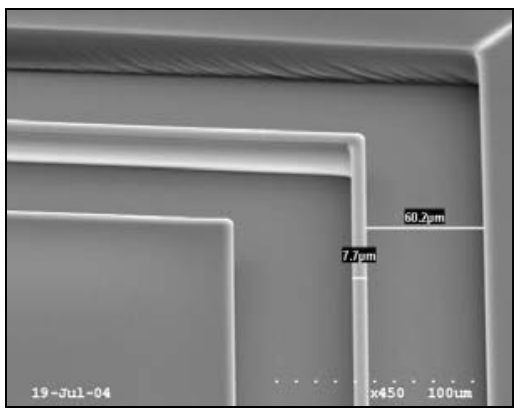

(c)

Figure 3-3. SEM pictures of (a) a $17 \mu m$ thick NR4-8000P used as the electroplating mold; (b) close-up view of the straight photoresist side-walls, and (c) high aspect-ratio (30:8) photoresist column.

Next, thick layer of $\mathrm{Cu}$ is electroplated in an electroplating tank. The electroplating current should be about $25 \mathrm{~mA} / \mathrm{cm}^{2}$ in order to have fine $\mathrm{Cu}$ grids [48]. The electroplating solution was prepared by mixing the chemicals shown in Table 3-4 in the vertical order. To enhance the $\mathrm{Cu}$ grid size and the electroplating rate, the electrolyte is agitated by nitrogen gas bubbles (Fig.3-4). After electroplating for a period of time, the solution level in the electroplating bath goes down and the surface of electroplated $\mathrm{Cu}$ layer becomes 
rough (the $\mathrm{Cu}$ is not shinny anymore). By adding $10 \mathrm{ml}$ of Brightener and $10 \mathrm{ml}$ of Carrier (both from Techni PC 75) and sufficient amount of DI water this problem would be fixed.

Table 3-4. Electroplating solution, the chemical should be mixed in the order presented.

\begin{tabular}{|l|c|}
\hline \multicolumn{1}{|c|}{ Component } & To make 20 liters \\
\hline DI water & 15.8 liter \\
\hline Copper sulfate $\left(\mathrm{CuSO} 4: 5 \mathrm{H}_{2} \mathrm{O}\right)$ & $1.5 \mathrm{~kg}$ \\
\hline $51 \%$ sulfuric acid $\left(\mathrm{H}_{2} \mathrm{SO}_{4}\right)$ & 4 liter \\
\hline PC 75 Brightener & 0.1 liter \\
\hline PC 75 Carrier & 0.1 liter \\
\hline
\end{tabular}

The required electroplating current flow in this case is $800 \mathrm{~mA}$ and the electroplating rate is $0.25 \mu \mathrm{m} / \mathrm{min}$. After electroplating, the photoresist and the seed layer are removed. The photoresist is removed in Acetone and the solution used to remove the Cr layer is described in section 3.3.3. The thin $\mathrm{Cu}$ seed-layer is finally removed in a dilute mixture of $\mathrm{H}_{2} \mathrm{SO}_{4}: \mathrm{H}_{2} \mathrm{O}_{2}(1: 1)$.

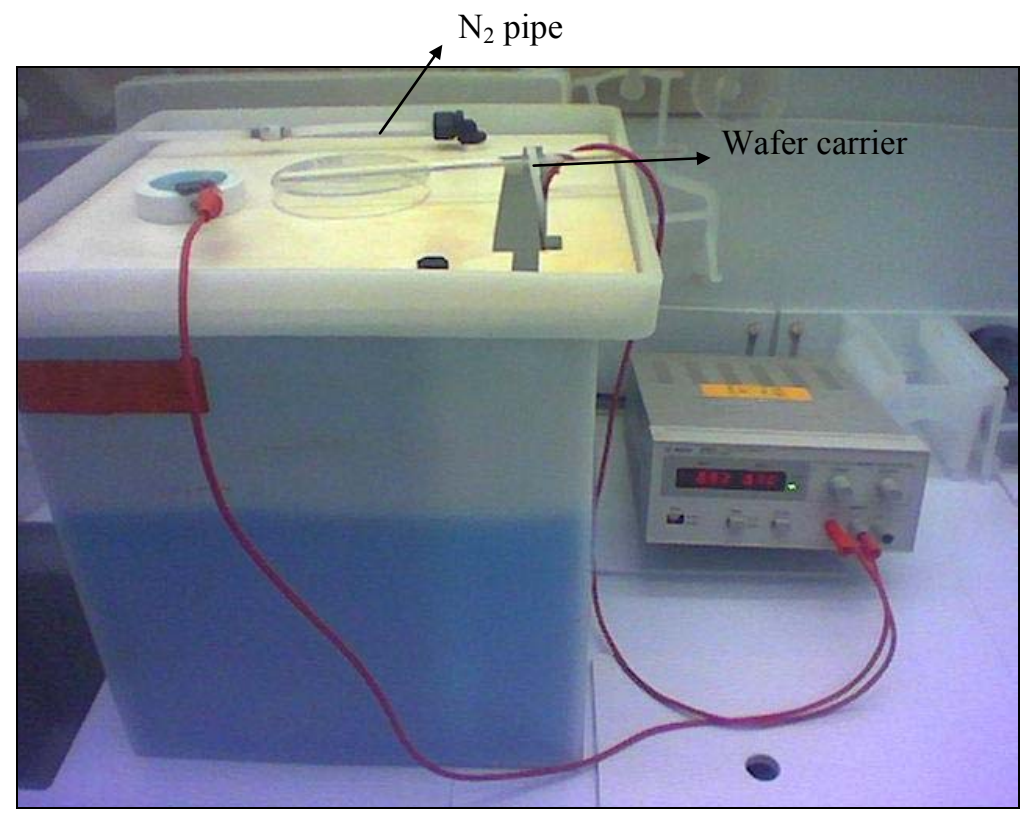

Figure 3-4. Picture of the electroplating tank, showing the electroplating set-up. 
Figure 3-5 shows SEM picture of a one-turn rectangular inductor on TSI. The Cu trace is separated from the substrate during the cleaving process. Figure 3-6 shows SEM picture of a one-turn round inductor on $60 \mu \mathrm{m}$ deep TSI.

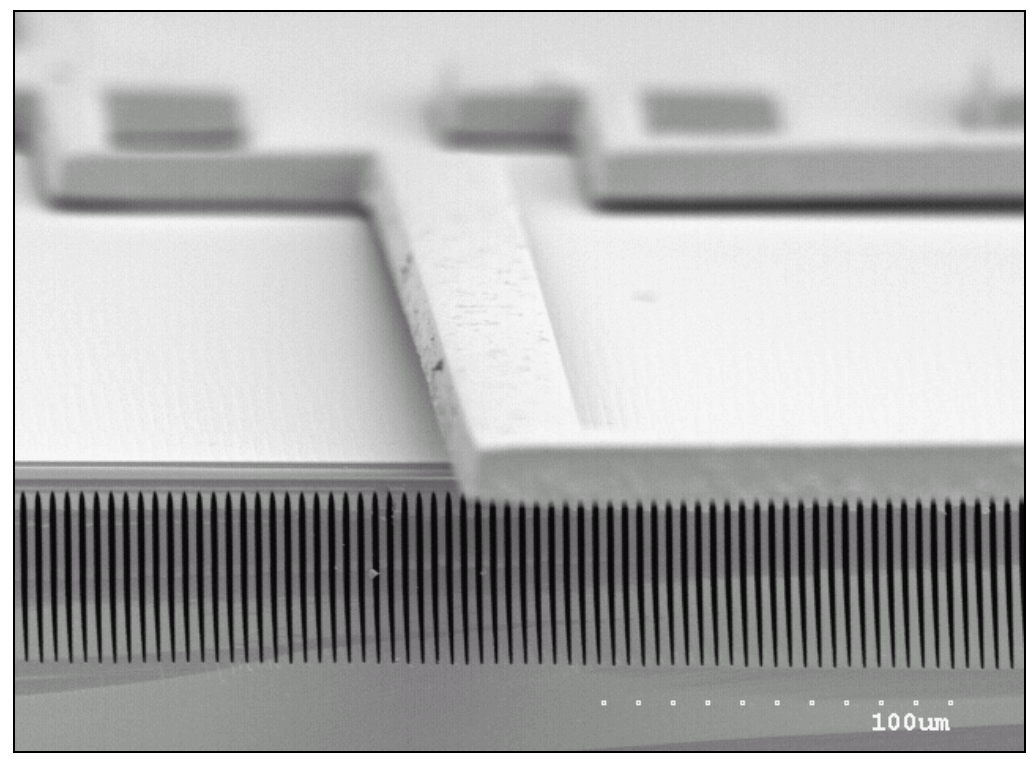

Figure 3-5. SEM picture of a one-turn inductor on top of TSI $\left(w=40 \mu \mathrm{m}, d_{\text {out }}=860 \mu \mathrm{m}\right.$, $\left.t_{\text {metal }}=26 \mu \mathrm{m}, Q=45\right)$.

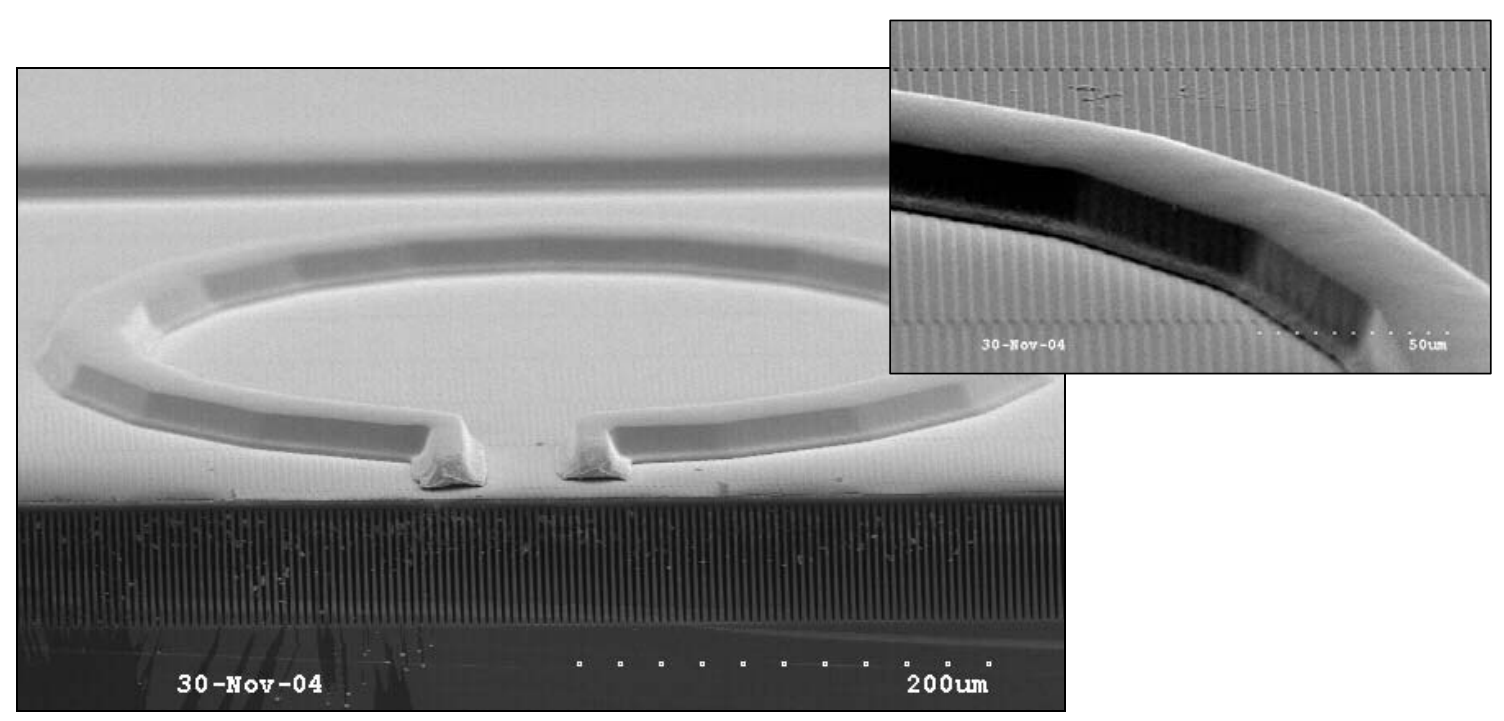

Figure 3-6. SEM picture of a one-turn round inductor on TSI with a close-up view of the thick electroplated $C u\left(w=50 \mu \mathrm{m}, d_{\text {out }}=500 \mu \mathrm{m}, t_{\text {metal }}=20 \mu \mathrm{m}\right.$, trench depth $\left.=60 \mu \mathrm{m}, Q=71\right)$. 
To evaluate the effectiveness of TSI in reducing the substrate loss, similar inductors were also fabricated on thick $\mathrm{SiO}_{2}$ islands $(O I)$ created by thermal oxidation of silicon left in between the trenches $\left(@ \sim 1100^{\circ} \mathrm{C}\right)[15,24]$. The SEM and microscope pictures of a three-turn spiral inductor on an $O I$ are shown in Fig. 3-7.
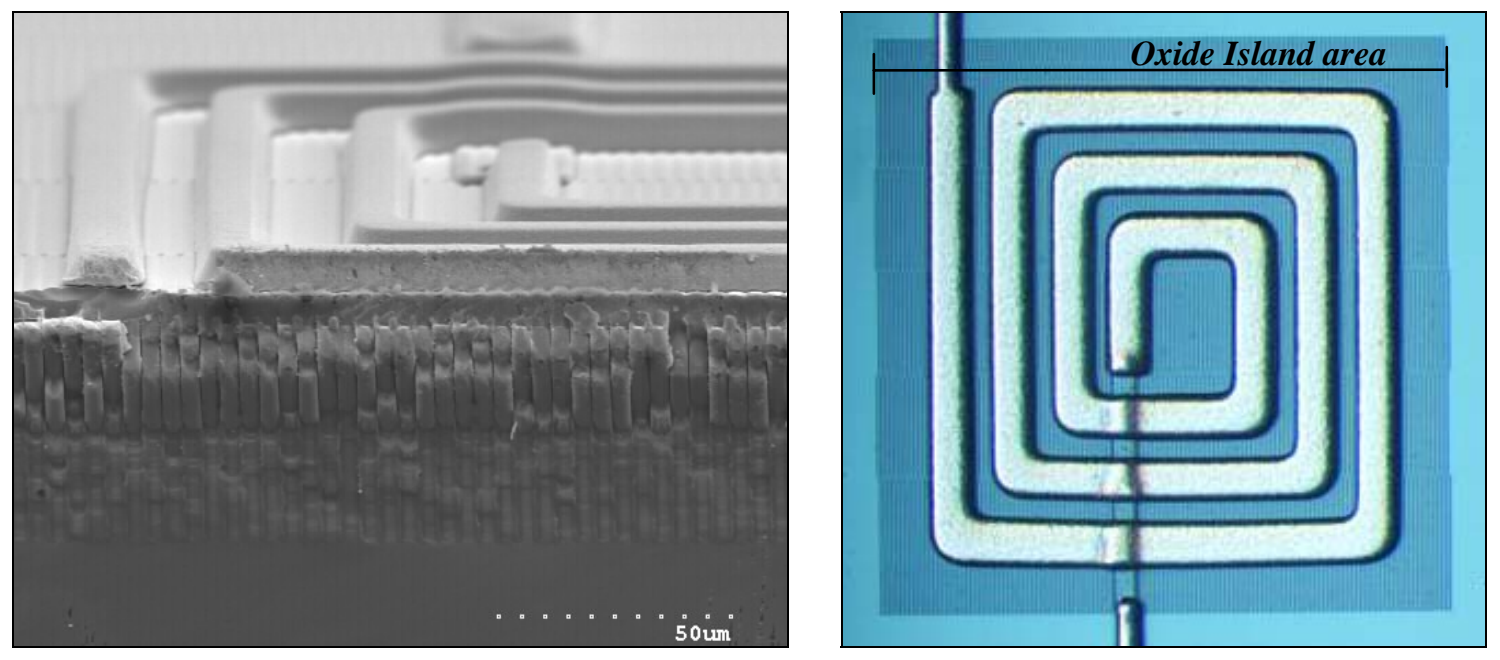

Figure 3-7. SEM (left) and microscope (right) picture of a 3-turn round-edge inductor, $w=15 \mu \mathrm{m}, d_{\text {out }}=400 \mu \mathrm{m}, \mathrm{s}=15 \mu \mathrm{m}, t_{\text {metal }}=8 \mu \mathrm{m}$.

\subsection{Covering the Trenches}

Two low-temperature approaches are adopted in this research to cover the trenches and create a rigid low-loss substrate on which the inductors can be firmly supported.

\subsubsection{Silicon Dioxide Bridge-over}

The main approach, as discussed in the fabrication process flow, is bridging over the open areas through deposition of a low loss-tangent PECVD dielectric layer (e.g., $\mathrm{SiO}_{2}$ ). 
The required film thickness to bridge over the open areas and create a smooth surface is in the order of the trench width. The width of the openings should be optimized for low substrate-loss and reasonable bridge-over film thickness. For a Trenched Si Island (TSI) with repeated trench width of $2 \mu \mathrm{m}$ and $\mathrm{Si}$ width of $2 \mu \mathrm{m}$, the required PECVD $\mathrm{SiO}_{2}$ thickness is about $3 \mu \mathrm{m}$. Figure 3-8 shows cross-section SEM view of a $50 \mu \mathrm{m}$ deep TSI. The opening width is $2 \mu \mathrm{m}$ and the bridge-over $\mathrm{SiO}_{2}$ layer is $2.7 \mu \mathrm{m}$ thick.

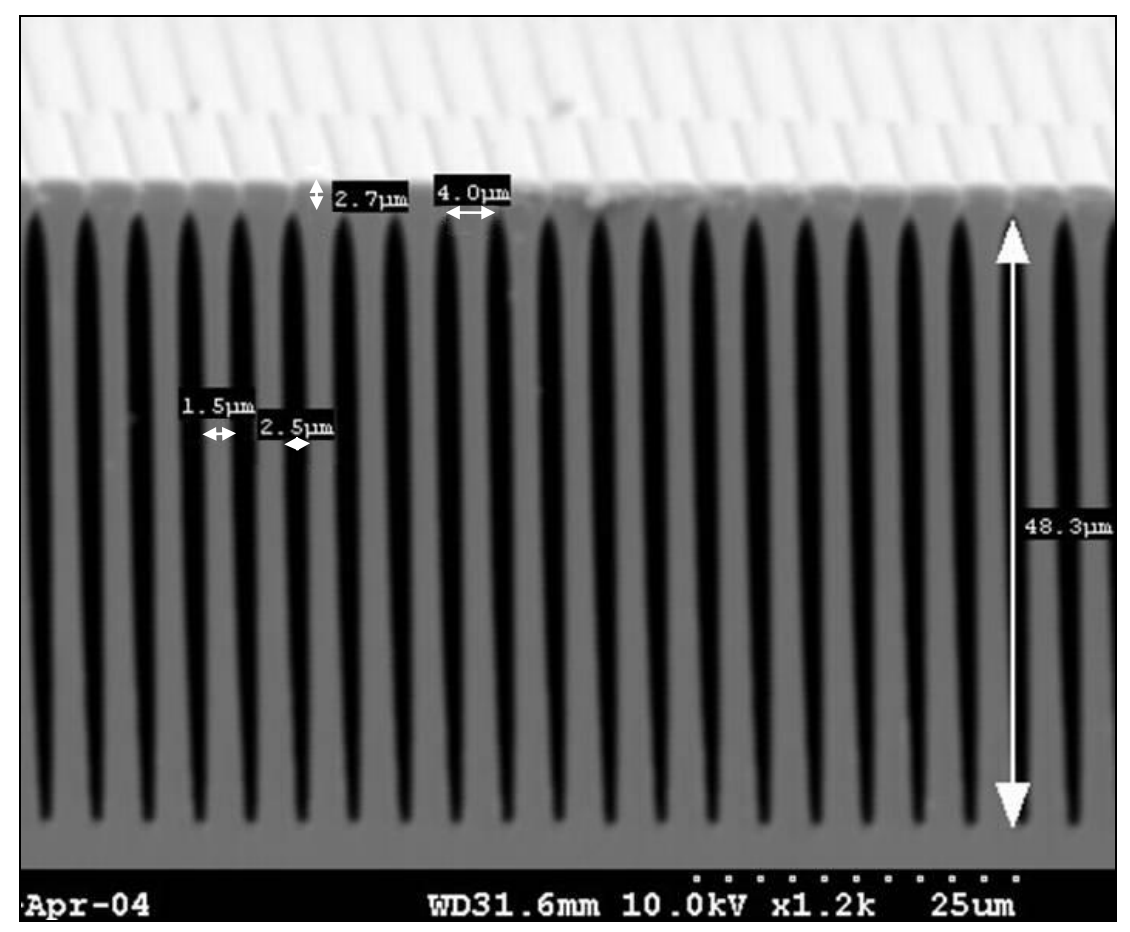

Figure 3-8. SEM picture of a 50 $\mu$ m deep Trenched Silicon Island (TSI)

Figure 3-9 demonstrates that the required $\mathrm{SiO} 2$ film thickness to bridge over a $2.5 \mu \mathrm{m}$ wide opening and to create a smooth surface (surface roughness of $0.3 \mu \mathrm{m}$ ) is about $3 \mu \mathrm{m}$. 


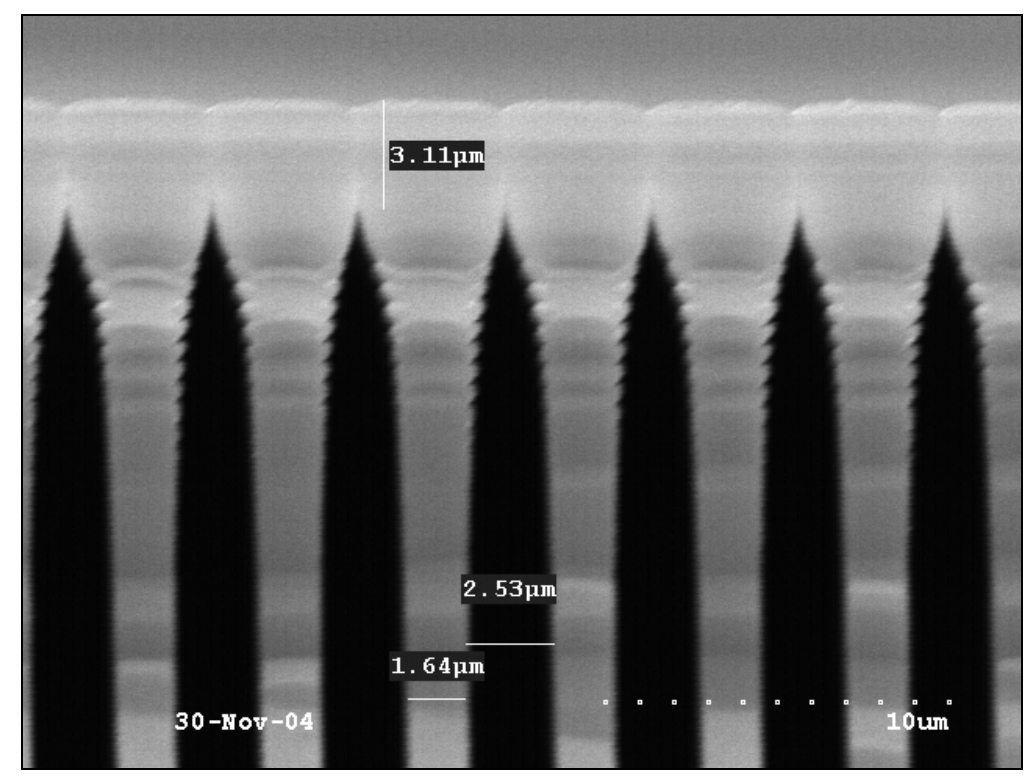

Figure 3-9. Close -up view of the smooth surface of a TSI (surface roughness $<0.3 \mu \mathrm{m})$.

\subsubsection{Avatrel Polymer Trench Refill}

An alternative low-temperature approach is to refill the trenched areas with a low loss dielectric material. Avatrel 2000P polymer from Promerous Inc. has been selected for this purpose since it has a low dielectric permittivity compared to other dielectric materials [49]. Table 3-4 compares the loss-tangent and permittivity of Avatrel with two other low$\mathrm{K}$ dielectrics commonly used as isolating layers.

Table 3-4. Comparison of electrical properties of Avatrel with BCB and polymide[49,50].

\begin{tabular}{|l|l|l|l|}
\hline & Avatrel $^{*}$ & Polyimide & BCB \\
\hline Moisture uptake, \% & $<0.1$ & $0.5-3$ & 0.23 \\
\hline Permittivity $\left(\varepsilon_{\mathrm{r}}\right)$ & 2.50 & $3.1-4.1$ & 2.7 \\
\hline $\tan \delta @ 1 \mathrm{GHz}$ & 0.009 & $0.01-0.015$ & 0.015 \\
\hline
\end{tabular}


The recipe used to fill the trenches with spin-coating of Avatrel is as follow:
o Spin speed:
3000rpm, 500rpm/sec for $40 \mathrm{sec}$
o Soft bake:
on hotplate at $110^{\circ} \mathrm{C}$ for $10 \mathrm{~min}$
o Expose: $500 \mathrm{~mJ}(100 \mathrm{sec}$ with lamp intensity of $5 \mathrm{~mJ} / \mathrm{sec}$, I-line (wave length: $365 \mathrm{~nm}$ ))

o Post Exposure Bake (PEB): in oven at $100^{\circ} \mathrm{C}$ for $20 \mathrm{~min}$

Followed by $60 \mathrm{~min}$ in oven at $160^{\circ} \mathrm{C}$

The resulting thickness of Avatrel on the non-trenched areas using this recipe is $20 \mu \mathrm{m}$. A $1 \mu \mathrm{m}$ thick $\mathrm{SiO}_{2}$ layer is then deposited to enhance the adhesion of the first metal layer to the substrate. The deposition temperature is reduced to $160^{\circ} \mathrm{C}$ to avoid bubbling of the Avatrel layer. Other $\mathrm{SiO}_{2}$ deposition parameters are as shown in Table 3-2. Figure 3-10 illustrates SEM picture of a $20 \mu \mathrm{m}$ thick layer of Avatrel on TSI after deposition of $\mathrm{SiO}_{2}$ at $300^{\circ} \mathrm{C}$, showing this deposition temperature results in bubbling of the Avatrel layer.

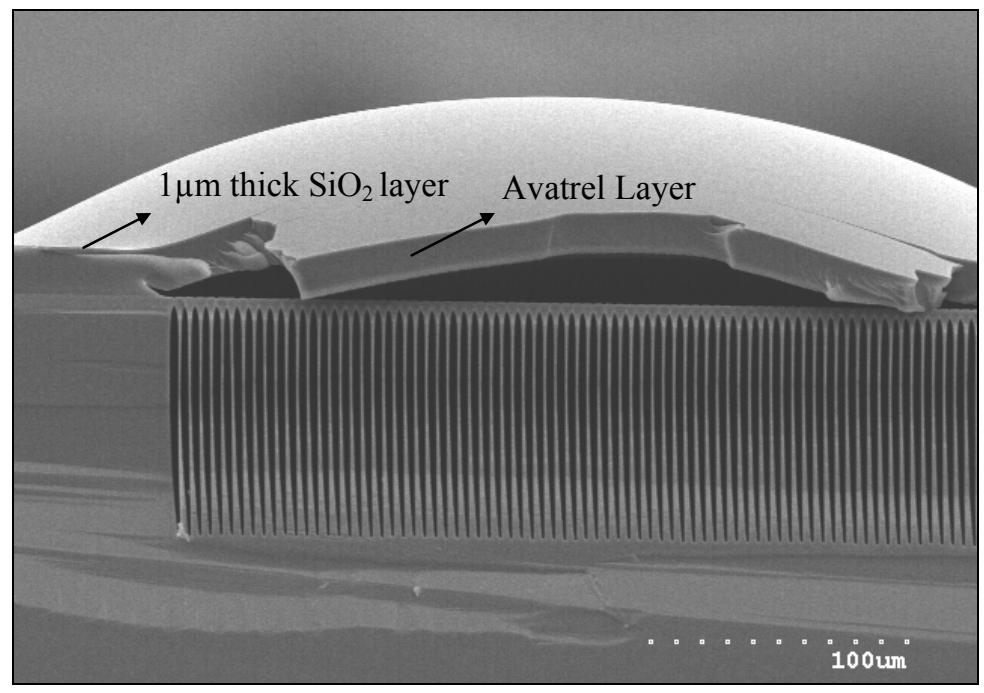

Figure 3-10. Flaking of Avatrel layer due to high-temperature processing $\left(300^{\circ} \mathrm{C}\right)$. 
Figure 3-11 shows a $90 \mu \mathrm{m}$ deep TSI refilled by spin-coating of Avatrel polymer. The thickness of $\mathrm{SiO}_{2}$ over-coat is $1 \mu \mathrm{m}$ and the $\mathrm{SiO}_{2}$ deposition temperature is $160^{\circ} \mathrm{C}$.

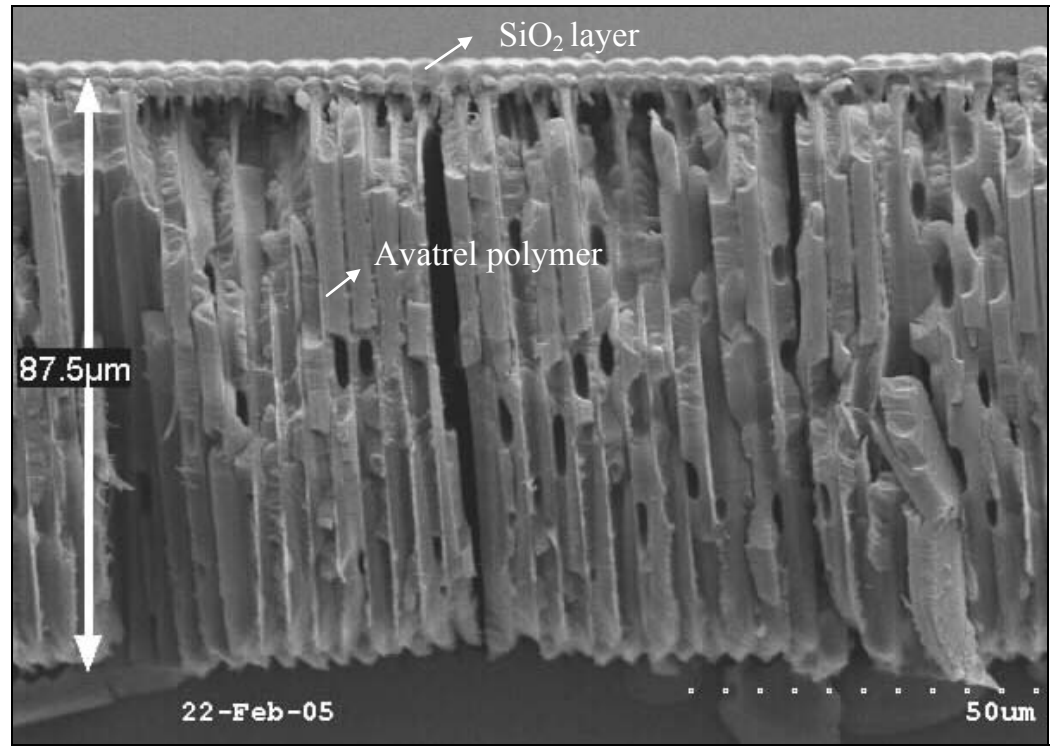

Figure 3-11. SEM picture of a 904m deep TSI refilled by Avatrel polymer.

\subsection{Process Issues}

\subsubsection{High Aspect-Ratio Si Etch}

Width and depth of the trenches determine the required $\mathrm{SiO}_{2}$ film thickness and the substrate loss, respectively. High-aspect-ratio trenches with opening-width in the range of $2-3 \mu \mathrm{m}$ are required to effectively reduce the substrate loss, while keeping the subsequent bridge-over $\mathrm{SiO}_{2}$ film thickness practical. The highest achievable aspect-ratio determined by the STS ICP processing constrains is about 1:30. Deep trenches having this aspect 
ratio (3:90) are very brittle and can be easily broken in the photo-resist stripper due to the capillary forces. Capillary forces result from trapped liquid that, due to Laplace pressure differences and surface tension forces produce an attractive force [51]. Solution to this problem is to dry etch (ash) the photoresist used as the mask right after the Si-etching step. Bridge-over $\mathrm{SiO}_{2}$ layer provides a firm support for the trenches and solves this issue for the subsequent processing steps.

\subsubsection{Electroplating Mold}

The most critical step is patterning the electroplating mold. The electroplating mold should be thick with straight sidewalls. Negative-tone photoresists are more appropriate for this purpose as they have improved sidewall profile over positive-tone photoresists with same film thickness. The electroplating mold should also have a proper adhesion to the $\mathrm{Cu}$ seed-layer. Therefore, the photoresist used as the electroplating mold needs an extensive characterization. The NR-4 $8000 \mathrm{P}$ photoresist employed in this research worked well using the following recipe:

o Spin speed:

$600 \mathrm{rpm}, 1500 \mathrm{rpm} / \mathrm{sec}$ for $5 \mathrm{sec}$

1200rpm, 500rpm/sec for $40 \mathrm{sec}$

o Soft bake:

on hotplate at $80^{\circ} \mathrm{C}$ ramps to $110^{\circ} \mathrm{C}$ for $10 \mathrm{~min}$

o Expose:

$360 \mathrm{~mJ}$ (60sec with lamp intensity of $6 \mathrm{~mJ} / \mathrm{sec}$, I-line (wave length: $365 \mathrm{~nm}$ ))

o Post Exposure Bake (PEB): on hotplate at $80^{\circ} \mathrm{C}$ ramps to $100^{\circ} \mathrm{C}$ for $5 \mathrm{~min}$

o Develop: $\quad$ in RD-6 resist developer for $3 \mathrm{~min}$ 
This photoresist does not need to be hard-baked before electroplating to ensure its adhesion to the $\mathrm{Cu}$ seed-layer and thus the photoresist can be easily removed in Acetone after the electroplating step. Possible residues of the photoresist are removed in the acidic solutions used to etch the seed-layer afterward.

\subsubsection{Chromium Etchant}

Chromium is used as an adhesion promoter between $\mathrm{Cu}$ and $\mathrm{SiO}_{2}$. Solvent used for etching the $\mathrm{Cr}$ seed layer, after the electroplating step, must have a good selectivity to $\mathrm{Cu}$. A mixture of $10 \mathrm{~g}$ Potassium Ferricyanide $\left(\mathrm{K}_{3} \mathrm{Fe}(\mathrm{CN})_{6}\right), 10 \mathrm{~g}$ Sodium Hydroxide $(\mathrm{NaOH})$, and $100 \mathrm{ml}$ DI water was developed for this purpose [52]. This wet etchant worked well and provided an etch rate of approximately $500 \mathrm{~A} \% \mathrm{~min}$.

The detailed processing steps are included in the Appendix A. 


\section{CHAPTER IV}

\section{MEASUREMENT AND CHARACTERIZATION}

Rectangular and circular type inductors of various dimensions were fabricated and tested on low-loss micromachined trenched $\mathrm{Si}$ substrates. On-wafer S-parameter measurements were carried out using an $h p 8517 \mathrm{~B}$ vector network analyzer and groundsignal-ground Cascade micro-probes. The pad size used for on-wafer measurements is $100 \mu \mathrm{m} \times 100 \mu \mathrm{m}$ with $150 \mu \mathrm{m}$ pitch. The pad-only characteristics were measured on the open pad structures. The pads parasitics were then de-embedded from the overall inductor characteristic by subtracting the Y-parameters of the pads from the Yparameters of the embedded inductors [53]. The equivalent circuit model shown in Fig. 2-2 is used to extract the electrical parameters. For one-turn one-port inductors, the second port in the model was grounded. Inductance and $Q$ are extracted using the following equations:

$$
\begin{array}{r}
L=\frac{\operatorname{Im}\left(1 / Y_{11}\right)}{2 \times \pi \times f} \\
Q=\frac{\operatorname{Im}\left(1 / Y_{11}\right)}{\operatorname{Re}\left(1 / Y_{11}\right)}
\end{array}
$$

The dependency of $Q$ on inductor physical parameters including oxide thickness, metal thickness, trench depth of TSI, and dielectric material have been extracted from the measured data. 


\subsection{Effect of TSI on $Q$}

Figure 4-1 demonstrates the effectiveness of the Trenched Si Islands in increasing the $Q$. As it is shown in Fig. 4-1(b) the $S_{11}$-parameter of the inductor fabricated on $50 \mu \mathrm{m}$ deep TSI (low-temperature processing) is very close to the one fabricated on $50 \mu \mathrm{m}$ thick solid $O I$ (high-temperature processing), and the inductor has a significant higher $Q$ compared to when it is fabricated on a $4 \mu \mathrm{m}$ thick $\mathrm{SiO}_{2}$-covered $\mathrm{Si}$.
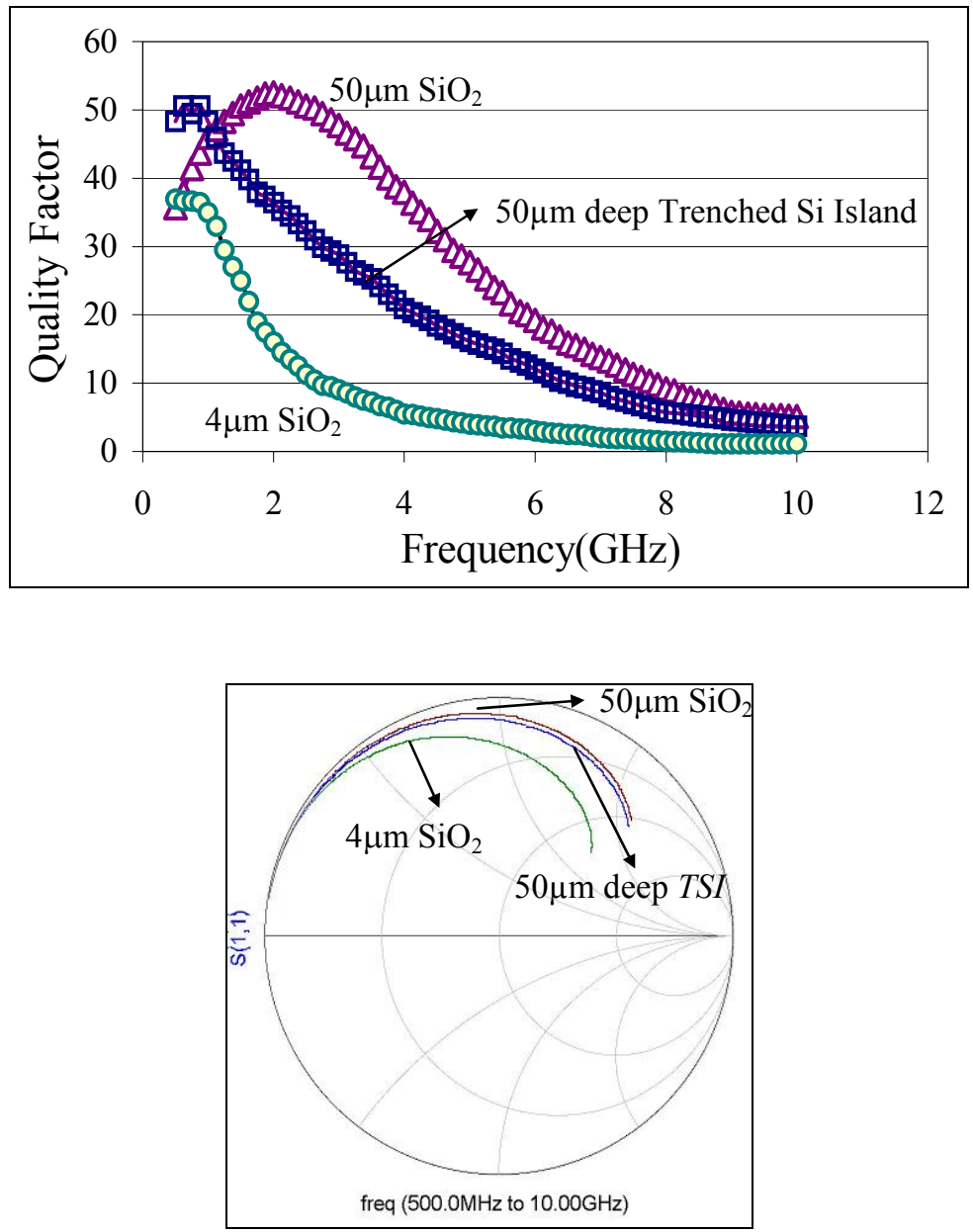

Figure 4-1. Comparison of (a) measured Q, and (b) S-parameter of inductors on OI, TSI and $4 \mu \mathrm{m} \mathrm{SiO}{ }_{2}$-covered Si substrate. $\left(t_{\text {metal }}=25-30 \mu \mathrm{m}, w=60 \mu \mathrm{m}, d_{\text {out }}=825 \mu \mathrm{m}\right)$. 
At high frequencies, where the substrate loss is dominant, $Q$ is improved significantly. From Fig. 4-1(a), it is also clear that the substrate loss has a considerable effect on the frequency of peak $Q$. To improve $Q$ and increase the frequency of maximum $Q$, while keeping the process CMOS compatible, the depth of trenches should be increased.

\subsection{Effect of Trench Depth}

Figure 4-2 illustrates the role of the trench depth in reducing the substrate loss. The $Q$ of a $1.07 \mathrm{nH}$ inductor on $40 \mu \mathrm{m}$ deep Trenched Si Island is $4 \times$ higher than the similar design (with identical metal thickness) fabricated on $10 \mu \mathrm{m}$ deep trenched-island $\left(Q_{40 \mu m}=32\right.$ @2.4GHz, $\left.Q_{10 \mu m}=7.5 @ 2.4 \mathrm{GHz}\right)$.

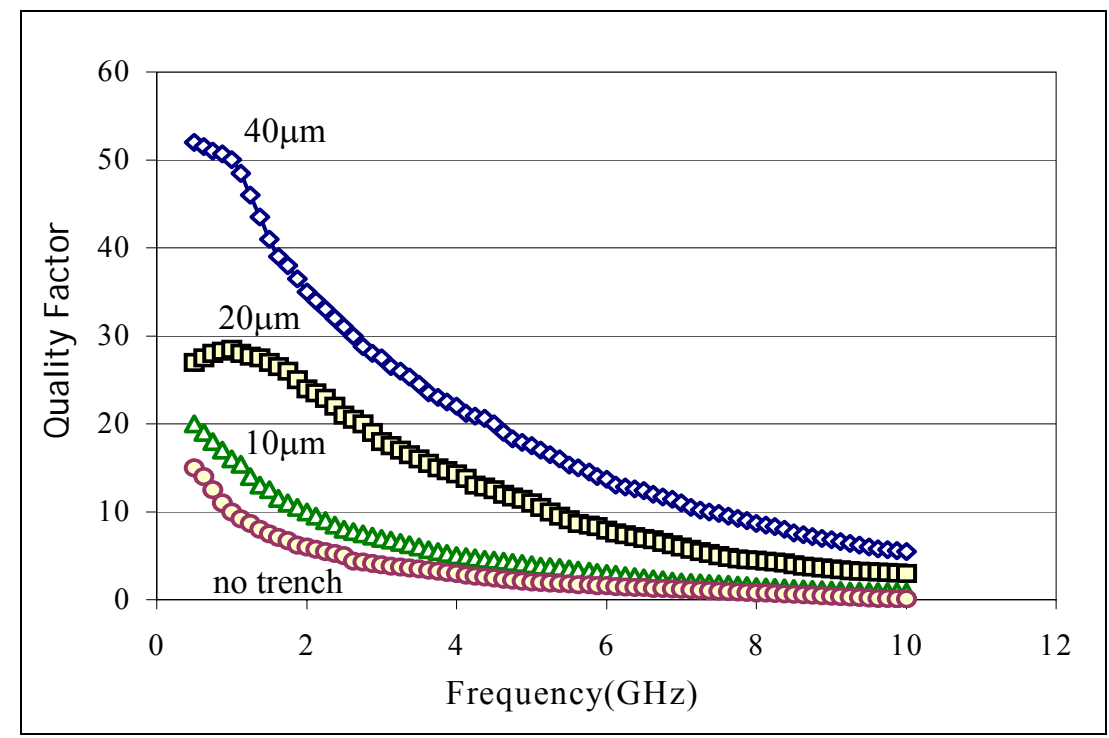

Figure 4-2. Measured $Q$ vs. frequency showing dependency of $Q$ on trench depth. $\left(t_{\text {metal }}=15 \mu \mathrm{m}, w=60 \mu \mathrm{m}, d_{\text {out }}=833 \mu \mathrm{m}\right)$. 
Similar to the inductors fabricated on thick oxide islands, there is a saturation point for $Q$ versus the trench depth. Quality factor does not increase by increasing the trench depth further than the saturation depth. Measured data indicate an increase in $Q$ with trench depth up to $90 \mu \mathrm{m}$. The saturation depth for inductors fabricated on TSI is more than the saturation thickness for inductors on $O I$ and needs to be determined by fabrication.

\subsection{Effect of Oxide Thickness}

To identify the dependency of $Q$ on the oxide thickness, identical inductors have been fabricated on

1) $50 \mu \mathrm{m}$ thick Oxide Islands $(\mathrm{OI})$

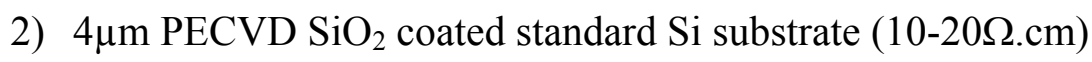

3) $7.5 \mu \mathrm{m} \mathrm{PECVD} \mathrm{SiO}_{2}$ coated standard $\mathrm{Si}$ substrate

Figure 4-3 depicts the effect of the oxide thickness on the measured $Q$ of a $1.3 \mathrm{nH}$ inductor on thick $O I$. As can be seen, $\mathrm{SiO}_{2}$ thickness has a significant effect on the frequency of the maximum $Q$ as well as the $Q$-values at high frequencies. 


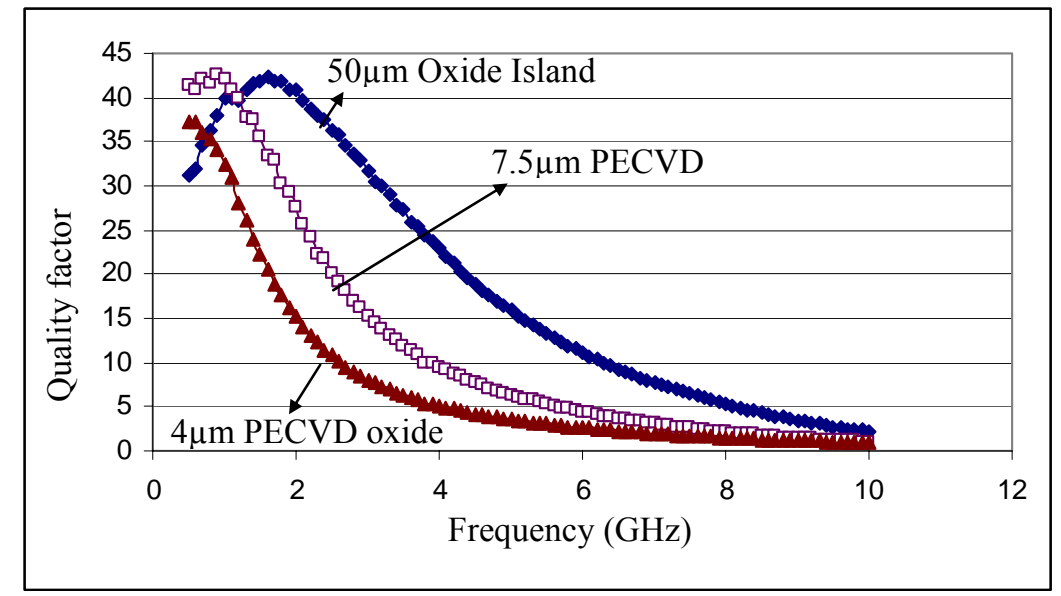

Figure 4-3. Quality factor vs. frequency, showing the dependency of $Q$ on oxide thickness for a one-turn round spiral inductor $\left(w=60 \mu \mathrm{m}, t=30 \mu \mathrm{m}, d_{\text {out }}=833 \mu \mathrm{m}\right.$ and $\left.L=1.3 \mathrm{nH}\right)$.

Figure 4-4(a) depicts the effect of the oxide thickness on the measured $Q$ of a $0.9 \mathrm{nH}$ inductor on thick $O I$, indicating good agreement with simulation results (Fig. 4-4(b)).

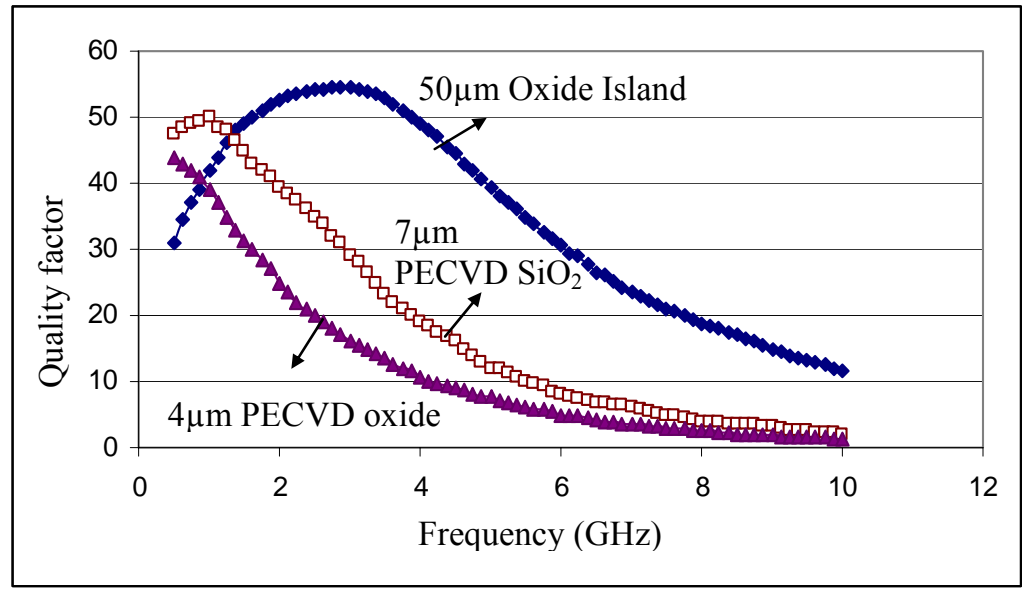

(a) 


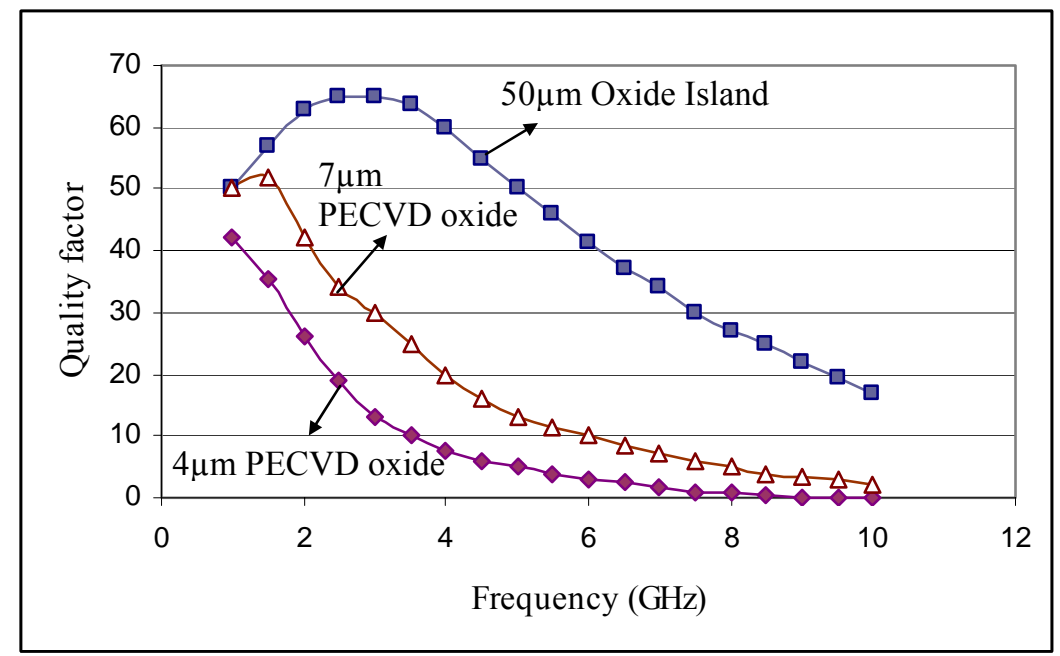

(b)

Figure 4-4. (a) Measured and (b) simulated $Q$ of a $0.9 n H$ inductor with various oxide thicknesses $\left(t_{\text {metal }}=15 \mu \mathrm{m}, w=60 \mu \mathrm{m}, d_{\text {out }}=600 \mu \mathrm{m}\right)$.

Nonetheless, measured $Q$ of the inductor on $50 \mu \mathrm{m}$ thick $O I$ is slightly different with the simulated values. This may come from the incomplete oxidation of Si bars as shown in Fig. 4-5. As can be seen, trenches are filled prior to the complete oxidation of Si due to the insufficient trench width.

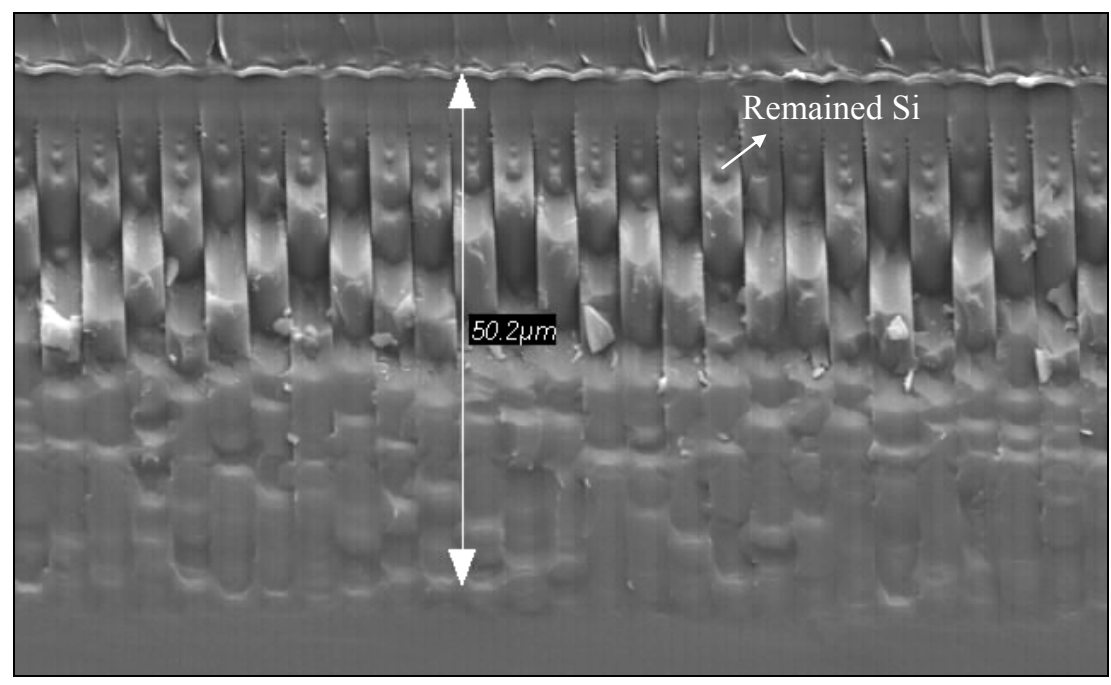

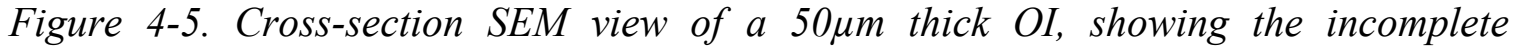
oxidation of $\mathrm{Si}$. 


\subsection{Effect of Trenched Area}

Another result extracted from measurement is the negligible dependency of $Q$ on the trenched island area. The change in $Q$ is less than $10 \%$ (at $2.4 \mathrm{GHz}$ ) if the trenched island area is extended beyond the $\mathrm{Cu}$ track area $(x>0$ in Figure 4-6), alleviating the need for trenching the entire area beneath the inductor (Fig. 4-6).

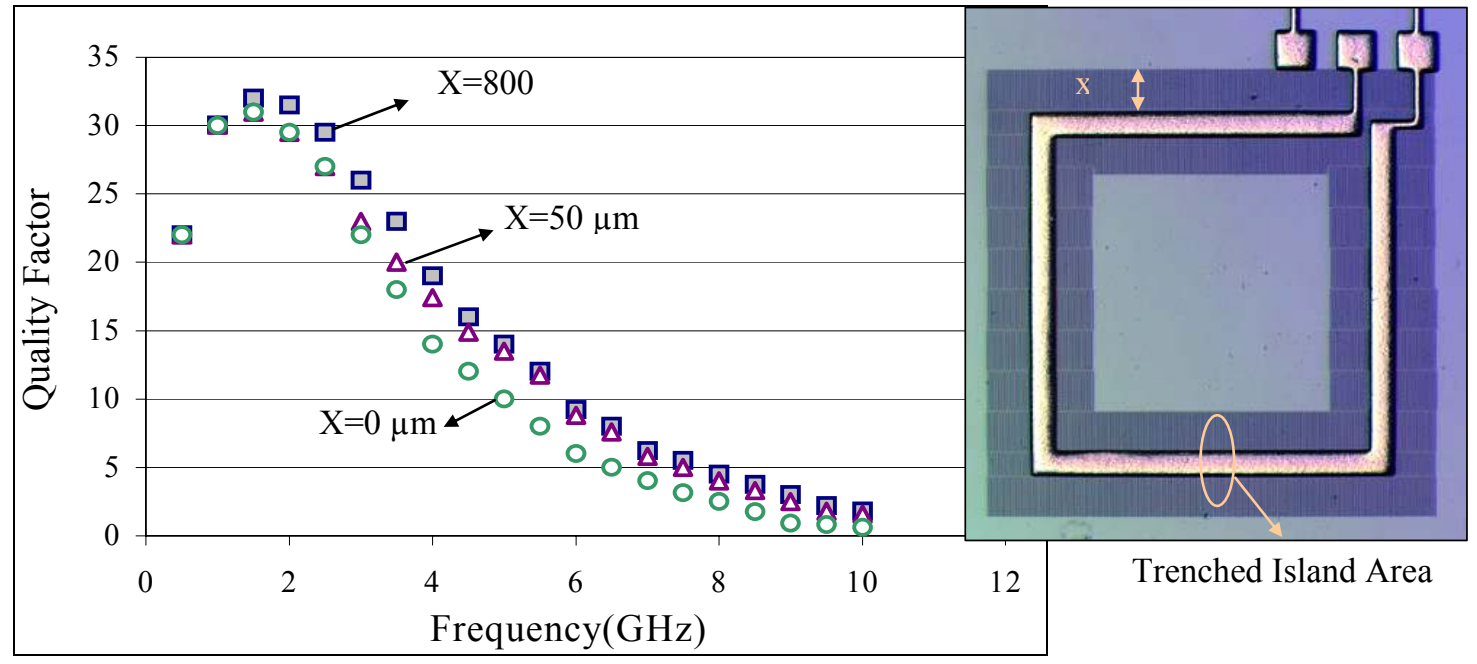

Figure 4-6. (Left) Measured $Q$ of a one-turn inductor on TSI with various trenched island area, and (right) Microscope picture of the inductor showing the definition of $x$. ( $t$ metal $\left.=30 \mu \mathrm{m}, w_{\text {metal }}=100 \mu \mathrm{m}, d_{\text {out }}=1200 \mu \mathrm{m}\right)$.

\subsection{Effect of Metal Thickness}

The $Q$ vs. frequency plots for a one-turn $\mathrm{Cu}$ inductor with two different metal thicknesses is shown in Fig. 4-7, confirming improvement in coplanar inductor $Q$ for metal 
thicknesses in excess of $5 \times$ skin depth at lower frequencies where metal loss is the dominant $Q$-limiting mechanism.

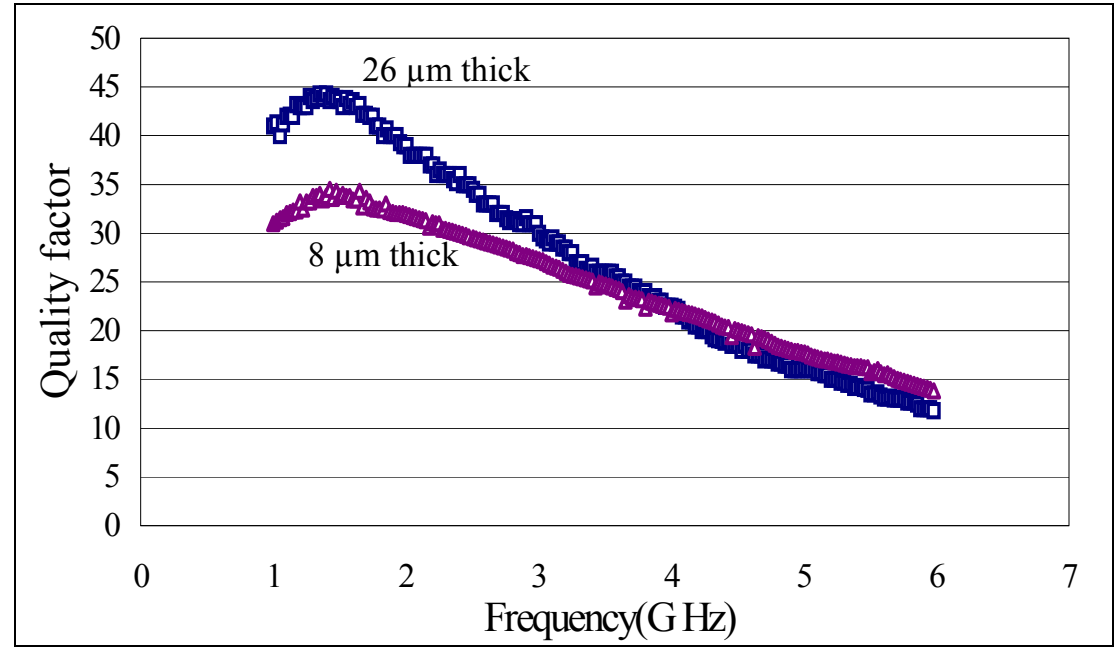

Figure 4-7. Measured $Q$ of a one-turn inductor on TSI with different metal thicknesses.

\subsection{Enhanced Design Test Results}

To further increase the $Q$ and the frequency at which maximum $Q$ occurs, improved design of inductors have been implemented using a revised mask on 70-100 $\mu \mathrm{m}$ deep TSI and the width of the Si bars has been reduced to smaller values $(1.5 \mu \mathrm{m}$ instead of $2 \mu \mathrm{m})$ by increasing the undercut in RIE. Smaller size inductors (smaller outer diameter) with optimized metal width exhibit higher $Q$ 's and are used on the new mask. As a result, the maximum $Q$ has been increased from 23 to 71 at $5 \mathrm{GHz}$ for a one-turn inductor fabricated on TSI (compare Fig. 4-4 with Fig. 4-8). However, smaller outer diameter, which resulted in $Q$-improvement, has the draw back of getting smaller inductance value. 
Figure 4-8 shows the embedded and de-embedded $Q$ and inductance of a one-turn round inductor fabricated on $70 \mu \mathrm{m}$ deep $T S I$. As it is shown, $Q$ is over 50 in the $5-10 \mathrm{GHz}$ range with a maximum of 70.6 at $8.75 \mathrm{GHz}$. The self resonance frequency of this inductor is much higher than $10 \mathrm{GHz}$.
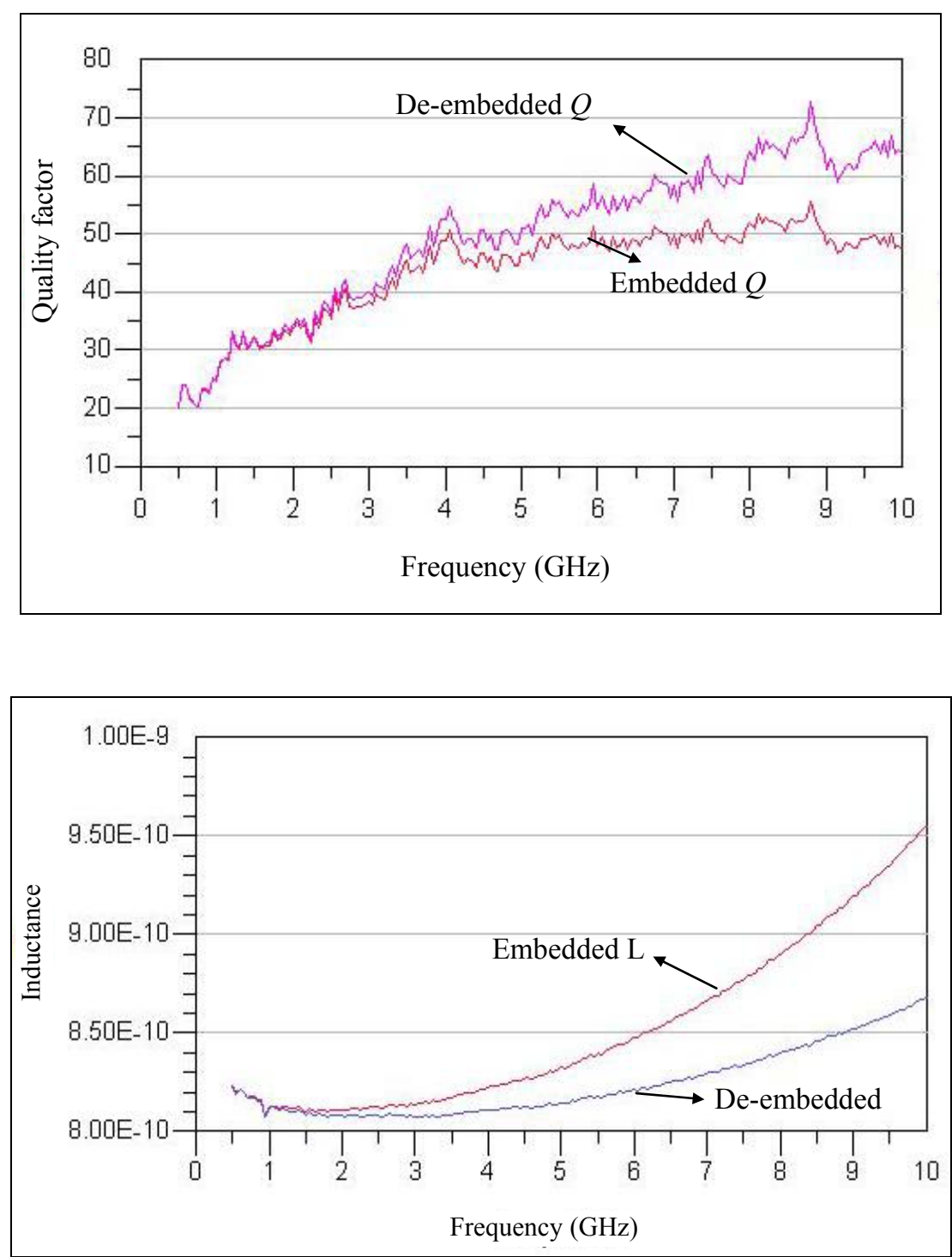

Figure 4-8. Measured (upper) $Q$, and (lower) inductance of a one-turn inductor on TSI $\left(t_{\text {metal }}=20 \mu \mathrm{m}, w=50 \mu \mathrm{m}, d_{\text {out }}=500 \mu \mathrm{m}, \rho=100 \Omega \mathrm{cm}\right)$. 
The measured $Q$ of a $0.9 \mathrm{nH}$ inductor on $70 \mu \mathrm{m}$ deep TSI is shown in Fig. 4-9. It is notable that inductors fabricated on TSI have high embedded- $Q$ in contrast to the suspended inductors reported in literature (Fig. 4-9) [15]. This is because parasitic capacitances of pads are reduced simultaneously by reduction of the substrate loss underneath them through trenching the Si.

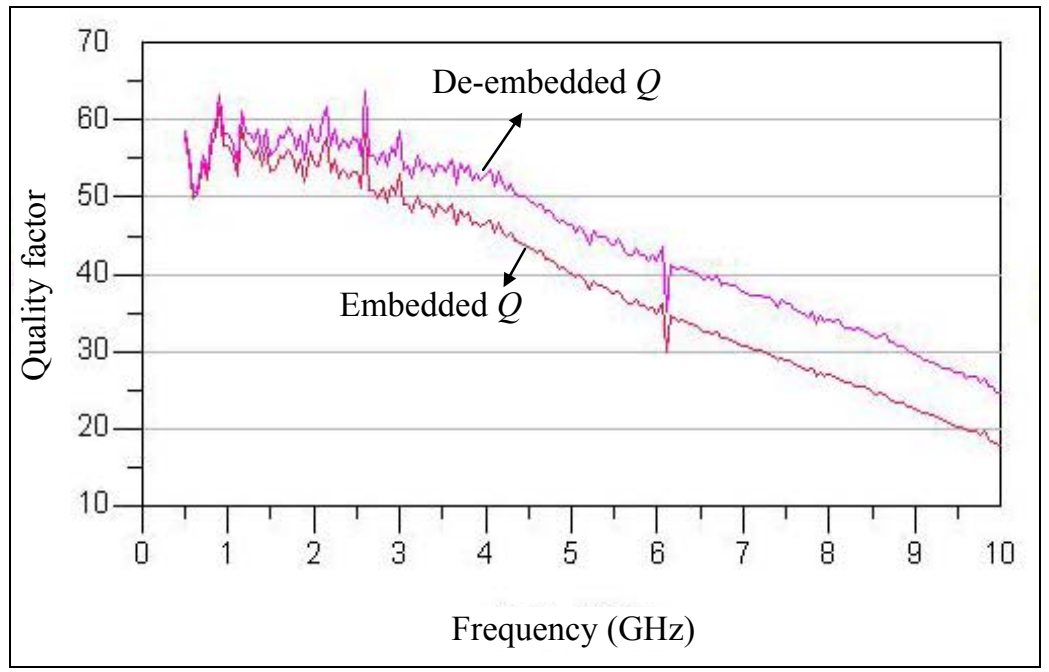

Figure 4-9. Measured $Q$ of a $0.9 n H$ inductor on TSI ( $t_{\text {metal }}=20 \mu \mathrm{m}, w=60 \mu \mathrm{m}, d_{\text {out }}=600 \mu \mathrm{m}$, trench depth $=70 \mu \mathrm{m})$.

\subsubsection{Avatrel Trench refilled}

As it was discussed in section 2.3, the alternate low-temperature method of reducing the substrate loss is disrupting the current path by making trenches in Si and subsequently refilling them with Avatrel Polymer. Figure 4-10 shows the $Q$ of a $0.9 \mathrm{nH}$ inductor on Avatrel refilled $90 \mu \mathrm{m}$ deep trenches, showing a maximum $Q$ of 60 at $1.75 \mathrm{GHz}$. The inductor is identical to the one in Figure $4-4$ (metal width $=60 \mu \mathrm{m}, \mathrm{d}_{\text {out }}=600 \mu \mathrm{m}$ ), and for 
comparison the two plots are combined in Fig. 4-11. As it can be seen in this figure, $Q_{\text {substrate }}$ in the two cases are almost equal, resulting in similar $Q$ values at high frequencies $(f \geq 4 \mathrm{GHz})$.
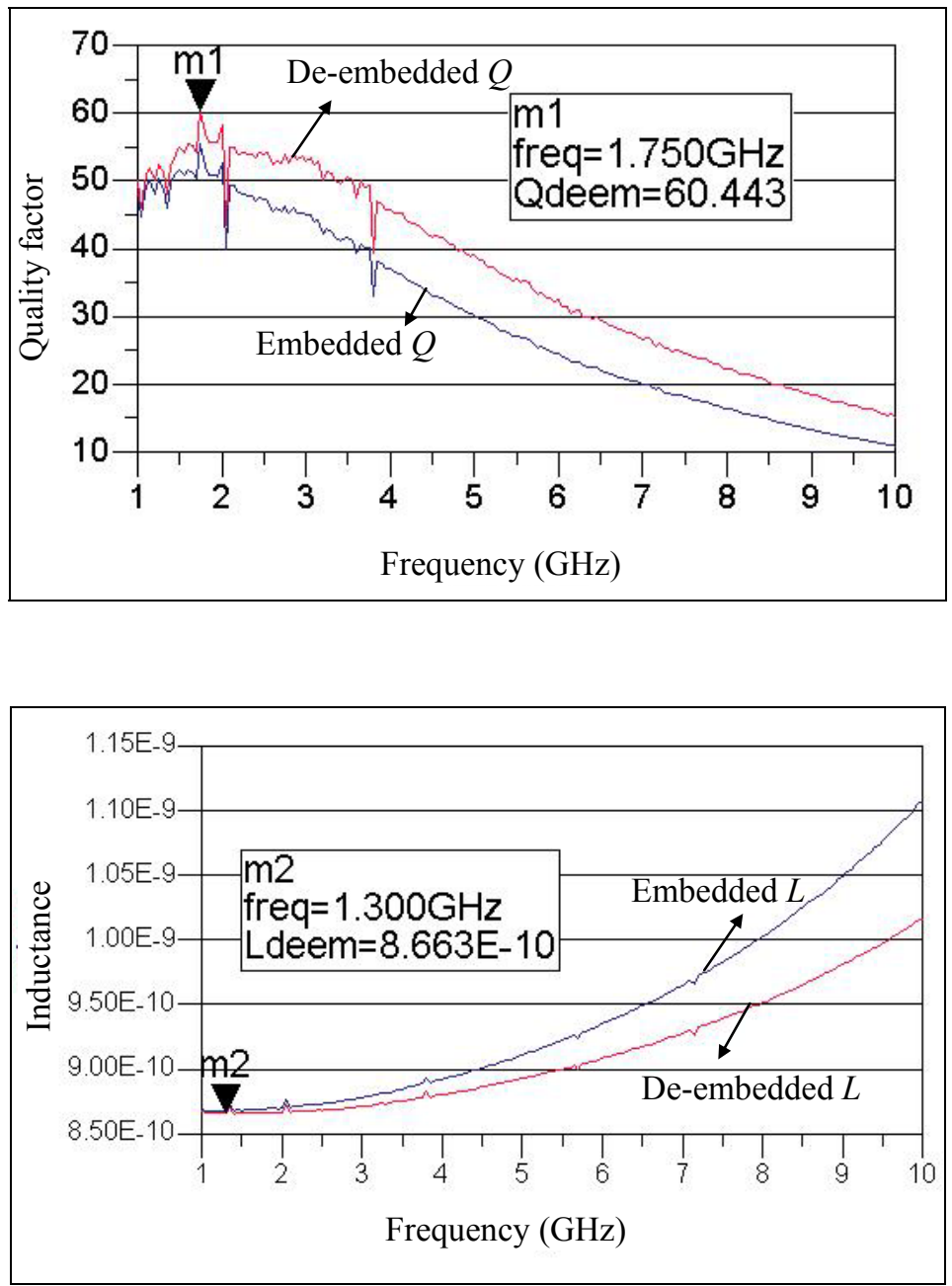

Figure 4-10. Measured (upper) $Q$ and (lower) $L$ of a one-turn inductor on $100 \mu \mathrm{m}$ deep Avatrel refilled Trenched $S i\left(w=60 \mu \mathrm{m}, d_{\text {out }}=600 \mu \mathrm{m}, \rho=10-20 \Omega \mathrm{cm}\right)$.

The inductor fabricated on $90 \mu \mathrm{m}$ deep Avatrel refilled trenched $\mathrm{Si}$ has a slightly improved performance over the identical one fabricated on $50 \mu \mathrm{m}$ deep TSI at higher 
frequencies $(f>6 \mathrm{GHz}$ in Fig. 4-11). The $Q$ improvement has two reasons. First, the trench depth is increased to $90 \mu \mathrm{m}$, and second, the Avatrel polymer is a better dielectric in terms of having lower permittivity and loss tangent compared to PECVD silicon dioxide.

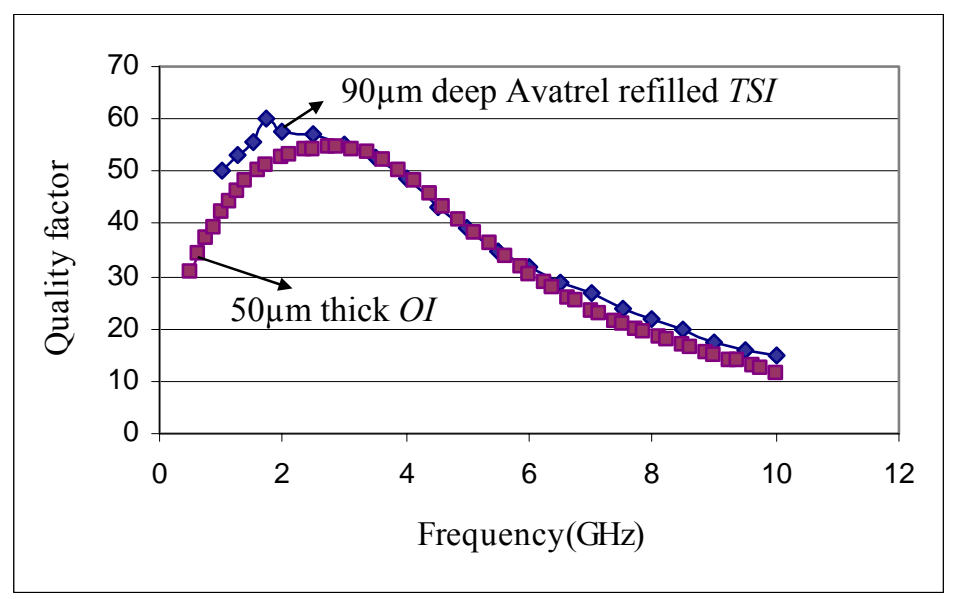

Figure 4-11. Comparison between measured $Q$ of a 0.9nH inductor fabricated on OI and Avatrel refilled TSI.

Figures 4-12 and 4-13 compare the effect of trench depth on the $Q$ when the substrate is coated with a thick layer of Avatrel. In Fig. 4-12, the trench depth is $90 \mu \mathrm{m}$ and trenches are filled with Avatrel. The thickness of the Avatrel on the surface of the refilled substrate is negligible (as it was shown in Fig. 3-11). The inductor in Fig.4-13, on the other hand, is fabricated on a $50 \mu \mathrm{m}$ deep trenched refilled island. The thickness of Avatrel layer covering the refilled trenches is about $20 \mu \mathrm{m}$, as shown in Fig. 4-14. The peak $Q$ is higher for the inductor fabricated on $90 \mu \mathrm{m}$ deep trenched Si without extra Avatrel coating. Comparing these two figures demonstrates that the substrate loss cannot be effectively reduced by merely coating it with a low-K dielectric. 


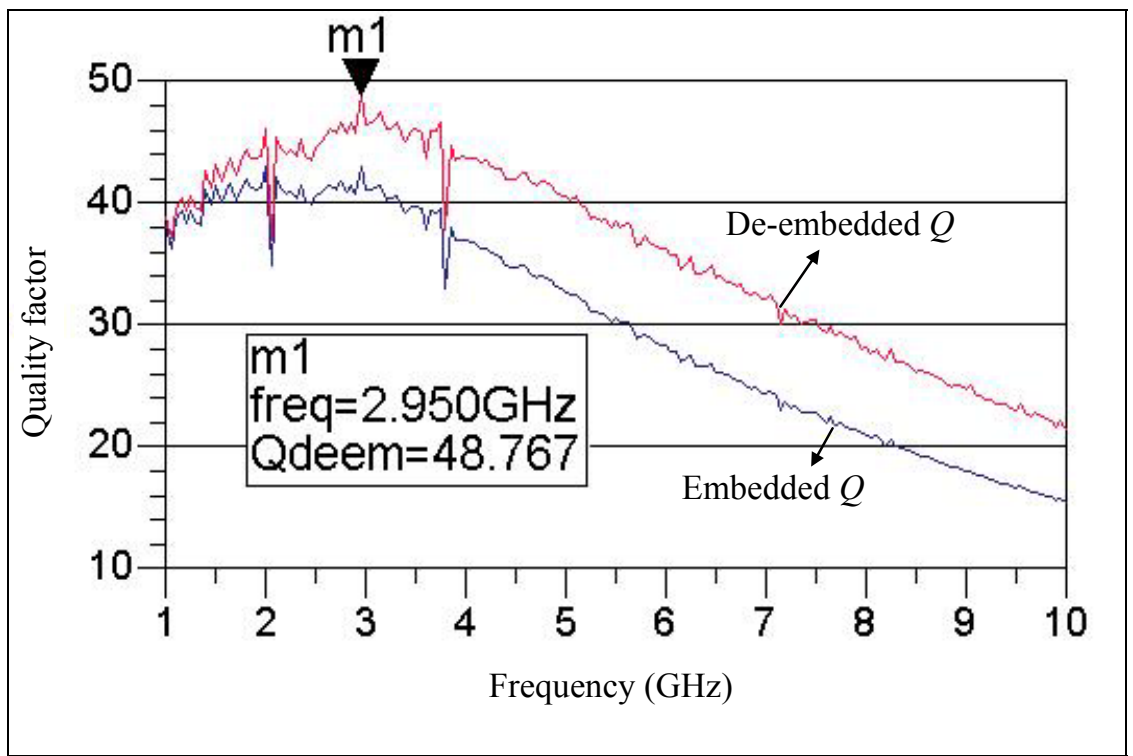

Figure 4-12. Measure $Q$ of a $0.8 n H$ inductor on $90 \mu \mathrm{m}$ deep Avatrel refilled TSI.

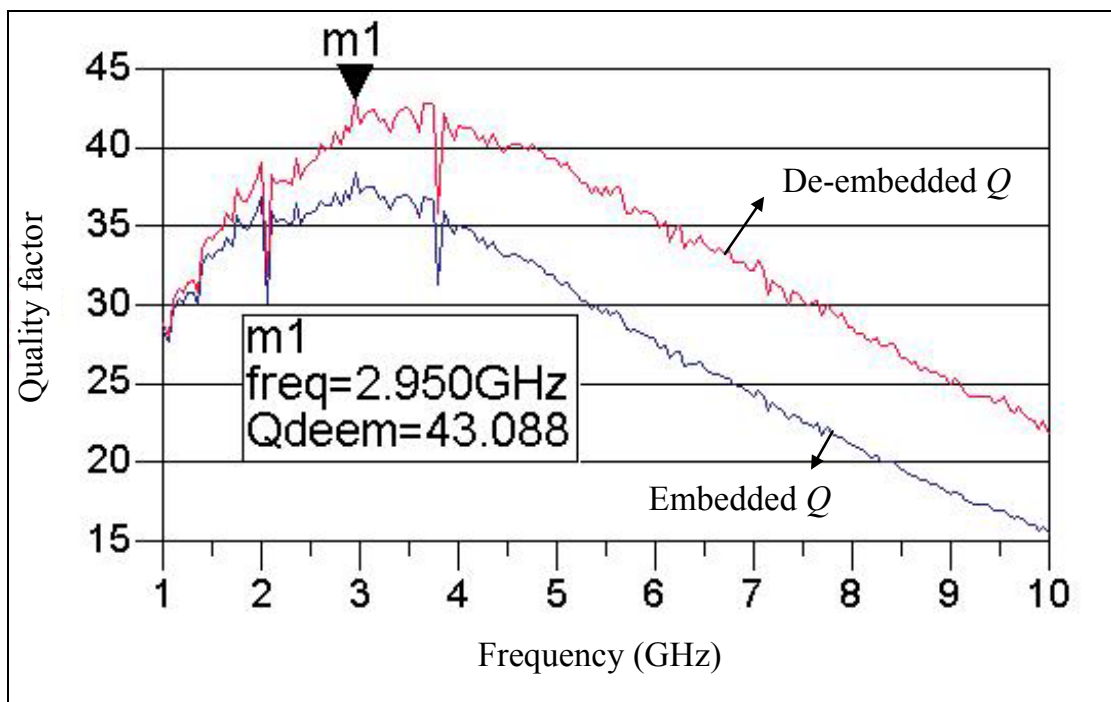

Figure 4-13. Measure $Q$ of a $0.8 n \mathrm{H}$ inductor on $50 \mu \mathrm{m}$ deep Avatrel refilled TSI coated with $20 \mu \mathrm{m}$ thick Avatrel layer. 


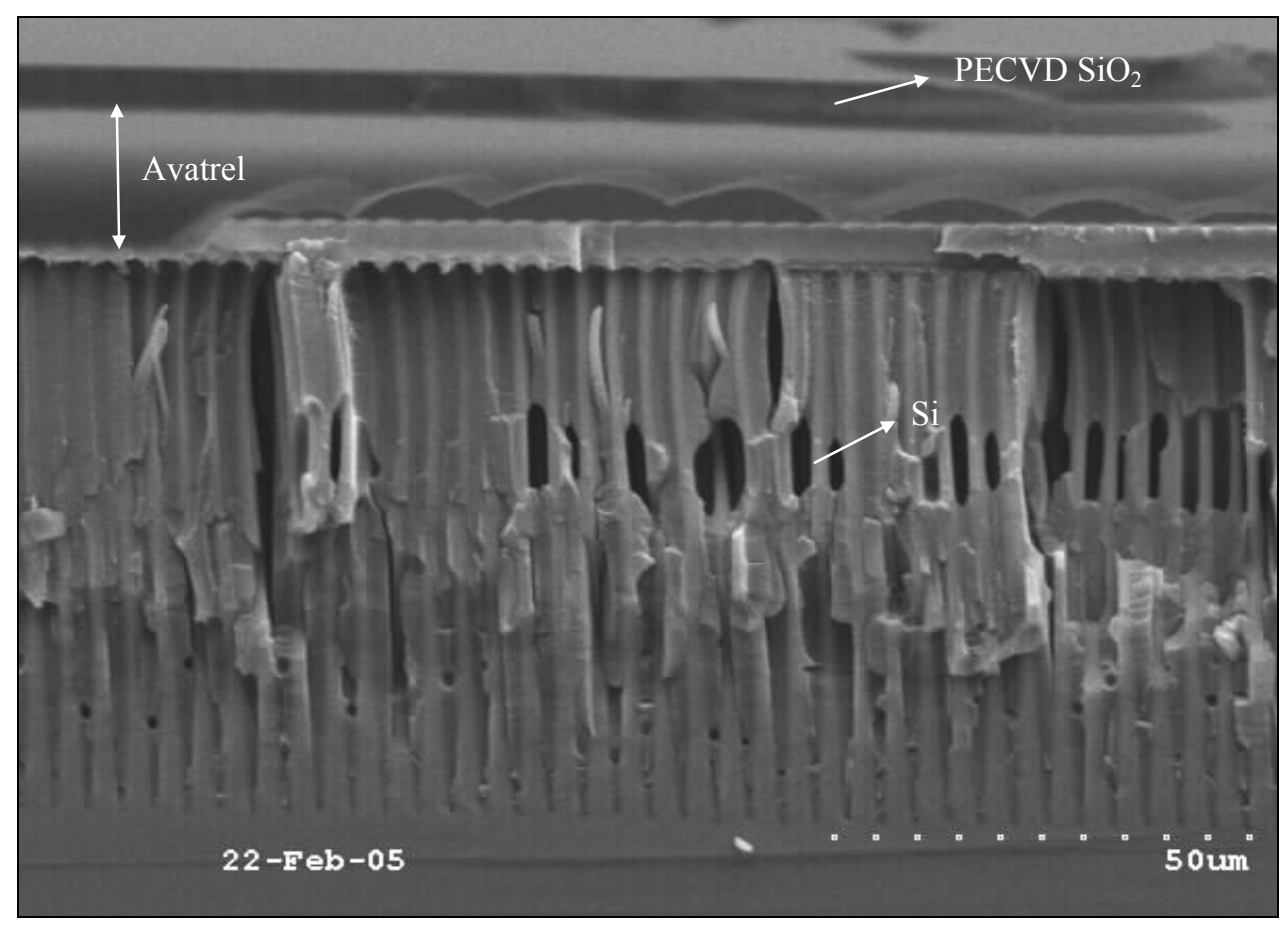

Figure 4-14. Cross-section SEM view of a TSI filled with Avatrel, and coated with a $20 \mu \mathrm{m}$ thick layer of Avatrel and $4 \mu \mathrm{m}$ thick layer of PECVD $\mathrm{SiO}_{2}$.

Figures 4-15 and 4-16 illustrate the de-embedded $Q$ of a $1 \mathrm{nH}$ inductor fabricated on $70 \mu \mathrm{m}$ deep TSI (covered with $\mathrm{SiO}_{2}$ ) and $90 \mu \mathrm{m}$ deep Avatrel refilled trenched $\mathrm{Si}$, respectively. Quality factor of the inductor on TSI is higher by $\sim 30 \%$ at $4 \mathrm{GHz}$ compared to when it is fabricated on Avatrel refilled trenched $\mathrm{Si}(Q$ on TSI=55@4GHz, and $Q$ on Avatrel=50@4GHz). 


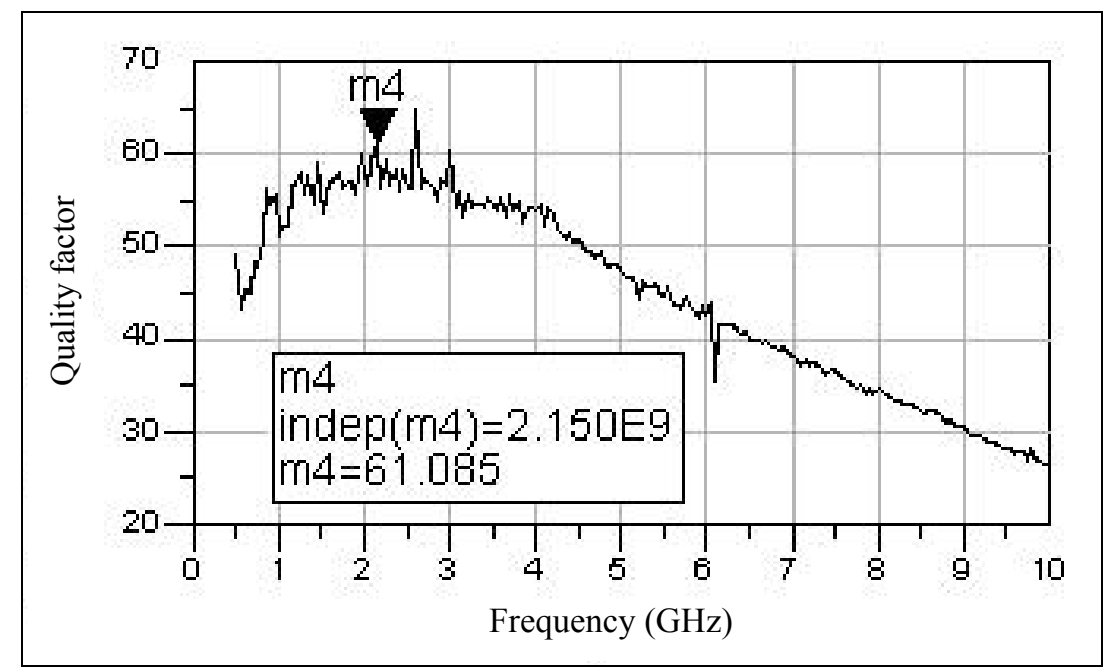

Figure 4-15. Extracted de-embedded $Q$ of a $1 n H$ inductor on $70 \mu m$ deep TSI $(w=60 \mu m$, $d_{\text {out }}=600 \mu \mathrm{m}, \rho=100 \Omega$.cm).

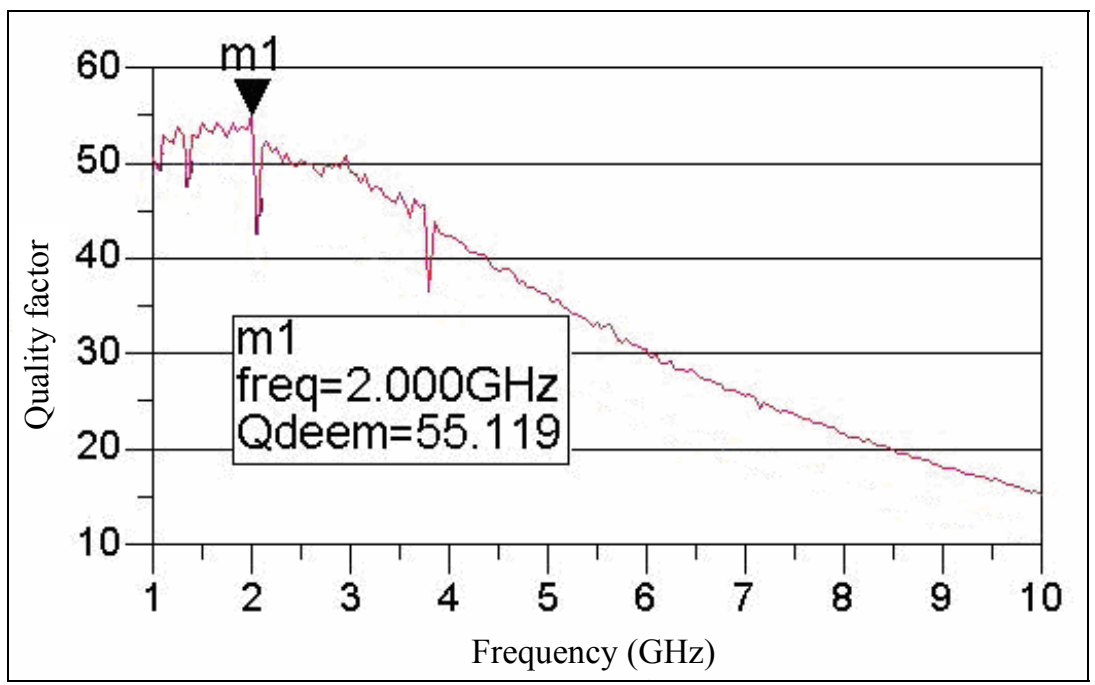

Figure 4-16. De-embedded $Q$ of a $1 \mathrm{nH}$ inductor on $90 \mu \mathrm{m}$ deep Avatrel refilled trenched $\mathrm{Si}\left(w=60 \mu \mathrm{m}, d_{\text {out }}=600 \mu \mathrm{m}, \rho=10 \Omega \mathrm{cm}\right)$. 


\subsubsection{Thick PECVD $\mathrm{SiO}_{2}$}

Although deposition of a thick $\mathrm{SiO}_{2}$ layer might seem an easy way of reducing the substrate loss, there are some issues associated with it:

1) The deposition rate of $\mathrm{PECVD} \mathrm{SiO}_{2}$ is about $1 \mu \mathrm{m}$ per $15 \mathrm{~min}$. Therefore, it takes about 5hours to deposit a $20 \mu \mathrm{m}$ thick $\mathrm{SiO}_{2}$ layer. Whereas, etching $100 \mu \mathrm{m}$ deep trenches using Bosch process takes about 1hour.

2) Thick layer of $\mathrm{SiO}_{2}$ is highly stressed and can crack or peeled off. In addition, it induces stress to the substrate and makes the substrate prone to fracture.

Despite these facts and for the sake of comparison, inductors have also been fabricated on a $20 \mu \mathrm{m}$ thick $\mathrm{SiO}_{2}$ coated standard $\mathrm{Si}$ substrate. Figure 4-17 depicts $Q$ of a $0.9 \mathrm{nH}$ inductor fabricated on a $20 \mu \mathrm{m}$ thick PECVD SiO2 covered standard Si substrate, showing good agreement with SONNET simulation result (Fig. 4-18).

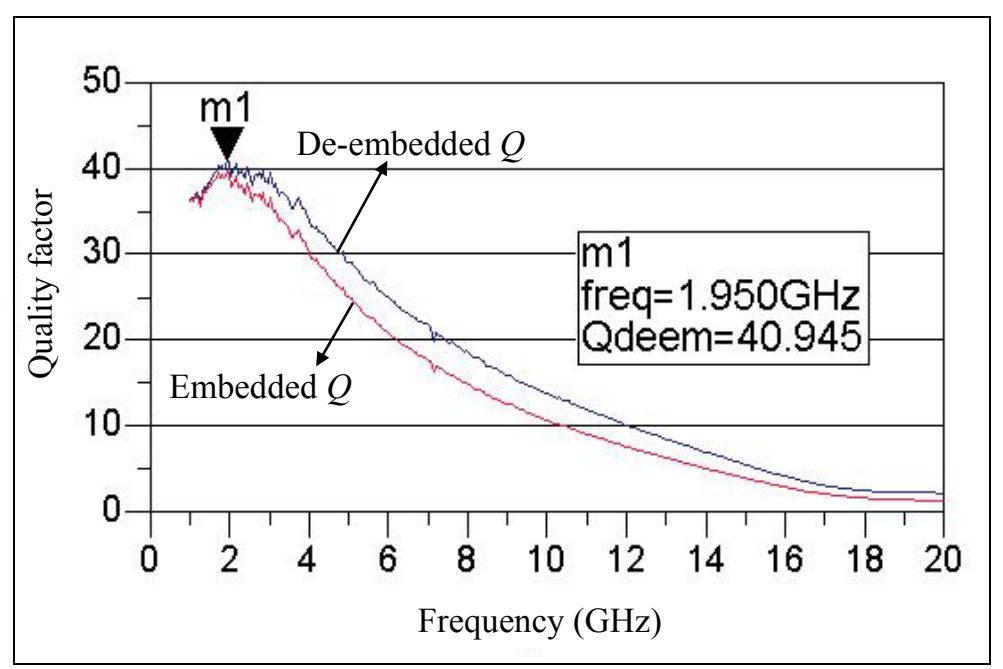

Figure 4-17. Measured $Q$ of a $0.9 n \mathrm{H}$ inductor on a $20 \mu \mathrm{m}$ thick $\mathrm{SiO}_{2}$ coated Si substrate $\left(w=50 \mu \mathrm{m}, d_{\text {out }}=50 \mu \mathrm{m}\right)$. 


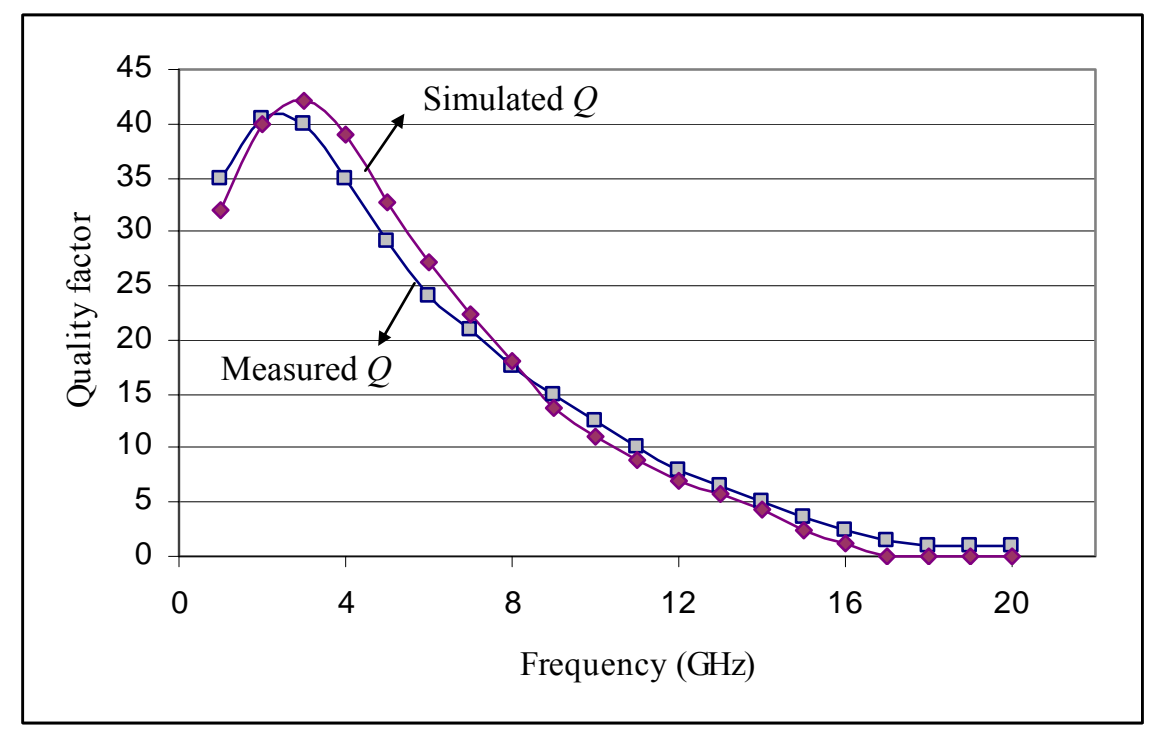

Figure 4-18. Simulated and measured $Q$ of a $0.9 n \mathrm{H}$ inductor on $20 \mu \mathrm{m}$ thick $\mathrm{SiO}_{2}$ coated $10 \Omega . c m$ Si substrate.

Quality factor of a $1 \mathrm{nH}$ inductor on $20 \mu \mathrm{m}$ thick $\mathrm{SiO}_{2}$ substrate is shown in Fig. 4-19. This inductor is identical to the one in figures 4-15 and 4-16.

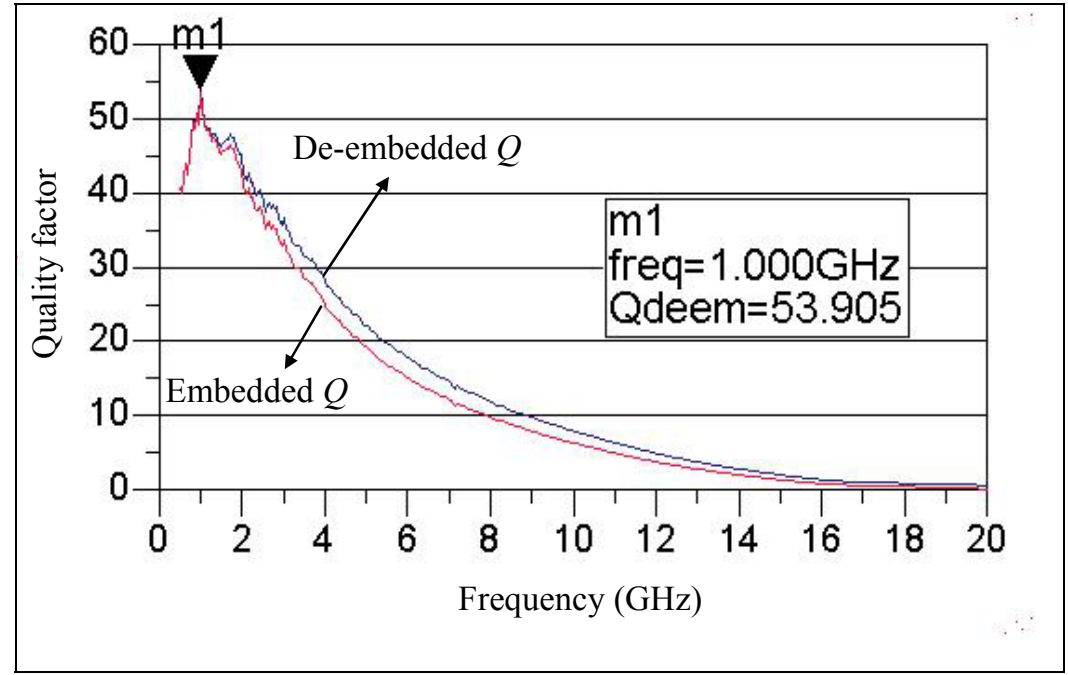

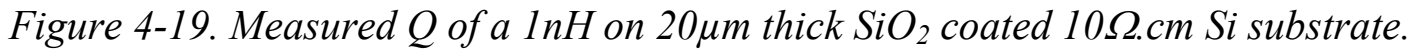


Comparing the measured $Q$ of identical inductors on different type of micromachined substrates reveals that TSI (without refilling) presents the lowest-loss compared to other low-temperature micromachined Si substrates (Fig. 4-20).

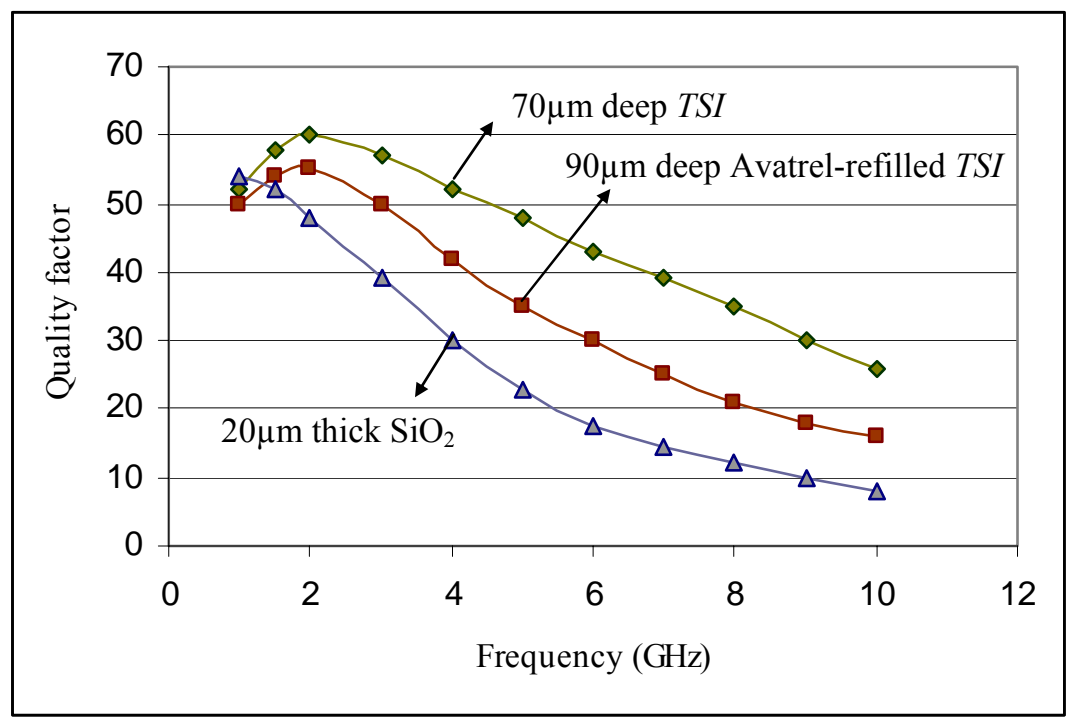

Figure 4-20. Measured $Q$ of a $1 n H$ inductor on $70 \mu m$ deep TSI, 20 $\mu$ m thick PECVD $\mathrm{SiO}_{2}$

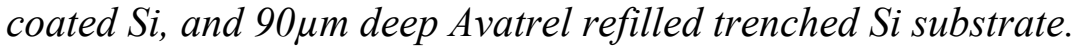

\subsection{High-turn inductors}

High-turn inductors $(\mathrm{n}>1)$ suffer from high metal loss, due to the fact that the first metal layer used for routing is only $1.5 \mu \mathrm{m}$ thick and is located between two $\mathrm{SiO}_{2}$ layers. For this reason, $Q$ of high-turn inductors is lower than the $Q$ of one-turn inductors. Figures 421 to 4-24 are the measured $Q$ 's of some high-turn inductors on different types of micromachined substrates, showing the highest $Q$ of 35 (@3.25GHz) for a 1.5-turn inductor on $20 \mu \mathrm{m}$ thick $\mathrm{SiO}_{2}$ coated $\mathrm{Si}$ substrate. Although the $Q$ 's presented here are higher than what can be achieved on standard Si substrates due to the reduction of 
substrate loss, there is still room to improve this factor by reducing the number of turns to one at the cost of chip area or by increasing the thickness of the first metal layer.

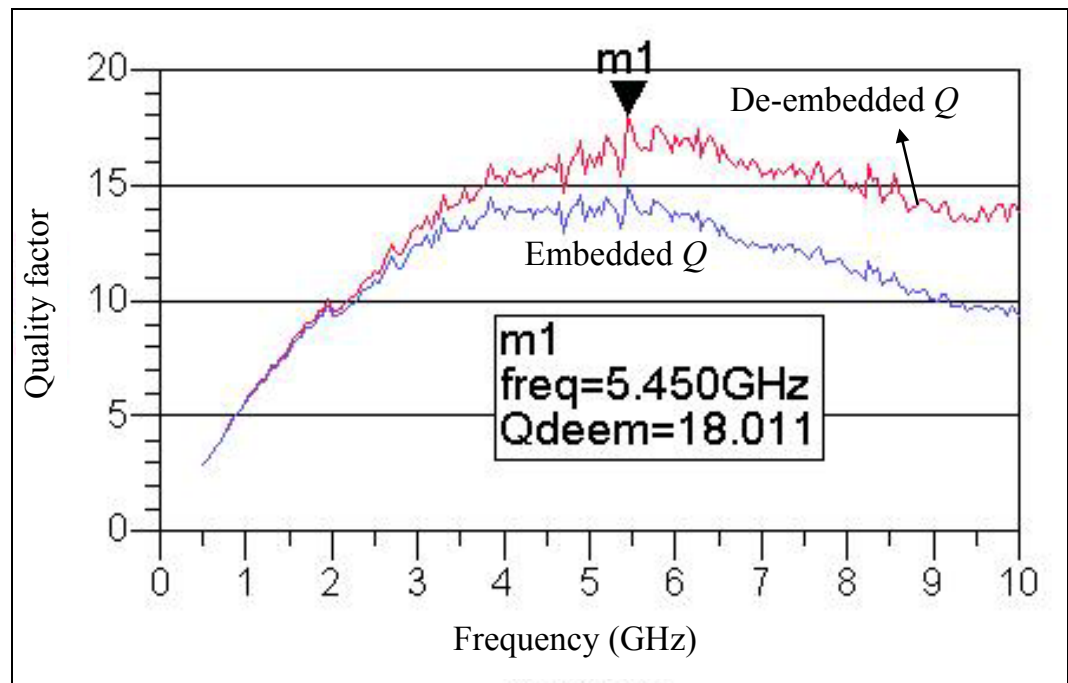

Figure 4-21. Measured $Q$ of a $1.1 n H$ inductor on TSI $\left(t_{\text {metall }}=1.5 \mu m, n=1.5, w=40 \mu m\right.$, $s=20 \mu \mathrm{m}$, and $d_{\text {out }}=300 \mu \mathrm{m}$ ).

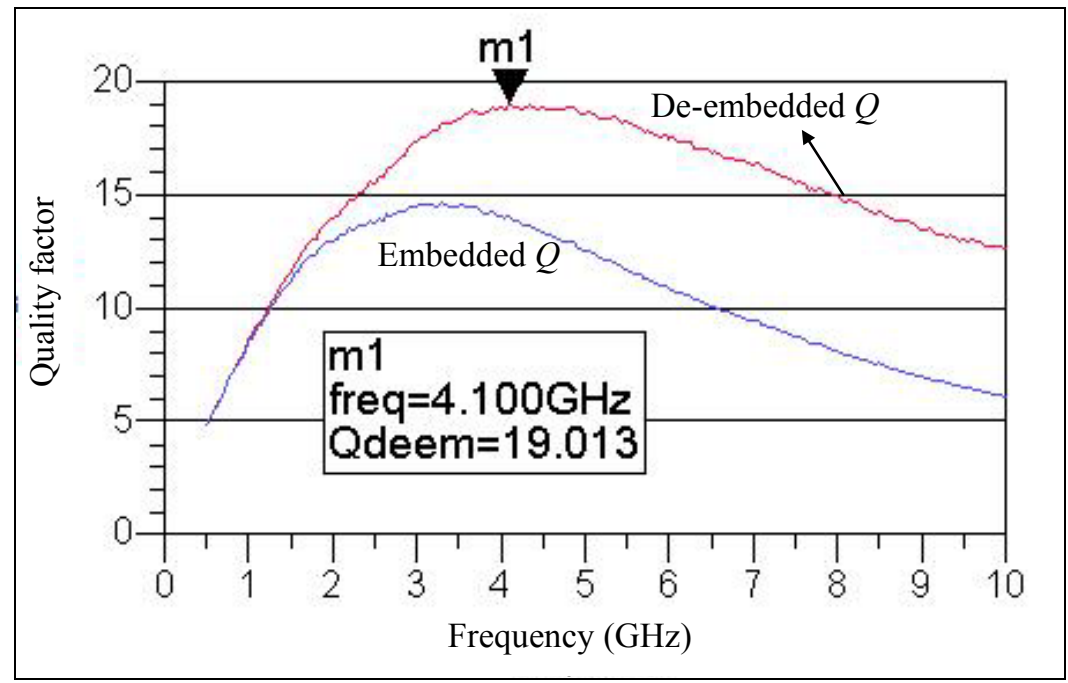

Figure 4-22. Measured $Q$ of a $1.3 n H$ inductor on TSI $\left(t_{\text {metall }}=1.5 \mu m, n=1.5, w=30 \mu m\right.$, $s=20 \mu \mathrm{m}$, and $\left.d_{\text {out }}=300 \mu \mathrm{m}\right)$. 

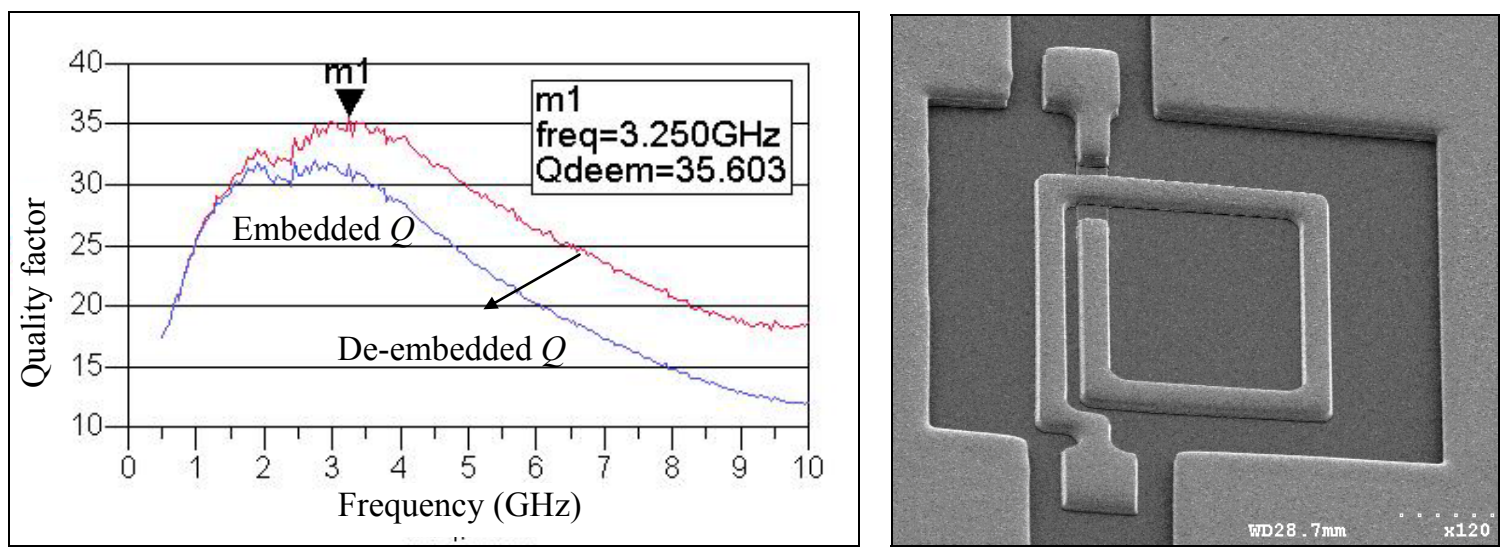

Figure 4-23. (Left) Measured $Q$ of a $1.2 n H$ inductor on $20 \mu$ thick PECVD SiO , (right) SEM picture of this inductor $\left(t_{\text {metall }}=1.5 \mu \mathrm{m}, n=1.5, w=30 \mu \mathrm{m}, \mathrm{s}=20 \mu \mathrm{m}\right.$, and $\left.d_{\text {out }}=300 \mu \mathrm{m}\right)$.
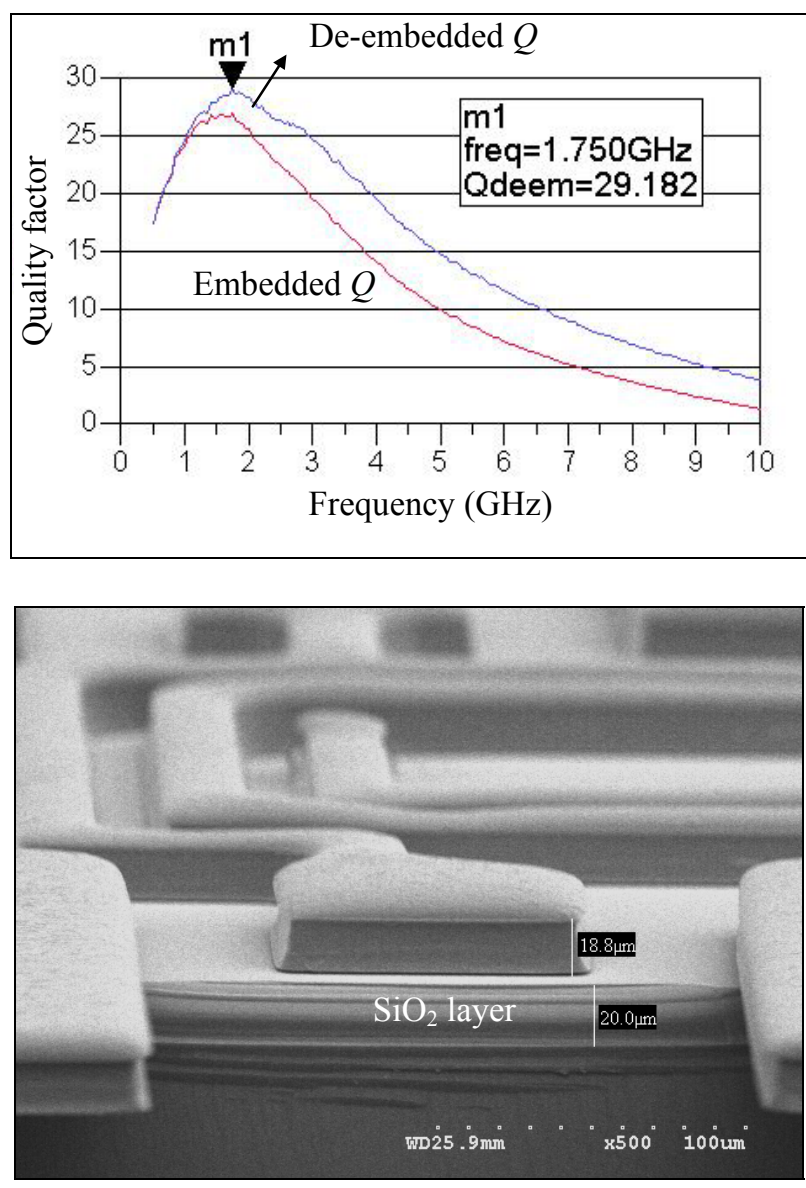

Figure 4-24. (Upper) Measured $Q$ of a $3.3 n \mathrm{H}$ inductor on $20 \mu \mathrm{m}$ thick PECVD $\mathrm{SiO}_{2}$, (lower) SEM picture of the inductor $\left(t_{\text {metall }}=1.5 \mu m, n=2.5, w=20 \mu \mathrm{m}, s=20 \mu \mathrm{m}\right.$, and $\left.d_{\text {out }}=400 \mu \mathrm{m}\right)$. 


\subsection{Modeling and Parameter Extraction}

Inductors fabricated on TSI and $O I$ have been modeled using the equivalent electrical model shown in Fig. 2.2. The series resistance is extracted from co-planar model and has an excellent match with the measured data. Figure 4-25 shows the measured and modeled $Q$ of a $1 \mathrm{nH}$ inductor on TSI.

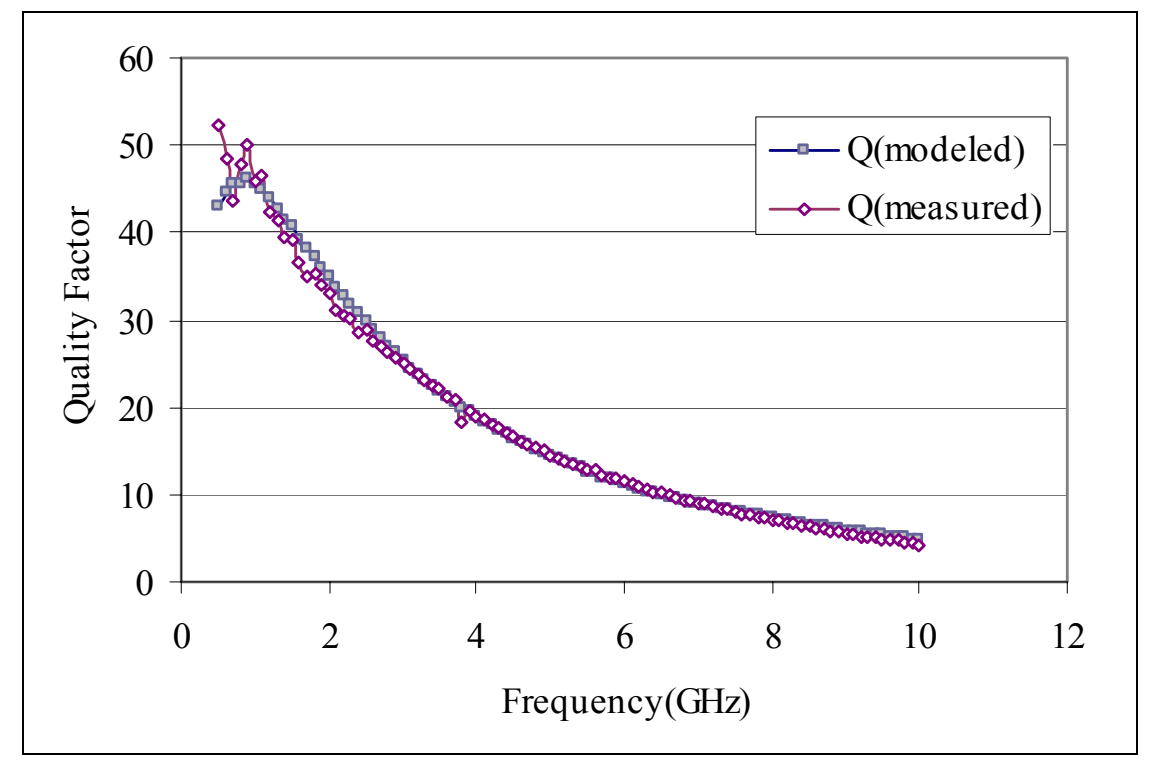

Figure 4-25. Measured and modeled Q vs. frequency of a 1.04nH inductor on TSI.

The inductance value is extracted from the measured $L$ at lower frequencies assuming the substrate loss is not present at this frequency range. Figure 4-26 shows the contribution of the metal and the substrate loss on the measured $Q$, demonstrating that the metal loss is the dominant loss mechanism at lower frequencies. 


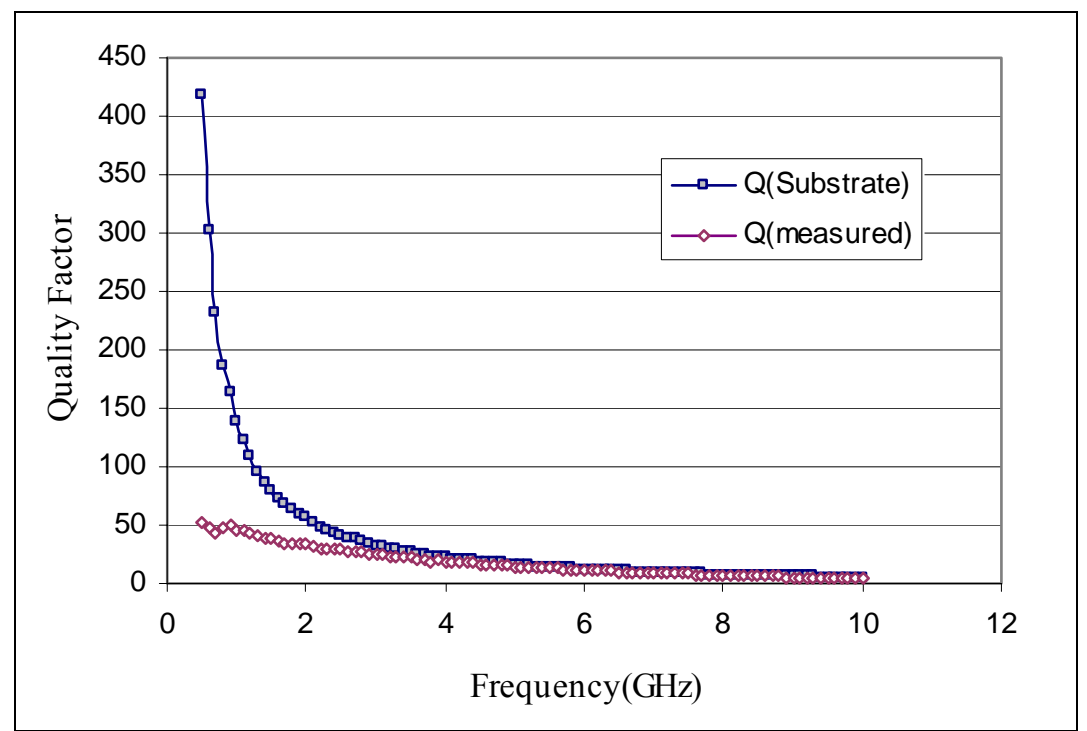

(a)

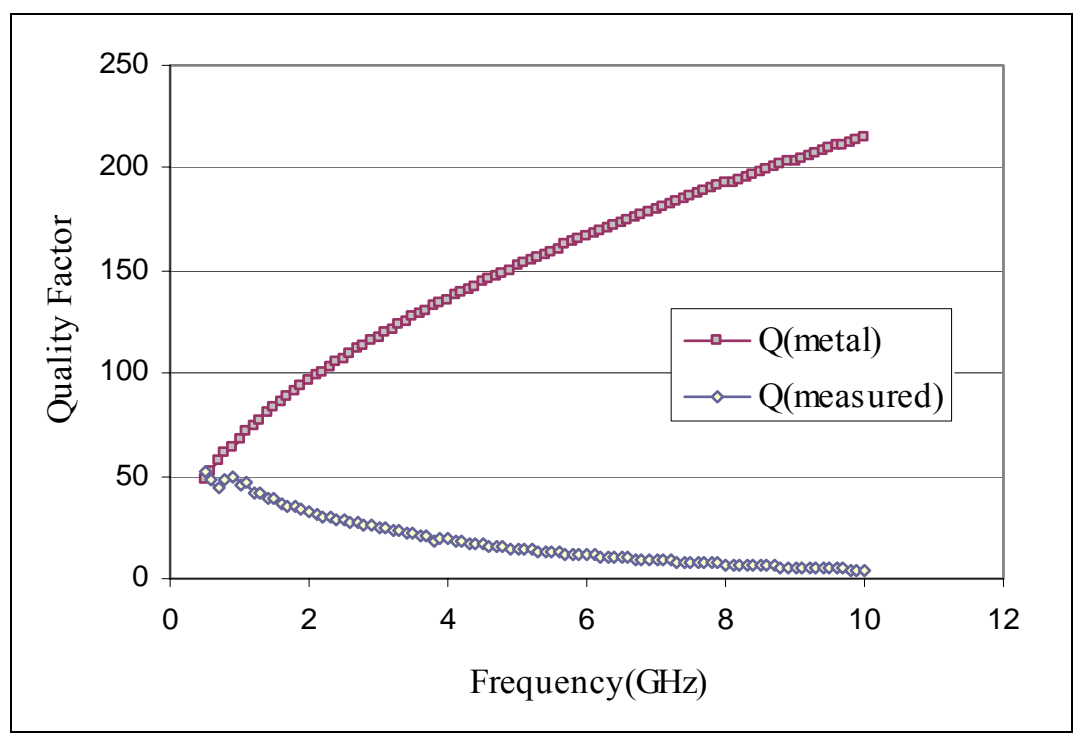

(b)

Figure 4-26. (a) Extracted $Q_{\text {substrate, }}$ and (b) $Q_{\text {metal }}$ of a $1.04 n H$ inductor on TSI.

To better understand the effect of trenching the $\mathrm{Si}$ on the substrate loss, the equivalent $T S I^{`}$ s resistivity has been extracted from the measured data and is plotted in Fig. 4-27(b). Table 4-1 summarizes the modeled parameter of the inductor fabricated on TSI. 


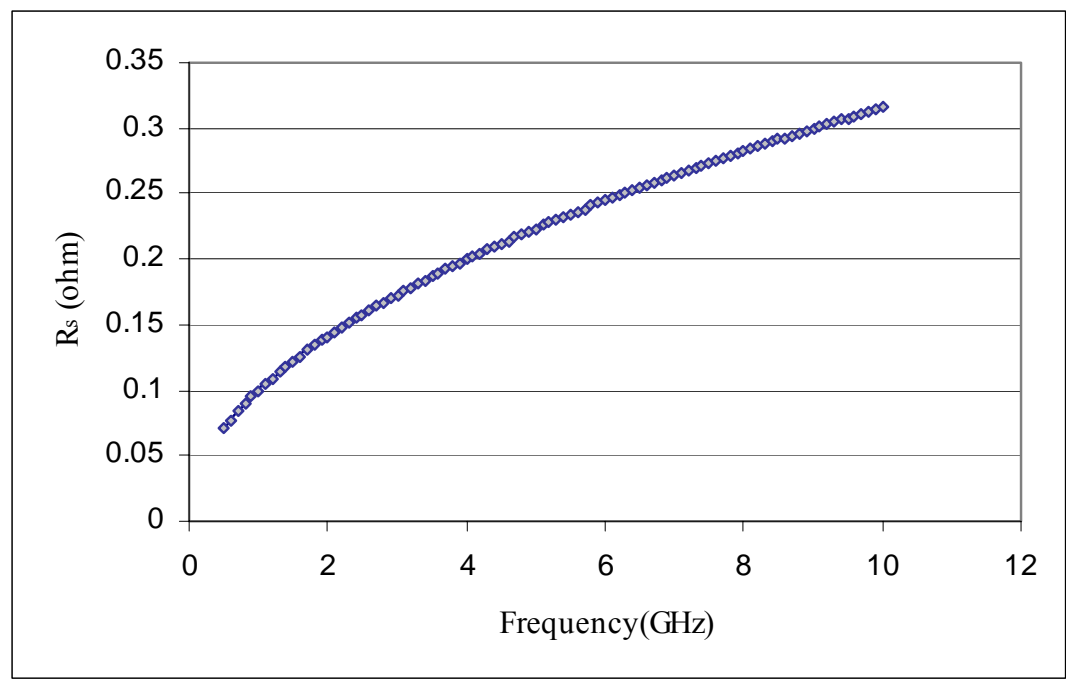

(a)

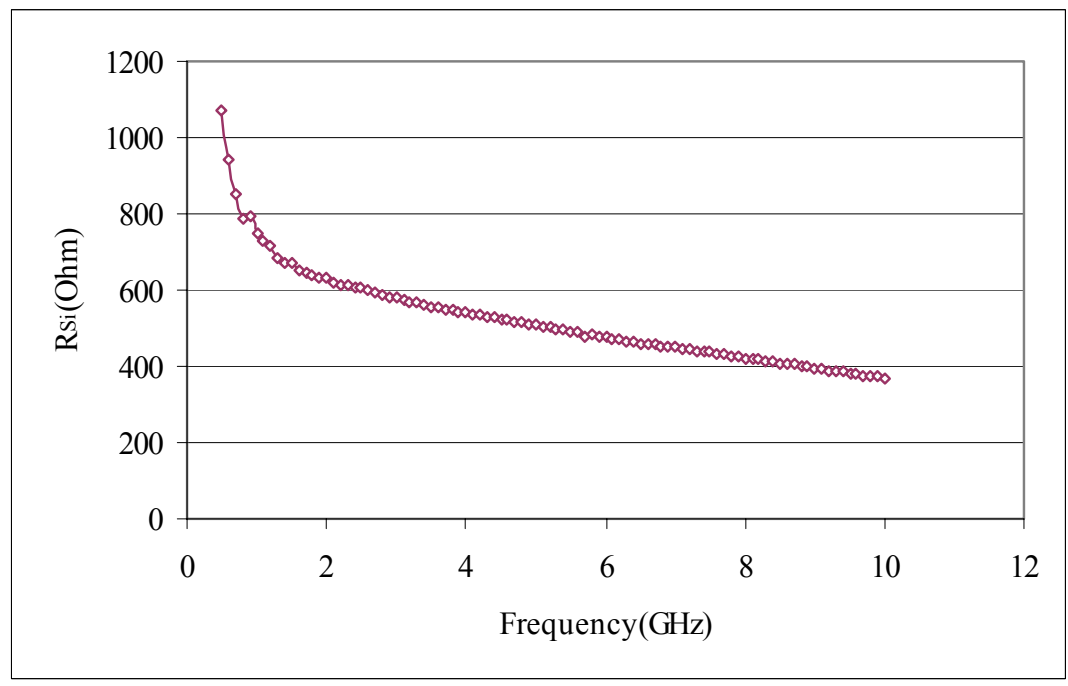

(b)

Figure 4-27. Modeled (a) metal resistance, and (b) substrate resistance of the inductor shown in Fig. 4-25.

Table 4-1. Extracted equivalent parameters of a 1 nH inductor fabricated on TSI

\begin{tabular}{|l|l|l|l|l|l|}
\hline $\mathrm{f}(\mathrm{GHz})$ & $\mathrm{R}_{\mathrm{s}}(\Omega)$ & $\mathrm{L}_{\mathrm{s}}(\mathrm{nH})$ & $\mathrm{R}_{\mathrm{si}}(\Omega)$ & $\mathrm{C}_{\mathrm{si}}(\mathrm{fF})$ & $\mathrm{C}_{\text {ox }}(\mathrm{pF})$ \\
\hline 1 & 0.0998 & 1.08 & 747.65 & 86.64 & 0.887 \\
\hline 2.4 & 0.1547 & 1.08 & 604.326 & 77.26 & 0.887 \\
\hline 6 & 0.2466 & 1.08 & 475.74 & 53.06 & 0.887 \\
\hline
\end{tabular}


Identical structure on $O I$ exhibits lower substrate parasitic $\left(R_{s i}\right.$ and $\left.C_{s i}\right)$ shown in the table below. Modeled $Q$ of this inductor is shown in Fig. 4-28.

Table 4-2. Extracted equivalent parameters of a 0.9nH inductor fabricated on OI.

\begin{tabular}{|l|l|l|l|l|l|}
\hline $\mathrm{f}(\mathrm{GHz})$ & $\mathrm{R}_{\mathrm{s}}(\Omega)$ & $\mathrm{L}_{\mathrm{s}}(\mathrm{nH})$ & $\mathrm{R}_{\mathrm{si}}(\Omega)$ & $\mathrm{C}_{\mathrm{si}}(\mathrm{fF})$ & $\mathrm{C}_{\mathrm{ox}}(\mathrm{pF})$ \\
\hline 1 & 0.13982 & 0.883 & 6909.688 & 5.963 & 0.887 \\
\hline 2.4 & 0.21660 & 0.883 & 2270.26 & 5.5782 & 0.887 \\
\hline 6 & 0.34249 & 0.883 & 1168.02 & 5.0564 & 0.887 \\
\hline
\end{tabular}

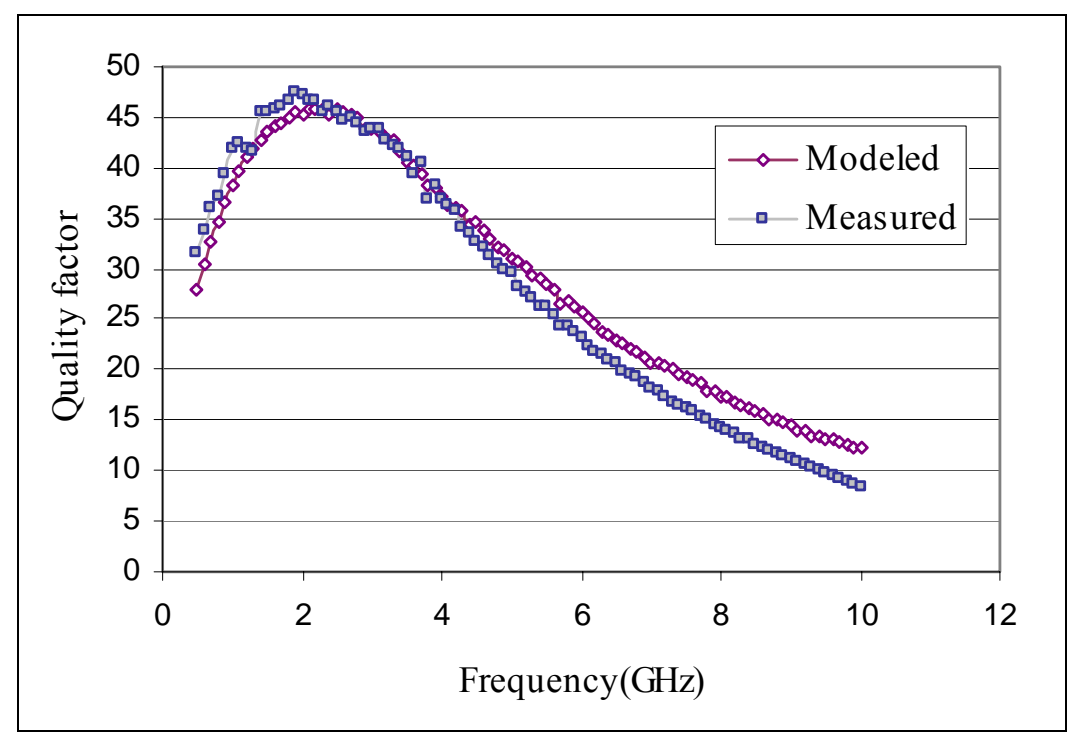

Figure 4-28. Measured and modeled $Q$ vs. frequency of a $0.9 n H$ inductor on OI. 


\section{CHAPTER V}

\section{CONCLUSION AND FUTURE DIRECTIONS}

This thesis introduced a new implementation of high- $Q$ integrated $\mathrm{Cu}$ inductors on CMOS-grade Si substrates using a fully CMOS-compatible process. A new fabrication sequence has been used to reduce the loss of Si substrate at RF frequencies by trenching

the Si. Two approaches were taken to cover the trenches and make a smooth surface: 1) High aspect-ratio (30:1) trenches were bridged-over by depositing a thin layer $(3 \mu \mathrm{m})$ of $\mathrm{SiO}_{2}$ at $300^{\circ} \mathrm{C}$, and 2) trenches were refilled by spin-coating of Avatrel Polymer. Metal loss of inductors was reduced by electroplating thick $(\sim 20 \mu \mathrm{m}) \mathrm{Cu}$ layer.

Several inductors were designed and simulated using SONNET simulation tool. Inductor parameters were optimized to have high $Q$ and small size. For simplicity, inductors were simulated on $4 \mu \mathrm{m}$ thick $\mathrm{SiO}_{2}$ coated standard $\mathrm{Si}$ substrate, as simulating the behavior of TSI is computationally intensive. A one-turn round inductor with metal width of $50 \mu \mathrm{m}$ and outer diameter of $500 \mu \mathrm{m}$ exhibits the highest- $Q$ of 28.5 at $2-10 \mathrm{GHz}$ frequency range (assuming the substrate is $10 \Omega . \mathrm{cm}$ and the thickness of $\mathrm{SiO} 2$ layer is $4 \mu \mathrm{m}$ ). Quality factor and inductance value of simulated inductors is shown in the Appendix B.

The inductors were fabricated on several micromachined standard Si substrates including Oxide Islands, Trenched Si Islands, Avatrel refilled trenched Si and thick PECVD $\mathrm{SiO}_{2}$ coated Si. Comparing the measured $Q$ of identical inductors on different type of micromachined substrates revealed that the TSI (without refilling) exhibits the lowest-loss 
compared to other low-temperature micromachined Si substrates. Measurement results indicate a significant improvement in the $Q$ compared to the inductors fabricated on the conventional low-resistivity Si substrates. A $0.8 \mathrm{nH} \mathrm{Cu}$ inductor fabricated on Trenched Silicon Islands exhibits high $Q$ of 71 at $8.75 \mathrm{GHz}$ and self resonance frequency of over $15 \mathrm{GHz}$. Whereas, the identical inductor fabricated on a $20 \mu \mathrm{m}$ thick $\mathrm{SiO}_{2}$ coated $\mathrm{Si}$ substrate has a maximum $Q$ of 41 at $1.95 \mathrm{GHz}$. A $0.9 \mathrm{nH}$ inductor fabricated on Avatrel refilled trenched Si substrate has a high $Q$ of 60.4 at $1.75 \mathrm{GHz}$. Test results show that the same inductor fabricated on $50 \mu \mathrm{m}$ deep Oxide Island has a similar $Q$ at high frequencies ( $f \geq 4 \mathrm{GHZ}$ ). Therefore, a $90 \mu \mathrm{m}$ deep Avatrel refilled trenched Si substrate is the lowtemperature $\left(300^{\circ} \mathrm{C}\right)$ processed alternative for a $50 \mu \mathrm{m}$ deep Oxide Island (processing temperature $=1100^{\circ} \mathrm{C}$.

Finally, the electrical equivalent circuit of inductors on Trenched Si Islands as well as other substrates was derived. The series resistance was extracted using isolated strip formula. Modeled $Q$ showed an excellent agreement with measured results.

To further increase the inductor $Q$, the trench depth should be increased. The saturation behavior of the $Q$ versus the trench depth was not observed with trench depth up to $90 \mu \mathrm{m}$ and needs to be determined in later fabrications.

Also, the TSI coated with a low-K dielectric is expected to exhibit lower loss compared to the TSI coated with $\mathrm{SiO}_{2}$ with the dielectric constant of 3.9. For instance, the substrate shown in Fig. 5-1 is a $90 \mu \mathrm{m}$ deep TSI coated with a $18 \mu \mathrm{m}$ thick layer of Avatrel 
$\operatorname{polymer}\left(\varepsilon_{\mathrm{r}}=2.5\right)$ and has a lower loss compared to the TSI with no Avatrel over-coat. Fabrication of inductors on this type of substrate is not yet complete.

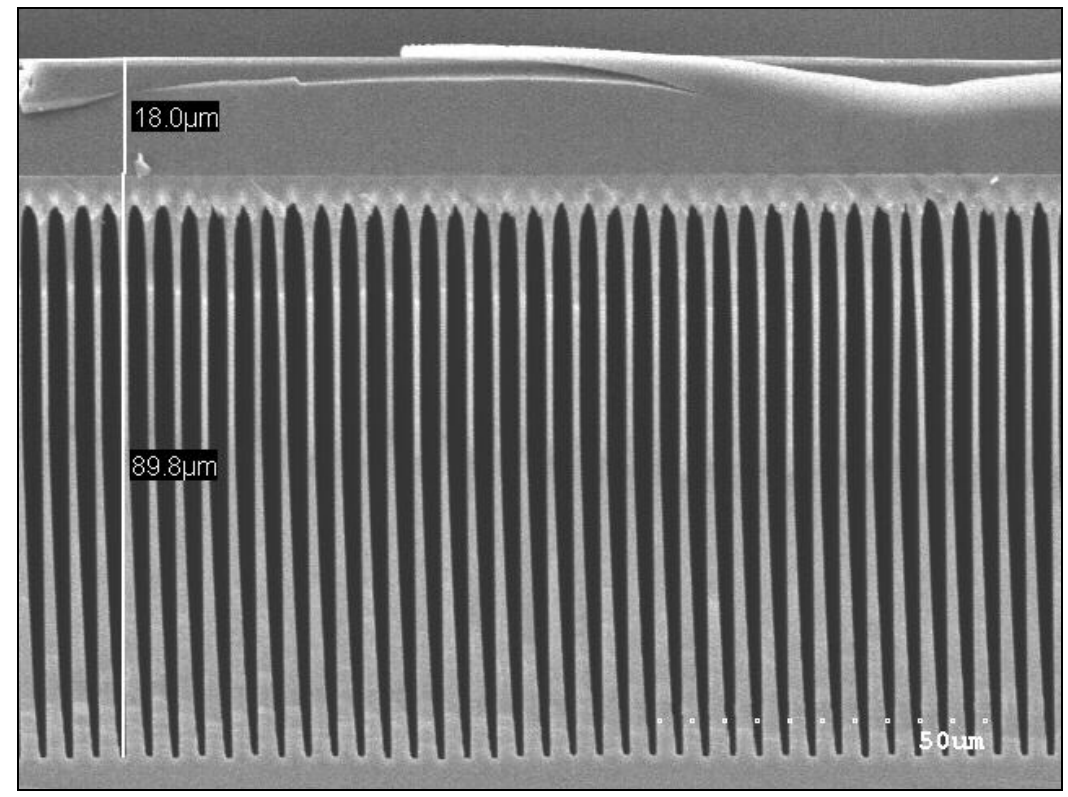

Figure 5-1. Cross-section SEM view of a 90um deep TSI coated with a $18 \mu \mathrm{m}$ thick layer of low-K dielectric.

A new mask set was also designed to improve $Q$ of the inductors and reduce the inductor size. The trench mask as seen in Fig. 5-2 was modified to have trenches perpendicular to the inductor traces to further reduce the substrate loss. The trench profile as it can be seen is similar to the patterned ground shield profile. Inductors fabricated on perpendicularly trenched Si substrate have not been yet measured to see the effect of the trench direction on the reduction of the substrate loss. 


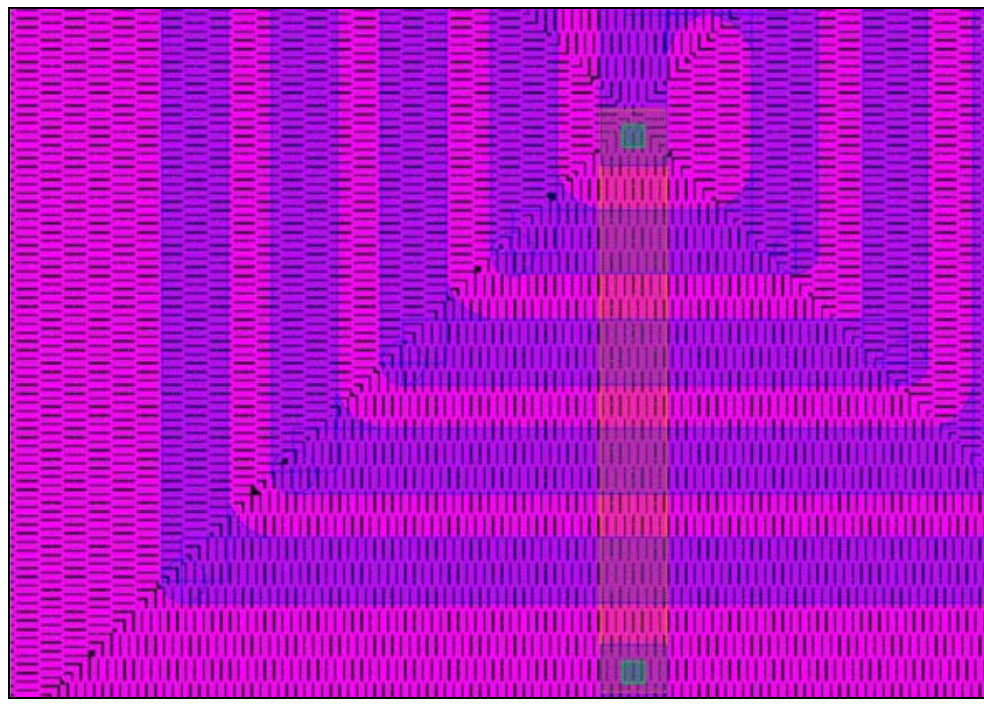

Metal 1

Trench

Via

Metal2

Figure 5-2. Snap-shot of a four-turn inductor mask with trenches perpendicular to the metal trace. 


\section{APPENDIX A}

\section{PROCESS FLOW}

\section{Mask 1. SI TRENCHES}

\begin{tabular}{|c|c|c|}
\hline Process step & Process Description & Recipes and Comments \\
\hline 1 & Clean wafer & $\begin{array}{l}\text { Acetone, Methanol, DI water, dry } \\
\mathrm{N}_{2} \text { gun }\end{array}$ \\
\hline 2 & Dehydration & $3 \mathrm{~min}$ at $115^{\circ} \mathrm{C}$ on hotplate \\
\hline 3 & $\begin{array}{l}\text { Spin/bake HMDS and Spin } \\
\text { Photo-Resist }\end{array}$ & $\begin{array}{l}\text { Cover } 1 / 3 \text { of the wafer with } \\
\text { HMDS: } 4000 \mathrm{rpm}, 1000 \mathrm{rpm} / \mathrm{s}, 20 \\
\text { sec. } \\
\text { Bake HMDS } 115^{\circ} \mathrm{C} \text { for } 30 \mathrm{sec} \text {. } \\
\text { Cover } 2 / 3 \text { of wafer with } 1813: \\
1000 \mathrm{rpm}, 1500 \mathrm{rpm} / \mathrm{s}, 5 \mathrm{sec} \text {. } \\
2000 \mathrm{rpm}, 500 \mathrm{r} / \mathrm{s}, 30 \mathrm{sec} .\end{array}$ \\
\hline 4 & Soft bake & $115^{\circ} \mathrm{C}$ for $1 \mathrm{~min}$ on hotplate \\
\hline 5 & Exposure & $\begin{array}{l}\text { I-line, intensity } 20 \mathrm{~mJ} / \mathrm{sec} \text {, vacuum } \\
\text { contact, with } 25 \mu \mathrm{m} \text { alignment gap, } \\
8 \mathrm{sec} \text {. }\end{array}$ \\
\hline 6 & Develop & $\begin{array}{l}\text { MF-319 developer for about } 1 \mathrm{~min} \\
\text { Dip in DI water for } 1 \mathrm{~min} \\
\text { Wash with DI water }\end{array}$ \\
\hline 7 & Dehydration and bake & $\begin{array}{l}\text { dry } \mathrm{N}_{2} \text { gun , bake } 5 \mathrm{~min} \text { at } 115^{\circ} \mathrm{C} \\
\text { on hotplate }\end{array}$ \\
\hline 8 & DRIE & $\begin{array}{l}\text { Using STS ICP machine to etch } \\
\text { 90um of Si for 1hour }\end{array}$ \\
\hline 9 & Strip & $4 \times 30 \mathrm{sec}$ in Asher \\
\hline
\end{tabular}

Mask 2. FIRST METAL LAYER

\begin{tabular}{|c|l|l|}
\hline Process step & Process Description & Recipes and Comments \\
\hline 1 & Clean wafer & $\begin{array}{l}\text { Acetone, Methanol, DI water, dry } \\
\mathrm{N}_{2} \text { gun }\end{array}$ \\
\hline 2 & Dehydration & 3 min at $115^{\circ} \mathrm{C}$ \\
\hline 3 & $\mathrm{SiO}_{2}$ deposition & $\begin{array}{l}\text { Using UNAXIS PECVD, } \\
\text { Pressure: } 950 \mathrm{mTorr} \\
\end{array}$ \\
& & $\begin{array}{l}\mathrm{SiH}_{4}: 500 \mathrm{sccm} \\
\mathrm{N}_{2} \mathrm{O}: 500 \mathrm{sccm}\end{array}$ \\
\hline
\end{tabular}




\begin{tabular}{|c|c|c|}
\hline & & $\begin{array}{l}\mathrm{He}: 560 \mathrm{sccm} \\
\text { Deposition rate: } 1 \mu \mathrm{m} / 15 \mathrm{~min} \\
\text { RF Power: } 65 \mathrm{~W} \\
\text { Temperature: } 300^{\circ} \mathrm{C}\end{array}$ \\
\hline 4 & Clean wafer and Dehydrate & $\begin{array}{l}\text { Acetone, Methanol, DI water, dry } \\
\mathrm{N}_{2} \text { gun, } 3 \text { min at } 115^{\circ} \mathrm{C}\end{array}$ \\
\hline 5 & $\begin{array}{l}\text { Spin/bake HMDS } \\
\text { Spin Photo-Resist }\end{array}$ & $\begin{array}{l}\text { Cover } 1 / 3 \text { of the wafer with } \\
\text { HMDS: } 4000 \mathrm{rpm}, 2000 \mathrm{rpm} / \mathrm{s}, 20 \\
\text { sec. } \\
\text { Bake HMDS } 115^{\circ} \mathrm{C} \text { for } 30 \mathrm{sec} \text {. } \\
\text { Cover } 2 / 3 \text { of wafer with } \mathrm{AZ} 4620 \text { : } \\
\text { 300rpm, } 1500 \mathrm{rPM} / \mathrm{s}, 5 \mathrm{sec} \text {. } \\
1500 \mathrm{rpm}, 500 \mathrm{rpm} / \mathrm{s}, 40 \mathrm{sec} \text {. }\end{array}$ \\
\hline 6 & Soft bake & $\begin{array}{l}80^{\circ} \mathrm{C} \text { ramp to } 115^{\circ} \mathrm{C} \text { for } 4 \mathrm{~min} \text { on } \\
\text { hotplate }\end{array}$ \\
\hline 7 & Exposure & $\begin{array}{l}\text { Using MA-6, I-Line, hard contact, } \\
\text { with } 25 \mu \mathrm{m} \text { alignment gap, } 160 \mathrm{~mJ} \\
\text { exposure. }\end{array}$ \\
\hline 8 & Develop & 354 developer for $4 \mathrm{~min}$ \\
\hline 9 & Hard bake & $115^{\circ} \mathrm{C}$ for $3 \mathrm{~min}$ on hotplate \\
\hline 10 & $1^{\text {st }}$ Metal layer deposition & $\begin{array}{l}\text { Using CVC E-beam evaporator } \\
\mathrm{Cr} / \mathrm{Cu} / \mathrm{Cr}: 300 \mathrm{~A}^{\circ} / 15000 \mathrm{~A}^{\circ} / 300 \mathrm{~A}^{\circ} \\
\text { Deposition rate: } 3 \mathrm{~A}^{\circ} / \mathrm{sec}-6.5 \\
\mathrm{~A}^{\circ} / \mathrm{sec}-3 \mathrm{~A}^{\circ} / \mathrm{sec}\end{array}$ \\
\hline 11 & Lift-off & $\begin{array}{l}\text { Microposit remover } 1112 \text { at } 80^{\circ} \mathrm{C} \text {, } \\
\text { until resist cracks, } \\
\text { Acetone in Ultrasonic bath until } \\
\text { resist is completely pilled off. }\end{array}$ \\
\hline 12 & Clean wafer & $\begin{array}{l}\text { Aceton, Metanol, DI water to } \\
\text { remove any metallic residues, } \\
\text { Dry } \mathrm{N}_{2} \text { gun }\end{array}$ \\
\hline
\end{tabular}

Mask 3. SILICON DIOXIDE ETCH

\begin{tabular}{|c|l|l|}
\hline Process step & Process Description & Recipes and Comments \\
\hline 1 & Clean wafer & Acetone, Methanol, dry $\mathrm{N}_{2}$ gun \\
\hline 2 & Dehydration & 3 min at $115^{\circ} \mathrm{C}$ \\
\hline 3 & $\mathrm{SiO}_{2}$ deposition & Using UNAXIS PECVD, $3 \mu \mathrm{m}$ \\
& & thick \\
& & Pressure: $950 \mathrm{mTorr}$ \\
& & $\mathrm{SiH}_{4}: 500 \mathrm{sccm}$ \\
& & $\mathrm{N}_{2} \mathrm{O}: 500 \mathrm{sccm}$ \\
& & $\mathrm{He}: 560 \mathrm{sccm}$ \\
& & Deposition rate: $1 \mu \mathrm{m} / 15 \mathrm{~min}$ \\
\hline
\end{tabular}




\begin{tabular}{|c|c|c|}
\hline & & $\begin{array}{l}\text { RF Power: } 65 \mathrm{~W} \\
\text { Temperature: } 300^{\circ} \mathrm{C}\end{array}$ \\
\hline 4 & Clean wafer & Acetone, Methanol, dry $\mathrm{N}_{2}$ gun \\
\hline 5 & Dehydration & $3 \min$ at $115^{\circ} \mathrm{C}$ \\
\hline 6 & $\begin{array}{l}\text { Spin/bake HMDS and Spin } \\
\text { Photo-Resist }\end{array}$ & $\begin{array}{l}\text { Cover } 1 / 3 \text { of the wafer with } \\
\text { HMDS: } 4000 \mathrm{rpm}, 2000 \mathrm{rpm} / \mathrm{s}, 20 \\
\text { sec. } \\
\text { Bake HMDS } 115^{\circ} \mathrm{C} \text { for } 30 \mathrm{sec} \text {. } \\
\text { Cover } 2 / 3 \text { of wafer with SPR } 220 \text { : } \\
1500 \mathrm{rpm}, 500 \mathrm{rpm} / \mathrm{sec}, 5 \mathrm{sec} \text {. } \\
3000 \mathrm{rpm}, 500 \mathrm{rpm} / \mathrm{sec}, 30 \backslash 5 \mathrm{sec} \text {. }\end{array}$ \\
\hline 7 & Soft bake & $115^{\circ} \mathrm{C}$ for 2 min on hotplate \\
\hline 8 & Exposure & $\begin{array}{l}\text { Using MA-6, I-Line, hard contact, } \\
\text { with } 25 \mu \mathrm{m} \text { alignment gap, } 480 \mathrm{~mJ} \\
\text { exposure. }\end{array}$ \\
\hline 9 & Develop & MF-319 developer for $2 \mathrm{~min}$ \\
\hline 10 & Bake & $115^{\circ} \mathrm{C}$ for $20 \mathrm{~min}$ on hotplate \\
\hline 11 & RIE & $\begin{array}{l}\text { Using Plasma therm ICP } \\
25 \mathrm{~min} \text {, etch rate: } 1.1 \mu \mathrm{m} / \mathrm{sec} \\
\text { RF1 power: } 100 \mathrm{~W} \\
\text { RF2 power: } 250 \mathrm{~W} \\
\text { Pressure: } 5 \mathrm{mTorr} \\
\mathrm{H}_{2} \text { flow: } 2 \mathrm{sccm} \\
\mathrm{CF}_{4}: 20 \mathrm{sccm}\end{array}$ \\
\hline 12 & BOE Dip & $\begin{array}{l}\text { Place into BOE: } \mathrm{H}_{2} \mathrm{O}(1: 2) \text { for } \\
4 \mathrm{~min}\end{array}$ \\
\hline 13 & Strip & $\begin{array}{l}\text { In } 1112 \mathrm{~A} \text { resist remover at } 80^{\circ} \mathrm{C} \\
\text { for } 6 \mathrm{~min}\end{array}$ \\
\hline 14 & Rinse and dry & $\begin{array}{l}\text { DI water, dry on hot plate at } \\
100^{\circ} \mathrm{C}\end{array}$ \\
\hline
\end{tabular}

Mask 4. SECOND METAL LAYER

\begin{tabular}{|c|l|l|}
\hline Process step & Process Description & Recipes and Comments \\
\hline 1 & Clean wafer & Acetone, Methanol, dry $\mathrm{N}_{2}$ gun \\
\hline 2 & Dehydration & 3 min at $115^{\circ} \mathrm{C}$ \\
\hline 3 & Seed-layer deposition & $\begin{array}{l}\text { Using } \mathrm{CVC} \mathrm{DC} \mathrm{sputterer} \\
\mathrm{Cr} / \mathrm{Cu}: 1000 \mathrm{~A}^{\circ} / 3000 \mathrm{~A}^{\circ}\end{array}$ \\
\hline 4 & Clean wafer & Acetone, Methanol, dry $\mathrm{N}_{2}$ gun \\
\hline 5 & Dehydration & 3 min at $115^{\circ} \mathrm{C}$ \\
\hline 6 & Spin Photo-Resist & $\begin{array}{l}\text { Cover } 1 / 3 \text { of the wafer with NR4- } \\
8000 \mathrm{P}\end{array}$ \\
& & $600 \mathrm{rpm}, 1500 \mathrm{rpm} / \mathrm{s}, 5$ sec. \\
\hline
\end{tabular}




\begin{tabular}{|c|c|c|}
\hline & & $1200 \mathrm{rpm}, 500 \mathrm{rpm} / \mathrm{s}, 40 \mathrm{sec}$ \\
\hline 7 & Soft bake & $\begin{array}{l}80^{\circ} \mathrm{C} \text { to } 110^{\circ} \mathrm{C} \text { for } 10 \mathrm{~min} \text { on } \\
\text { hotplate }\end{array}$ \\
\hline 8 & Exposure & $\begin{array}{l}\text { Using MA-6, g-line, hard contact, } \\
\text { lamp intensity: } 6 \mathrm{~mJ} / \mathrm{sec} \text {, expose: } \\
63 \mathrm{sec}, \text { with } 30 \mu \mathrm{m} \text { alignment gap. }\end{array}$ \\
\hline 9 & Post exposure bake & $\begin{array}{l}80^{\circ} \mathrm{C} \text { to } 100^{\circ} \mathrm{C} \text { for } 5 \mathrm{~min} \text { on } \\
\text { hotplate }\end{array}$ \\
\hline 10 & Develop & RD-6 developer for $3 \mathrm{~min}$ \\
\hline 11 & Copper Oxide removal & $\begin{array}{l}\text { Short dip in dilute } \mathrm{H}_{2} \mathrm{SO}_{4} \text { to } \\
\text { remove the oxidized } \mathrm{Cu} \text { layer. }\end{array}$ \\
\hline 12 & Copper electroplating & $\begin{array}{l}\text { For } 1 \text { hour with } 750 \mathrm{~mA} \text { current } \\
\text { flow } \\
\text { In electroplating tank } \\
\text { Electroplating rate: } 0.25 \mu \mathrm{m} / \mathrm{min}\end{array}$ \\
\hline 13 & Strip & Place into Acetone \\
\hline 14 & Seed-layer etch & $\begin{array}{l}\text { Etch } \mathrm{Cu} \text { in } \mathrm{H}_{2} \mathrm{SO}_{4}: \mathrm{H}_{2} \mathrm{O}_{2}: \mathrm{H}_{2} \mathrm{O} \\
\text { solution until color change, } \\
\text { Etch } \mathrm{Cr} \text { in } \mathrm{K}_{3} \mathrm{Fe}(\mathrm{CN})_{6}: \mathrm{NaOH}: \mathrm{H}_{2} \mathrm{O} \\
\text { solution until color change }\end{array}$ \\
\hline 15 & Clean wafer & Acetone, Methanol, dry $\mathrm{N}_{2}$ gun \\
\hline
\end{tabular}




\section{APPENDIX B}

\section{SIMULATED $Q$ AND L OF FABRICATED INDUCTORS}

\begin{tabular}{|c|c|c|c|c|c|c|}
\hline $\begin{array}{l}\text { Code } \\
\text { number }\end{array}$ & $\begin{array}{l}\text { \# of } \\
\text { turns }\end{array}$ & $\mathrm{W}_{\text {metal }}$ & $S_{\text {metal }}$ & $\mathrm{d}_{\text {out }}$ & Comment & $Q_{\max } \& L$ \\
\hline 1 & 1 & 20 & 50 & 300 & $\begin{array}{l}\text { On } 4 \mu \mathrm{m} \mathrm{SiO}_{2} \text { coated standard } \\
\mathrm{Si}, \text { metal thickness }=15 \mu \mathrm{m}, \\
\text { round edge }\end{array}$ & $\begin{array}{l}21.06 @ 3.5 \mathrm{GHz} \\
0.69 \mathrm{nH}\end{array}$ \\
\hline 2 & 1 & 20 & 50 & 450 & $\begin{array}{l}\text { On } 4 \mu \mathrm{m} \mathrm{SiO}_{2} \text { coated standard } \\
\mathrm{Si}, \text { metal thickness }=15 \mu \mathrm{m}, \\
\text { round edge }\end{array}$ & $\begin{array}{l}19.83 @ 2 \mathrm{GHz} \\
1.12 \mathrm{nH}\end{array}$ \\
\hline 3 & 1 & 30 & 50 & 300 & $\begin{array}{l}\text { On } 4 \mu \mathrm{m} \mathrm{SiO}_{2} \text { coated standard } \\
\mathrm{Si}, \text { metal thickness }=15 \mu \mathrm{m}\end{array}$ & $\begin{array}{l}21.71 @ 2.5 \mathrm{GHz} \\
0.7 \mathrm{nH}\end{array}$ \\
\hline 4 & 1 & 30 & 50 & 400 & $\begin{array}{l}\text { On } 4 \mu \mathrm{m} \mathrm{SiO}_{2} \text { coated standard } \\
\mathrm{Si}, \text { metal thickness }=15 \mu \mathrm{m}\end{array}$ & $\begin{array}{l}21.97 @ 2 \mathrm{GHz} \\
0.89 \mathrm{nH}\end{array}$ \\
\hline 5 & 1 & 30 & 50 & 600 & $\begin{array}{l}\text { On } 4 \mu \mathrm{m} \mathrm{SiO}_{2} \text { coated standard } \\
\mathrm{Si}, \text { metal thickness }=15 \mu \mathrm{m}\end{array}$ & $\begin{array}{l}21.42 @ 1.5 \mathrm{GHz} \\
1.46 \mathrm{nH}\end{array}$ \\
\hline 6 & 1 & 50 & 50 & 400 & $\begin{array}{l}\text { On } 4 \mu \mathrm{m} \mathrm{SiO}_{2} \text { coated standard } \\
\mathrm{Si}, \text { metal thickness }=15 \mu \mathrm{m}\end{array}$ & $\begin{array}{l}22.23 @ 1.5 \mathrm{GHz} \\
0.79 \mathrm{nH}\end{array}$ \\
\hline 7 & 1 & 40 & 50 & 400 & $\begin{array}{l}\text { On } 4 \mu \mathrm{m} \mathrm{SiO}_{2} \text { coated standard } \\
\mathrm{Si}, \text { metal thickness }=15 \mu \mathrm{m}\end{array}$ & $\begin{array}{l}22.15 @ 1.5 \mathrm{GHz} \\
0.87 \mathrm{nH}\end{array}$ \\
\hline 8 & 1 & 40 & 50 & 500 & $\begin{array}{l}\text { On } 4 \mu \mathrm{m} \mathrm{SiO}_{2} \text { coated standard } \\
\mathrm{Si}, \text { metal thickness }=15 \mu \mathrm{m}\end{array}$ & $\begin{array}{l}22.60 @ 1.5 \mathrm{GHz} \\
1.04 \mathrm{nH}\end{array}$ \\
\hline 9 & 1 & 40 & 50 & 600 & $\begin{array}{l}\text { On } 4 \mu \mathrm{m} \mathrm{SiO}_{2} \text { coated standard } \\
\mathrm{Si}, \text { metal thickness }=15 \mu \mathrm{m}\end{array}$ & $\begin{array}{l}22.40 @ 1.5 \mathrm{GHz} \\
1.18 \mathrm{nH}\end{array}$ \\
\hline 10 & 1 & 50 & 50 & 500 & $\begin{array}{l}\text { On } 4 \mu \mathrm{m} \mathrm{SiO}_{2} \text { coated standard } \\
\mathrm{Si}, \text { metal thickness }=15 \mu \mathrm{m}\end{array}$ & $\begin{array}{l}22.67 @ 1.5 \mathrm{GHz} \\
0.95 \mathrm{nH}\end{array}$ \\
\hline 11 & 1 & 50 & 50 & 600 & $\begin{array}{l}\text { On } 4 \mu \mathrm{m} \mathrm{SiO}_{2} \text { coated standard } \\
\mathrm{Si}, \text { metal thickness }=15 \mu \mathrm{m}\end{array}$ & $\begin{array}{l}23.27 @ 1 \mathrm{GHz} \\
1.18 \mathrm{nH}\end{array}$ \\
\hline 12 & 1 & 50 & 50 & 700 & $\begin{array}{l}\text { On } 4 \mu \mathrm{m} \mathrm{SiO}_{2} \text { coated standard } \\
\mathrm{Si}, \text { metal thickness }=15 \mu \mathrm{m}\end{array}$ & $\begin{array}{l}\text { 22.95@1GHz } \\
1.31 \mathrm{nH}\end{array}$ \\
\hline 13 & 1 & 60 & 50 & 500 & $\begin{array}{l}\text { On } 4 \mu \mathrm{m} \mathrm{SiO}_{2} \text { coated standard } \\
\mathrm{Si}, \text { metal thickness }=15 \mu \mathrm{m}\end{array}$ & $\begin{array}{l}\text { 22.23@1GHz } \\
0.94 \mathrm{nH}\end{array}$ \\
\hline 14 & 1 & 60 & 50 & 600 & $\begin{array}{l}\text { On } 4 \mu \mathrm{m} \mathrm{SiO}_{2} \text { coated standard } \\
\mathrm{Si}, \text { metal thickness }=15 \mu \mathrm{m}\end{array}$ & $\begin{array}{l}23.76 @ 1 \mathrm{GHz} \\
1.1 \mathrm{nH}\end{array}$ \\
\hline 15 & 1 & 60 & 50 & 700 & $\begin{array}{l}\text { On } 4 \mu \mathrm{m} \mathrm{SiO}_{2} \text { coated standard } \\
\mathrm{Si}, \text { metal thickness }=15 \mu \mathrm{m}\end{array}$ & $\begin{array}{l}22.88 @ 1 \mathrm{GHz} \\
1.21 \mathrm{nH}\end{array}$ \\
\hline 16 & 1 & 70 & 50 & 600 & $\begin{array}{l}\text { On } 4 \mu \mathrm{m} \mathrm{SiO}_{2} \text { coated standard } \\
\mathrm{Si}, \text { metal thickness }=15 \mu \mathrm{m}\end{array}$ & $\begin{array}{l}24.10 @ 1 \mathrm{GHz} \\
1.01 \mathrm{nH}\end{array}$ \\
\hline 17 & 1 & 20 & 50 & 450 & $\begin{array}{l}\text { On } 4 \mu \mathrm{m} \mathrm{SiO}{ }_{2} \text { coated } \mathrm{Si} \text {, metal } \\
\text { thickness }=15 \mu \mathrm{m} \text {,round }\end{array}$ & $\begin{array}{l}19.74 @ 2.5 \mathrm{GHz} \\
1.08 \mathrm{nH}\end{array}$ \\
\hline
\end{tabular}




\begin{tabular}{|c|c|c|c|c|c|c|}
\hline $\begin{array}{l}\text { Code } \\
\text { number }\end{array}$ & $\begin{array}{l}\text { \# of } \\
\text { turns }\end{array}$ & $\mathrm{w}_{\text {metal }}$ & $\mathrm{S}_{\text {metal }}$ & $\mathrm{d}_{\text {out }}$ & Comment & $Q_{\max } \& L$ \\
\hline 18 & 1 & 30 & 50 & 500 & $\begin{array}{l}\text { On } 4 \mu \mathrm{m} \mathrm{SiO}_{2} \text { coated standard } \\
\mathrm{Si} \text {, metal thickness }=15 \mu \mathrm{m}, \\
\text { round inductor }\end{array}$ & $\begin{array}{l}23.35 @ 2 \mathrm{GHz} \\
0.98 \mathrm{nH}\end{array}$ \\
\hline 19 & 1 & 40 & 50 & 500 & $\begin{array}{l}\text { On } 4 \mu \mathrm{m} \mathrm{SiO} \mathrm{Si}_{2} \text { coated standard } \\
\mathrm{Si}, \text { metal thickness }=15 \mu \mathrm{m}, \\
\text { round inductor }\end{array}$ & $\begin{array}{l}25.50 @ 1.5 \mathrm{GHz} \\
0.96 \mathrm{nH}\end{array}$ \\
\hline 20 & 1 & 50 & 50 & 500 & $\begin{array}{l}\text { On } 4 \mu \mathrm{m} \mathrm{SiO}_{2} \text { coated standard } \\
\mathrm{Si} \text {, metal thickness }=15 \mu \mathrm{m}, \\
\text { round inductor }\end{array}$ & $\begin{array}{l}\text { 28.53@1.5GHz } \\
0.91 \mathrm{nH}\end{array}$ \\
\hline 21 & 1 & 60 & 50 & 600 & $\begin{array}{l}\text { On } 4 \mu \mathrm{m} \mathrm{SiO}_{2} \text { coated standard } \\
\mathrm{Si} \text {, metal thickness }=15 \mu \mathrm{m}, \\
\text { round inductor }\end{array}$ & $\begin{array}{l}27.47 @ 1 \mathrm{GHz} \\
1.00 \mathrm{nH}\end{array}$ \\
\hline 22 & 1 & 60 & 50 & 400 & $\begin{array}{l}\text { On } 4 \mu \mathrm{m} \mathrm{SiO}_{2} \text { coated standard } \\
\mathrm{Si} \text {, metal thickness }=15 \mu \mathrm{m}, \\
\text { round inductor }\end{array}$ & $\begin{array}{l}27.55 @ 1.5 \mathrm{GHz} \\
0.55 \mathrm{nH}\end{array}$ \\
\hline 23 & 1 & 60 & 50 & 450 & $\begin{array}{l}\text { On } 4 \mu \mathrm{m} \mathrm{SiO}_{2} \text { coated standard } \\
\mathrm{Si} \text {, metal thickness }=15 \mu \mathrm{m}, \\
\text { round inductor }\end{array}$ & $\begin{array}{l}27.58 @ 1.5 \mathrm{GHz} \\
0.62 \mathrm{nH}\end{array}$ \\
\hline 24 & 1.5 & 30 & 20 & 300 & $\begin{array}{l}\mathrm{SiO}_{2} \text { thickness }=5 \mu \mathrm{m}, 1^{\mathrm{st}} \text { metal } \\
\text { layer }=2 \mu \mathrm{m}, 2^{\text {nd }} \text { metal } \\
\text { layer }=15 \mu \mathrm{m}, \text { round edge }\end{array}$ & $\begin{array}{l}28.19 @ 2 \mathrm{GHz} \\
1.08 \mathrm{nH}\end{array}$ \\
\hline 25 & 1.5 & 40 & 20 & 300 & $\begin{array}{l}\mathrm{SiO}_{2} \text { thickness }=5 \mu \mathrm{m}, 1^{\text {st }} \text { metal } \\
\text { layer }=2 \mu \mathrm{m}, \\
2^{\text {nd }} \text { metal layer }=15 \mu \mathrm{m}\end{array}$ & $\begin{array}{l}28.07 @ 2 \mathrm{GHz} \\
0.91 \mathrm{nH}\end{array}$ \\
\hline 26 & 1.5 & 30 & 20 & 400 & $\begin{array}{l}\mathrm{SiO} \mathrm{O}_{2} \text { thickness }=5 \mu \mathrm{m}, 1^{\text {st }} \text { metal } \\
\text { layer }=2 \mu \mathrm{m}, 2^{\text {nd }} \text { metal } \\
\text { layer }=15 \mu \mathrm{m} \text {, round edge }\end{array}$ & $\begin{array}{l}28.04 @ 1.5 \mathrm{GHz} \\
1.73 \mathrm{nH}\end{array}$ \\
\hline 27 & 1.5 & 30 & 20 & 200 & $\begin{array}{l}\mathrm{SiO}_{2} \text { thickness }=5 \mu \mathrm{m}, 1^{\text {st }} \text { metal } \\
\text { layer }=2 \mu \mathrm{m}, 2^{\text {nd }} \text { metal } \\
\text { layer }=15 \mu \mathrm{m} \text {, round edge }\end{array}$ & $\begin{array}{l}27.3 @ 3.5 \mathrm{GHz} \\
0.43 \mathrm{nH}\end{array}$ \\
\hline 28 & 1.5 & 40 & 20 & 400 & $\begin{array}{l}\mathrm{SiO}_{2} \text { thickness }=4 \mu \mathrm{m}, 1^{\text {st }} \text { metal } \\
\text { layer }=1.5 \mu \mathrm{m}, 2^{\text {nd }} \text { metal } \\
\text { layer }=15 \mu \mathrm{m}, \text { round edge }\end{array}$ & $\begin{array}{l}23.15 @ 1.5 \mathrm{GHz} \\
1.4 \mathrm{nH}\end{array}$ \\
\hline 29 & 1.5 & 20 & 20 & 300 & $\begin{array}{l}\mathrm{SiO}_{2} \text { thickness }=5 \mu \mathrm{m}, 1^{\text {st }} \text { metal } \\
\text { layer }=2 \mu \mathrm{m}, \\
2^{\text {nd }} \text { metal layer }=15 \mu \mathrm{m}\end{array}$ & $\begin{array}{l}26.7 @ 2.25 \mathrm{GHz} \\
1.3 \mathrm{nH}\end{array}$ \\
\hline 30 & 1.5 & 50 & 20 & 400 & $\begin{array}{l}\mathrm{SiO}_{2} \text { thickness }=4 \mu \mathrm{m}, 1^{\mathrm{st}} \text { metal } \\
\text { layer }=1.5 \mu \mathrm{m}, \\
2^{\text {nd }} \text { metal layer }=15 \mu \mathrm{m}\end{array}$ & $\begin{array}{l}22.825 @ 1 \mathrm{GHz} \\
1.23 \mathrm{nH}\end{array}$ \\
\hline 31 & 2.5 & 20 & 20 & 300 & $\begin{array}{l}\mathrm{SiO}_{2} \text { thickness }=5 \mu \mathrm{m}, 1^{\text {st }} \text { metal } \\
\text { layer }=1.5 \mu \mathrm{m}, \\
2^{\text {nd }} \text { metal layer }=15 \mu \mathrm{m}\end{array}$ & $\begin{array}{l}20.70 @ 1.5 \mathrm{GHz} \\
2.02 \mathrm{nH}\end{array}$ \\
\hline 32 & 2.5 & 20 & 20 & 350 & $\begin{array}{l}\mathrm{SiO}_{2} \text { thickness }=5 \mu \mathrm{m}, 1^{\text {st }} \text { metal } \\
\text { layer }=1.5 \mu \mathrm{m}, 2^{\text {nd }} \text { metal }=15 \mu \mathrm{m}\end{array}$ & $\begin{array}{l}20.76 @ 1 \mathrm{GHz} \\
2.52 \mathrm{nH}\end{array}$ \\
\hline
\end{tabular}




\begin{tabular}{|c|c|c|c|c|c|c|}
\hline $\begin{array}{l}\text { Code } \\
\text { number }\end{array}$ & $\begin{array}{l}\text { \# of } \\
\text { turns }\end{array}$ & $\mathrm{w}_{\text {metal }}$ & $\mathrm{s}_{\text {metal }}$ & $\mathrm{d}_{\text {out }}$ & Comment & $Q_{\max } \& L$ \\
\hline 33 & 2.5 & 20 & 20 & 400 & $\begin{array}{l}\mathrm{SiO}_{2} \text { thickness }=5 \mu \mathrm{m}, 1^{\text {st }} \text { metal } \\
\text { layer }=1.5 \mu \mathrm{m}, 2^{\text {nd }} \text { metal }=15 \mu \mathrm{m}\end{array}$ & \begin{tabular}{|l|}
$21.05 @ 1 \mathrm{GHz}$ \\
$2.94 \mathrm{nH}$ \\
\end{tabular} \\
\hline 34 & 2.5 & 20 & 20 & 500 & $\begin{array}{l}\mathrm{SiO}_{2} \text { thickness }=5 \mu \mathrm{m}, 1^{\text {st }} \text { metal } \\
\text { layer }=1.5 \mu \mathrm{m}, 2^{\text {nd }} \text { metal }=15 \mu \mathrm{m}\end{array}$ & $\begin{array}{l}19.65 @ 1 \mathrm{GHz} \\
4.1 \mathrm{nH}\end{array}$ \\
\hline 35 & 2.5 & 30 & 20 & 350 & $\begin{array}{l}\mathrm{SiO}_{2} \text { thickness }=5 \mu \mathrm{m}, 1^{\text {st }} \text { metal } \\
\text { layer }=1.5 \mu \mathrm{m}, 2^{\text {nd }} \text { metal }=15 \mu \mathrm{m}\end{array}$ & $\begin{array}{l}\text { 19.79@1GHz } \\
\text { 2.15nH }\end{array}$ \\
\hline 36 & 2.5 & 30 & 20 & 400 & $\begin{array}{l}\mathrm{SiO}_{2} \text { thickness }=5 \mu \mathrm{m}, 1^{\mathrm{st}} \text { metal } \\
\text { layer }=1.5 \mu \mathrm{m}, 2^{\text {nd }} \text { metal }=15 \mu \mathrm{m} \\
\text { round edge inductor }\end{array}$ & $\begin{array}{l}20.54 @ 1 \mathrm{GHz} \\
2.6 \mathrm{nH}\end{array}$ \\
\hline 37 & 2.5 & 30 & 20 & 500 & $\begin{array}{l}\mathrm{SiO}_{2} \text { thickness }=5 \mu \mathrm{m}, 1^{\mathrm{st}} \text { metal } \\
\text { layer }=1.5 \mu \mathrm{m}, 2^{\text {nd }} \text { metal }=15 \mu \mathrm{m} \\
\text { round edge inductor }\end{array}$ & $\begin{array}{l}\text { 20.04@1GHz } \\
3.43 \mathrm{nH}\end{array}$ \\
\hline 38 & 2.5 & 40 & 20 & 400 & $\begin{array}{l}\mathrm{SiO}_{2} \text { thickness }=5 \mu \mathrm{m}, 1^{\mathrm{st}} \text { metal } \\
\text { layer }=1.5 \mu \mathrm{m}, 2^{\text {nd }} \text { metal }=15 \mu \mathrm{m} \\
\text { round edge inductor }\end{array}$ & $\begin{array}{l}\text { 19.23@1GHz } \\
2.14 \mathrm{nH}\end{array}$ \\
\hline 39 & 2.5 & 40 & 20 & 400 & $\begin{array}{l}\mathrm{SiO}_{2} \text { thickness }=5 \mu \mathrm{m}, 1^{\text {st }} \text { metal } \\
\text { layer }=1.5 \mu \mathrm{m}, 2^{\text {nd }} \text { metal }=15 \mu \mathrm{m} \\
\text { round inductor }\end{array}$ & $\begin{array}{l}19.04 @ 1 \mathrm{GHz} \\
1.55 \mathrm{nH}\end{array}$ \\
\hline 40 & 2.5 & 40 & 20 & 500 & $\begin{array}{l}\mathrm{SiO}_{2} \text { thickness }=5 \mu \mathrm{m}, 1^{\mathrm{st}} \text { metal } \\
\text { layer }=1.5 \mu \mathrm{m}, 2^{\text {nd }} \text { metal }=15 \mu \mathrm{m} \\
\text { round inductor }\end{array}$ & $\begin{array}{l}\text { 19.69@0.5GHz } \\
3.08 \mathrm{nH}\end{array}$ \\
\hline 41 & 2.5 & 40 & 20 & 500 & $\begin{array}{l}\mathrm{SiO}_{2} \text { thickness }=5 \mu \mathrm{m}, 1^{\text {st }} \text { metal } \\
\text { layer }=1.5 \mu \mathrm{m}, 2^{\text {nd }} \text { metal }=15 \mu \mathrm{m}\end{array}$ & $\begin{array}{l}\text { 19.69@0.5GHz } \\
3.08 \mathrm{nH}\end{array}$ \\
\hline 42 & 2.5 & 50 & 20 & 400 & $\begin{array}{l}\mathrm{SiO}_{2} \text { thickness }=5 \mu \mathrm{m}, 1^{\text {st }} \text { metal } \\
\text { layer }=1.5 \mu \mathrm{m}, 2^{\text {nd }} \text { metal }=15 \mu \mathrm{m}, \\
\text { round edge inductor }\end{array}$ & $\begin{array}{l}17.19 @ 1 \mathrm{GHz} \\
1.72 \mathrm{nH}\end{array}$ \\
\hline
\end{tabular}




\section{REFERENCES}

[1] C. C. Tang, et al., "Miniature 3-D Inductors in Standard CMOS Process," IEEE J. Solid-State Circuits, vol. 37, Apr. 2002, pp. 471-478.

[2] K. B. Ashby, W. C. Finley, J.J. Bastek, S. Moinian, and I. A. Koullias, "High $Q$ inductors for wireless application in complementary silicon bipolar process," IEEE $J$. solid-State Circuits, vol. 31, Jan. 1996, pp. 4-9, .

[3] X. Huo, et al., "Silicon-Based High-Q Inductors Incorporating Electroplated Copper and Low-K BCB Dielectric," IEEE Electron Device Letters, vol. 23, No. 9, Sep. 2002, pp. 520-522.

[4] K. L. Scott, T. Hirano, H. Yang, H. Singh, R. T. Howe, A. M. Niknejad, "HighPerformance Inductors Using Capillary Based Fluidic Self-Assembly," IEEE J. microelectromechanical systems, vol. 13, No.2, April 2004.

[5] J. N. Burghartz, M. Soyuer, and K. Jenkis, "Microwave inductors and capacitors in standard multilevel interconnect silicon technology," IEEE Trans. Microwave Theory Tech., vol. 44, Jan 1996, pp. 100-103.

[6] R. B. Merril, T. W. Lee, H. You, R. Rasmussen, and L. A. Moberly, "Optimization of high $Q$ integrated inductors for multi-level metal CMOS," IEDM, 1995, pp.38.7.1-38.7.3.

[7] M. Park, S. Lee, H. K. Yu, J. G. Koo, K. S. Nam, "High $Q$ CMOS Compatible Microwave Inductors Using Double-Metal Interconnection Silicon Technology," IEEE Microwave and Guided wave lett., vol. 7, No. 2, Feb. 1997.

[8] G. Lihui, Y. Mingbin, C. Zhen, H. Han, and Z. Yi, "High Q Multilayer Spiral Inductor on Silicon Chip for 5 6 GHz," IEEE Electron Device Letts., vol. 23, No. 8, Aug. 2002.

[9] S. Musunuri and P.L. Chapman, "Multi-Leyar Inductor Design for Monolithic DCDC Converters," IEEE Industry Applications Conference, 2003. 38th IAS Annual Meeting. Conference Record of the, vol.2, Oct. 2003, pp. 1270 - 1275. 
[10] H. Lakdawala, et al., "Micromachined High- $Q$ Inductors in $0.18-\mu \mathrm{m}$ Copper Interconnect Low-K Dielectric CMOS Process," IEEE J. Solid-State Circuits, vol. 37, No.3, Aug. 1990, pp. 394-403.

[11] Choong-Mo Nam and Young-Se Kwon, "High-Performance Planar Inductor on Thick Oxidized Porous Silicon (OPS) Substrate," IEEE microwave guided wave lett., vol. 7, No. 8, Aug. 1997.

[12] D. W. Kim, I. J. Jeong, H. S. Sung, T.O. Kong, J. S. Lee, C. M. Nam and Y. S. Kwon, "High Performance RF Passive Integration on Si Smart Substrate," IEEE MTT-S, vol. 3, June2002, pp. 1561-1564.

[13] H. S. Kim, K. Chong, Y.H. Xie, Marc Devincentis, T. Itoh, A. J. Becker, and K. A. Jenkis, "A porous Si based novel isolation technology for Mixed-Sinal Integrated Circuits," IEEE Symposium on VLSI technology, June 2002, pp. 160-161.

[14] A.S. Royet, R. Cuchet, D. Pellisier, P. Ancey, "On the investigation of spiral inductors processed on Si substrates with thick porous Si layer," European Solid-State Device Research, Sep. 2003, pp.111-114.

[15] H. Jiang, Ye Wang, J. A. Yeh, N. C. Tien, "On-chip Spiral Inductors Suspended over Deep Copper-Lined Cavities," IEEE tran. MTT, vol. 48, No. 12, Dec. 2000, pp. 2415-2423.

[16] Jun-Bo Yoon, Y. Seok Choi, B. Kim, and E. Yoon, "CMOS-Compatible SurfaceMicromachined Suspended- Spiral Inductors for Multi-GHz Silicon RF ICs," IEEE Electron Device Lett. , vol. 23, No. 10, Oct. 2002, pp. 591-593.

[17] R. P. Ribas, J. Lescot, J. Leclercq, J. M. Karam, F. Ndagijimana, "Micromachined Microwave Planar Spiral Inductors and Transformers," IEEE MTT, vol. 48, No. 8, Aug. 2000, pp. 1326-1335.

[18] D. H. Weon, J. H. Jeon, J. Kim, S. Mohammadi, L. Katehi, "High-Q Integrated 3-D Inductors and Transformers for High Frequency Applications," IEEE MTT-S Digest, 2004, pp.887-880. 
[19] C. L. Chua, D. K. Fork, K. V.Schuylenbergh, J. P. Lu, "Out-of-Plane High-Q Inductors on Low-Resistance Silicon," IEEE J. Microelectromechanical Systems, vol. 12, No. 6, Dec. 2003, pp. 989-995.

[20] J. Y. Park, M. G. Allen, "Packaging-Compatible High Q Microinductors and Microfilters for Wireless Applications," IEEE Trans. Advanced Packaging, vol. 22, No. 2, May 1999, pp. 207-213.

[21] S. Dalmia, F. Ayazi, M. Swaminathan, S. H. Min, S. H. Lee, W. Kim, S. Bhattacharaya, V. Sundaram, G. White, and R. Tummala, " Design of Inductors in Organic Substrates For 1-3GHz Wireless Application," IEEE MTT-S, vol.3, June 2002, pp.1405-1408.

[22] G. J. Carchon, X. Sun, W. De Raedt, "High-Q Above-IC Inductors and Transmission Lines- Comparison to $\mathrm{Cu}$ Back-End Performance," IEEE Electron Components and Technology Conference, 2004, pp.1118-23.

[23] Yun-Seok Choi, Euisik Yoon, and Jun-Bo Yoon, "Encapsulation of the Micromachined Air-Suspended Inductors," IEEE MTT-S Digest, 2003, pp.1637-1640.

[24] G. Wang, A. Bacon, R. Abdolvand, F. Ayazi, J. apapolymerou, and E. M. Tentzeris, "Finite Ground Coplanar Lines on CMOS Grade Silicon with a Thick Embedded Silicon Oxide Layer Using Micromachining Techniques," Digest of the 12th International Conference on Solid State Sensors, Actuators and Microsystems, June 2003, pp. 324-327.

[25] M.Raieszadeh, P. Monajemi, S. Yoon, J. Laskar, F. Ayazi, "High-Q Integrated Inductors on Trenched Si Islands," IEEE International Conference on MEMS, Jan. 2005, pp.199-202.

[26] C. Patrick Yue, S. Simon Wong, "Physical Modeling of Spiral Inductors on Silicon," IEEE Tran. Electron Devices, vol. 47, No. 3, Mar. 2000, pp. 560-568.

[27] Jan Craninckx and Michiel S. J. Steyaert, "A 1.8-GHz Low-Phase-Noise CMOS VCO Using Optimized Hollow Spiral Inductors," IEEE J. Solid-State Circuits, vol. 32, No. 5, May 1997, pp.736-744. 
[28] C. Patrick Yue, S. Simon Wong, "Design Strategy of On-Chip Inductors for Highly Integrated RF Systems," Proceeding on Design Automation Conference, June 1999, pp. 982-987.

[29] Paolo Arcioni, et al., "An Improved Lumped-Element Equivalent Circuit for on Silicon Integrated Inductors," IEEE Radio and Wireless Conference RAWCON, Aug. 1998, pp 301-304.

[30] Paolo Arcioni, et al., "An Innovative Modelization of Loss Mechanism in Silicon Integrated Inductor," IEEE Tran. on Analog and Digital Signal Processing, vol. 46, No. 12, Dec. 1999.

[31] Ali M. Niknejad, Robert G. Meyer, "Analysis, Design and Optimization of Spiral Inductors and Transformers for Si RF IC's," IEEE J. Solid-State Circuits, vol. 33, No. 10, Oct. 1998, pp. 1470-1481.

[32] Joachim N. Burghatz, Behzad Rajaei, "On the Design of RF Spiral Inductors on Silicon," IEEE Trans. On Electron Devices, vol. 50, No. 3, Mar. 2003, pp 718-729.

[33] William B. Kuhn, Naveen K. Yanduru, "Spiral Inductor Substrate Loss Modeling in Silicon RFICs," IEEE RAWCON Proceeding, Jan. 1998, pp. 305-308.

[34] H. M. Greenhouse, "Design of planar rectangular microelectronic inductors," IEEE Transactions on Parts, Hybrids, and Packaging, vol. 10, Issue: 2, Jun 1974, pp.101 - 109.

[35] R. Faraji-Dana, Y. Chow, "Edge condition of the field and a.c. resistance of a rectangular strip conductor," IEE Proceeding on Microwaves, Antennas and Propagation, vol. 137, No.2, April 1990, pp. 133-140.

[36] H. A. Wheeler, "Formulas for the skin effect," in Proc. I. R. E., vol. 30, Sept. 1942, pp. 412-424.

[37] J. A. Tegopoulos and E. E. Kriezis, Eddy Currents in Linear Conducting Media, New York, NY: Elsevier, 1985. 
[38] Y. Eo and W. R. Eisenstadt, "High-speed VLSI interconnect modeling based on Sparameter measurements," IEEE Trans. Components, Hybrids, and Manufacturing Technology, vol. 16, Issue 5, Aug. 1993, pp. 555-562.

[39] R. A. Pucel, D. J. Massé, and C. P. Hartwig, "Losses in microstrip," IEEE Trans. MTT, vol. 16, June 1968, pp. 342-350.

[40] R. Faraji-Dana and Y. L. Chow, "The current distribution and ac resistance of a microstrip structure," IEEE Trans. MTT, vol. 38, pp. 1268-1277, Sept. 1990.

[41] James C. Routio, "An Investigation of Microstrip Conductor Loss," IEEE Microwave Magazine, Dec. 2000, pp. 60-67.

[42] S.S. Mohan, M. Hershenson, S. P. Boyd and T.H. Lee, "Simple Accurate Expression for Planar Spiral Inductor," IEEE J. Solid-State Circuits, vol. 34, Issue 10, Oct. 1999, pp. $1419-1424$.

[43] Paolo Arcioni, et al., "An Innovative Modelization of Loss Mechanism in Silicon Integrated Inductor," IEEE Trans. Circuit and Systems, vol. 46, No.12, Dec. 1999, pp.1453-1460.

[44] F. W. Grover, Inductance Calculation, Princeton, New Jeresey: Van Nostrand, 1946. Printed by New York, New York Dover Publication, 1962.

[45] D.M. Pozar, Microwave engineering, Amherst, MA: John Wliley \& Sons, 1998.

[46] Jong-Min Lee, et al., "Comparison of frequency response of spiral inductors with different figures," Semiconductor Science Technology, vol. 16, pp.66-71, 2001.

[47] http://www.futurrux.com

[48] G. Forrest, D. Reed, "Current density effects [impact on electroplated copper]," Printed Circuit Fabrication, vol 17, no 6, June 1994, pp 26-30. 
[49] K. S. Patel, P. A. Kohl, S. A. Bidstrup-Allen, "Three-Dimensional Dielectric Characterization of Polymer Films," Journal of Applied Polymer Science, vol. 80, 2001.

[50] T. A. Manial, R. H. Heistand, P. E. Garrou "Benzocyclobutene (BCB) dielectric for advanced MCM packaging," Surface Mount International Conference and Exposition. Proceedings of the Technical Program, vol.1, 1992, pp. 39-47.

[51] Shweta Humad, "Piezo-on-Silicon Micromechanical Resonators," M. S. thesis, GT 2004.

[52] S. K. Ghandhi, VLSI fabrication principles: silicon and gallium arsenide, $2^{\text {nd }}$ Edition, New York: John Wliley \& Sons, 1994.

[53] S. A. Wartenberg, RF measurement of die and packaging, Artech House, 2002. 